\section{CLLVAR. CLIVARExchanges}

CLIVAR Ocean and Climate: Variability, Predictability and Change is the World Climate Research Programme's core project on the Ocean-Atmosphere System

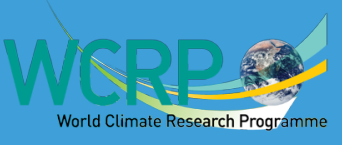

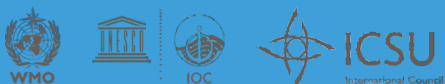

\title{
Decadal Climate Variability
}

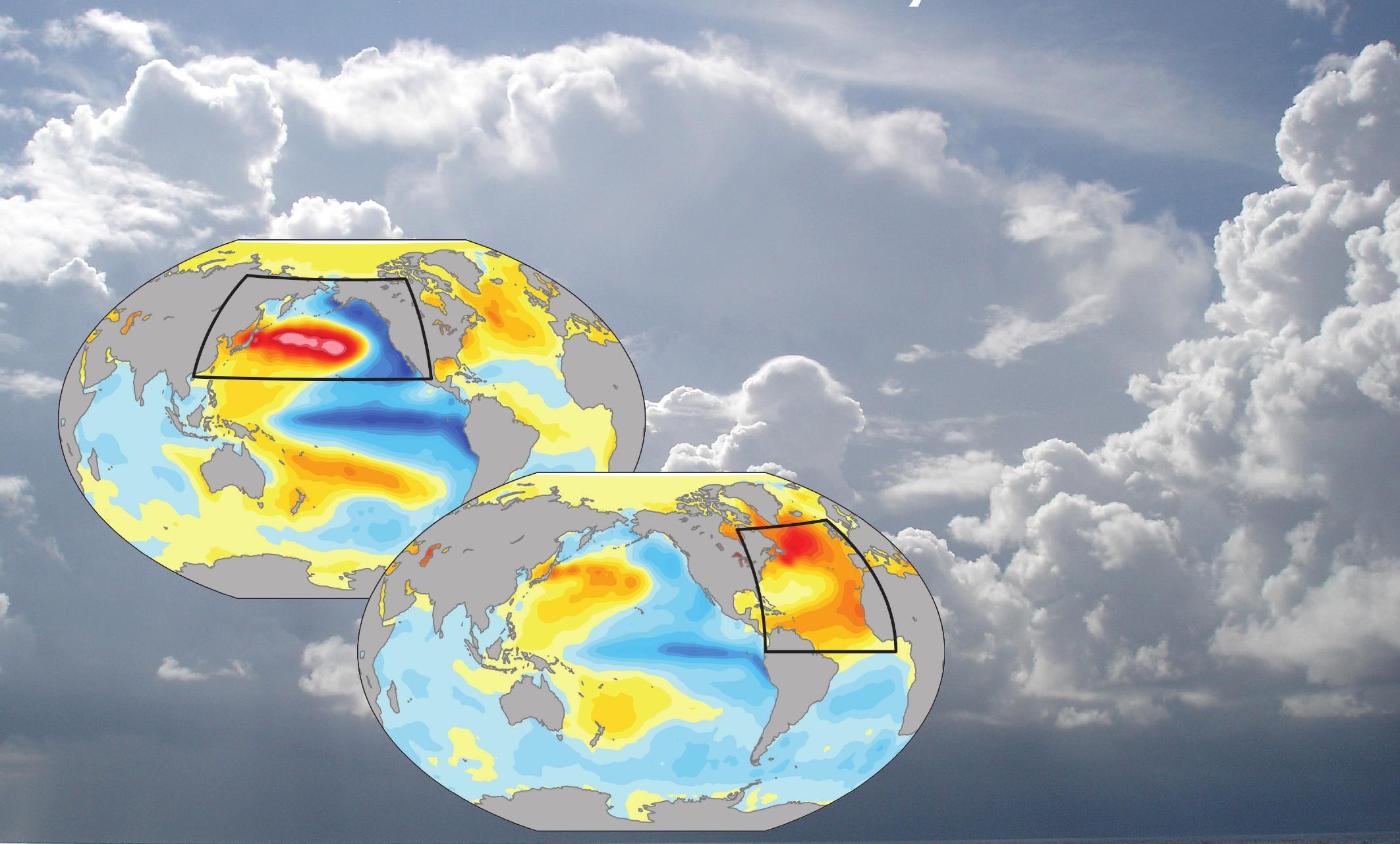

(2)

Volume 25, No. 1

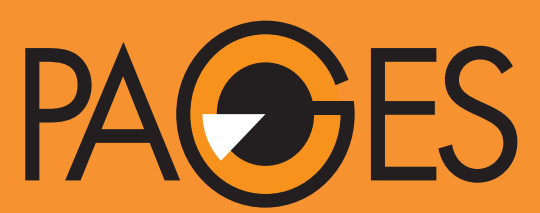

Past Global Changes Magazine

PAST GLOBAL CHANGES 


\section{Yochanan Kushnir, Christophe Cassou, Scott St George}

The study of Decadal Climate Variability and Predictability (DCVP) is the interdisciplinary scientific enterprise to characterize, understand, attribute, simulate, and predict the slow, multi-year variations of climate on global and regional scales. Particular interest in decadal climate variations and their role in the global surface climate change stems from the need to detect and attribute the uneven rise in global mean surface temperatures (GMST) since the beginning of the industrial period. The most recent expression of decadal variability in GMST has been the slowdown in warming between roughly 1998 and 2012. This period, often termed as the "hiatus", triggered intensive debate in the public domain, even if global temperatures had exhibited long undulations before, including two cooling events in the late 19th to early 20th century and in the mid 20th century and two intervals of rapid warming, one from about 1910 to 1940 and the other between the early 1970s and 1998. While these departures from the expected warming due to the steady increase in greenhouse gas forcing have been attributed in part to natural (volcanic) and anthropogenic (industrial) aerosols, there is ample evidence that long-term internal interactions between climate system components - the ocean and the atmosphere, in particular - have also been involved.

Decadal and longer variations in sea surface temperatures (SSTs) have a rich and non-uniform spatial pattern related to variations in the distribution of precipitation and associated atmospheric convection in the tropics, to alterations in position and strength of the storm tracks at midlatitudes, to changes in sea-ice extent at polar latitudes in both hemispheres, etc. Changes in atmospheric circulation thus contributes to changes in regional climates worldwide and importantly over the continents, directly affecting humans and their environment. The most prominent example of the terrestrial response to decadal climate variability is the long-lasting decline of rainfall in the North African Sahel in the second half of the 20th century, which included the devastating famines of the 1970s \& 1980s. These decadal-scale shifts have been attributed to slow variations in North Atlantic SSTs, which have also affected Atlantic tropical cyclone activity over the same time frames. Similarly, the multi-year pulses of North American droughts (e.g., the Great Plains "dust bowl" in the 1930s and the recent protracted dry period in the Southwest US), which impacted lives and livelihoods in the US and northern Mexico, have been attributed to the state of the tropical Pacific and tropical Atlantic Oceans. For the Mediterranean region, in South European countries along the northern rim and in the Maghreb and the Middle East, recurrent heat waves and prolonged dry spells since the mid 1960s, attributed to a combination of internal decadal variability and greenhouse gas forcing, have devastated regional agriculture productivity, lead to loss of life and, perhaps arguably, to widespread societal instability and in Syria to violent conflict and war.

In order to anticipate the impacts of climate change, it is important for society to know how the climate response to anthropogenic forcing and the climate impact of natural variability will mix together to affect the nearterm future. The study of DCVP aims to provide sciencebased information to decision makers through research, observations, and decadal predictions. This goal remains challenging despite decades of research and of extensive progress in observing and modeling the climate system. Predicting the impact of internal decadal climate variability is complicated by our incomplete understanding of the nature of the underlying phenomena, in particular their physical origins and their interaction with external forcing. Existing obstacles in DCVP research thus test our ability to attribute past variations to the combined role of internal variability and external forcing, as well as to reliably predict the near-term climate on global and regional scales.

Progress in DCVP research can only be made through international, cross disciplinary collaborations between scientists. Because of the difficulties to observe and model the Earth's climate at timescales of a decade or longer, this area of research is wholly dependent on emerging connections between those who perform, collect and analyze instrumental observations of the present, those who develop and analyze proxies of past climate, and with scientists who develop models and perform dedicated modeling experiments. To review ongoing research on DCVP and propose the road to future progress on the subject, the International WCRP CLIVAR Project and PAGES held an international workshop with representatives of these various disciplines in November of 2015, under the patronage of the International Centre for Theoretical Physics in Trieste Italy. This issue of Exchanges grew out from the presentations and discussions features in this workshop.

The articles in this issue of Exchanges were selected and reviewed by the members of the CLIVAR Working Group on DCVP and the PAGES $2 \mathrm{k}$ Network. These contributions are meant to provide brief reviews that address the progress made in understanding and resolving different key issues in DCVP. We greatly appreciate the voluntary efforts made by these authors to capture the exciting and rapidly growing literature on the subject in these brief summaries and hope that they will stimulate further research collaboration on the subject. 


\title{
An overview of decadal-scale \\ sea surface temperature variability in the \\ observational record
}

\section{Clara Deser, Adam Phillips}

doi: $10.22498 /$ pages.25.1.2

\author{
National Center for Atmospheric Research, Boulder, USA
}

\section{Introduction}

Due to their thermal and mechanical inertia, the oceans play a key role in decadal-scale climate variability (DCV) and provide a potential source of initial-value predictability for low-frequency climate fluctuations. Characterizing oceanic DCV is challenging, however, due to the limited duration of the observational record combined with the sparse and irregular data coverage. These constraints also hinder assessments of the robustness of the patterns and timescales of DCV, and understanding of the governing mechanisms. In this brief note, we provide an overview of the main phenomena of DCV in the historical sea surface temperature (SST) data record, discuss proposed interpretations and causal mechanisms, and highlight outstanding research questions.

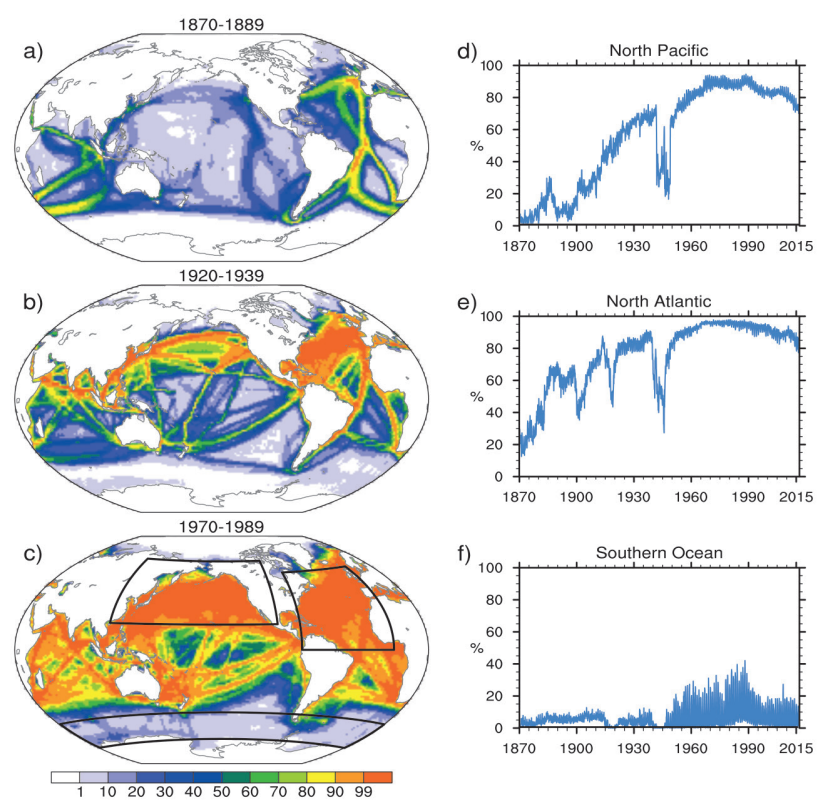

Figure 1: Distribution of sea surface temperature observations from the International Comprehensive Ocean Atmosphere Data Set. Maps show the percentage of months with at least one measurement in a 2 degree latitude by 2 degree longitude grid box during (a) 1870-1899, (b) 1920-1939, and (c) 19701989. Timeseries (1870-2015) show the percentage of grid boxes that have at least one observation per month within the regions outlined in Fig. 1c. (d) North Pacific $\left(20^{\circ}-70^{\circ} \mathrm{N}\right.$, $\left.110^{\circ} \mathrm{E}-100^{\circ} \mathrm{W}\right),\left(\right.$ e) North Atlantic $\left(0^{\circ}-60^{\circ} \mathrm{N}, 80^{\circ} \mathrm{W}-0^{\circ} \mathrm{W}\right)$, and (f) Southern Ocean $\left(50^{\circ}-70^{\circ} \mathrm{S}, 0^{\circ} \mathrm{W}-360^{\circ} \mathrm{E}\right)$.

\section{SST data coverage}

Our focus on SST is motivated by both practical and physical considerations. On the practical side, the longest ocean temperature records are measured near the surface from ships-of-opportunity, starting with bucket samples in the $19^{\text {th }}$ and early $20^{\text {th }}$ centuries followed by engine-intake measurements (e.g., Woodruff et al., 2008). On the physical side, SSTs are the main agent of communication between the atmosphere and the ocean, and thus represent a key quantity for probing DCV (for a discussion of the upper-ocean mixed layer heat budget, c.f. Deser et al., 2010).

Fig. 1 (left column) shows maps of SST data coverage based on the International Comprehensive Ocean Atmosphere Data Set (ICOADS) (Woodruff et al., 2008) during three representative 20-year periods spanning the late 19th and 20th centuries: 1870-1899, 1920-1939, and 1970-1989. These maps show the percentage of months with at least one measurement in a $2^{\circ}$ latitude by $2^{\circ}$ longitude grid box in the 20 -year period indicated. We note that the instrumental coverage falls off rapidly before 1870 , and that satellites provide nearly global coverage starting in the 1980s (see Woodruff et al., 2008 and Deser et al., 2010). The discrete outlines of commercial shipping routes and their changes over time are readily apparent, especially in the earlier time periods (Fig. 1). Broadly speaking, the North Atlantic, western South Atlantic, and northern Indian Ocean contain the highest density of observations, with reasonable coverage back to approximately 1870 . Data coverage in the North Pacific is limited before about 1920, in the Tropics before about 1960, and in the Southern Ocean before the advent of satellite remote sensing (Fig. 1). The uneven and changing spatial coverage of SST measurements from historical ship-based archives must be taken into account in any analysis of DCV. Further information on the spatiotemporal coverage of other SST data sets is available at climatedataguide.ucar.edu.

\section{The main phenomena of DCV}

In our view, there is no unique "best" approach to defining the main phenomena of DCV. Here, we adopt a basin-specific perspective, which has the advantage that 
any inter-basin linkages (including those lagged in time) are not built-in to the analysis protocol. Similarly, we analyze monthly data (lightly smoothed with a 3-point running mean) so as to avoid artificially building in any low-frequency behavior. In this regard, it is important to bear in mind the null hypothesis that any low-pass filtered time series will exhibit DCV, but it need not be physically meaningful (i.e., it may not be distinguishable from a random process).

We use the NOAA Extended Reconstruction Sea Surface Temperature, version 3b (ERSSTv3b) dataset, which employs a statistical procedure on the ICOADS data to fill in missing grid boxes (Smith et al., 2008); other data sets yield similar results (not shown). Following previous studies, we subtract the global mean SST anomaly (SSTA) from the SSTA at each grid box for each month and year (hereafter, we use the nomenclature SSTA* to denote this residual from the global mean) unless noted otherwise. This procedure is intended to remove any secular global trends that may be associated with changes in external radiative forcing such as those due to human-induced increases in greenhouse gas concentrations and sulfate aerosols accompanying fossil fuel burning. We shall return to the issue of how well this procedure achieves its intended purpose in Section 5.

We define the main phenomena of DCV for each basin separately as follows. North Pacific (NPAC): leading principal component (PC) time series of monthly SSTA* over the domain $\left(20^{\circ}-70^{\circ} \mathrm{N}, 110^{\circ} \mathrm{E}-100^{\circ} \mathrm{W}\right)$ following Mantua et al. (1997). North Atlantic (NATL): time series of SSTA* averaged over the domain $\left(0^{\circ}-60^{\circ} \mathrm{N}, 80^{\circ} \mathrm{W}-0^{\circ} \mathrm{W}\right)$ following Trenberth and Shea (2006). Southern Ocean (SO): time series of SSTA (not SSTA*) averaged over the domain $\left(50^{\circ}-70^{\circ} \mathrm{S}, 0^{\circ} \mathrm{W}-360^{\circ} \mathrm{E}\right)$ following Fan et al. (2014). We have inverted the SO time series to facilitate comparison with NPAC and NATL. These regions are outlined in Fig. 1c. To obtain the global-scale patterns associated with each time series, we regress SSTA* (SSTA for the case of the SO) at each grid box on the standardized index time series.

Before showing the spatial patterns of DCV, we return to the issue of data coverage. The right-hand panels of Fig. 1 show time series of data coverage in each region defined above, represented as the percentage of grid boxes that have at least one observation in each month. Consistent with the data coverage maps, the NPAC region shows $>50 \%$ of grid boxes with at least one observation starting around 1920 except during the 1940s (Fig. 1d). The NATL region shows $>50 \%$ of grid boxes present since about 1885 except for the World Wars and around 1900 (Fig. $1 \mathrm{e}$. Finally, coverage in the SO region is always $<40 \%$, and $<10 \%$ before 1950 (Fig. 1f). A large seasonal cycle is evident in the SO region, with peak coverage during summer (Fan et al., 2014). In view of these results, we choose to show the NPAC and NATL time series starting in 1890 (mindful of the reduced coverage in NPAC before 1920 ), and the SO record starting in 1950 . However, the global regression maps are all based on the period since 1950 to accommodate the lack of data over the Southern Ocean (and to a lesser extent, the Tropical Pacific) before that time.

The three SSTA* patterns show a great deal of similarity in their global structures, despite that they are based on different index regions. For example, NPAC shows a pan-Indo/Pacific pattern with symmetry about the equator, reminiscent of the low-frequency "tail" of ENSO (also termed the "Pacific Decadal Oscillation PDO or "Inter-Decadal Pacific Oscillation IPO) (Zhang et al., 1997; Power et al., 1999; Vimont, 2005; Newman et al., 2016). It also features linkages to the Atlantic in the form of alternating polarities with latitude, with positive values over the northern North Atlantic, and negative values over the Pacific sector of the Southern Ocean (Fig. 2a). NATL exhibits an out-of-phase relationship between SSTA* in the North and South Atlantic, distinct from that based on NPAC (Fig. 2b). However, it shares the same SSTA* polarity over the northern NATL and the same PDO-like structure, albeit with weaker magnitude, as that based on NPAC, and it shows negative values throughout the Southern Ocean (Fig. 2b).
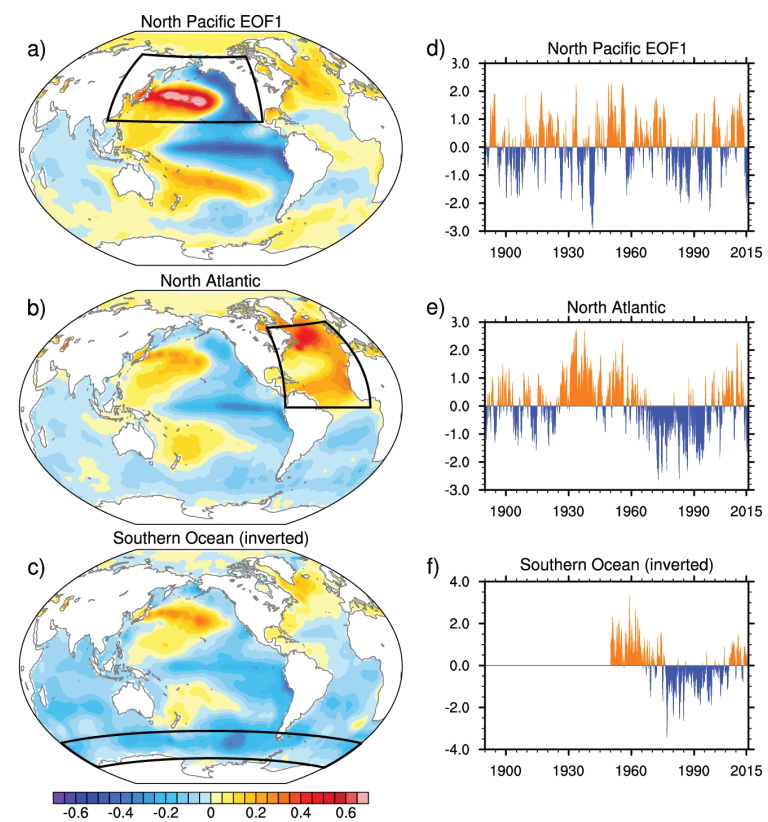

Figure 2: Spatial and temporal characteristics of sea surface temperature anomaly (SSTA) variability in selected ocean basins. (Left column) Global SSTA* regression maps (degrees C) based on the (a) leading principal component of North Pacific SSTA*, (b) North Atlantic SSTA*, and (c) inverted Southern Ocean SSTA. All indices were standardized prior to computing the regression maps. Index regions are outlined by black boxes. (Right column) Standardized 3-month running mean time series (1880-2015) of the (a) leading principal component of North Pacific SSTA*, (b) North Atlantic SSTA*, and (c) inverted Southern Ocean SSTA. Asterisk indicates that the global mean SSTA was removed prior to computing the time series and regression maps. 
Finally, the pattern based on the (inverted) SO index is very similar to that based on NATL, except for the sign over the northern tropical Atlantic (Fig. 2c).

The NPAC, NATL and SO index time series are remarkably similar during their period of overlap (1950-2015), with pronounced decadal-scale variability evident even in 3-month running mean data (Figs. 2d-f). In particular, each record swings from positive to negative and back to positive during 1950-2015, with a suggestion that NATL leads NPAC and SO by 10-20 years. Before 1950, NPAC shows less prominent decadal-scale variability and a weaker relationship with NATL than after 1950. We refrain from quantifying these statements due to the low number of degrees of freedom associated with such short records of DCV.

\section{Causes of DCV}

The substantial degree of commonality in the global-scale patterns associated with Pacific, Atlantic and Southern Ocean DCV, combined with the fact that they are based on short records and sparse sampling, make it challenging to identify these phenomena robustly in terms of spatial and temporal character. These constraints also make it difficult to assess whether they arise from distinctive dynamical processes operating on decadal time scales and/or whether they are best viewed as manifestations of a "random walk" process or processes (see also Newman et al., 2016). The concept of global-scale SSTA "hypermodes" (Dommenget and Latif, 2008; Dommenget, 2010; Clement et al., 2011) has been advanced to account for the similarity of global-scale SSTA patterns regardless of how they originate. This concept relies on the notion that the lower the frequency, the more global the pattern, due to the interplay between SSTA and the large-scale atmospheric circulation.

These issues highlight the need for a combined approach based on observations, paleo-climate records and modeling to delineate robust phenomena of DCV and to understand their causes. Indeed, modeling studies based on thousands of years of simulation for robust statistics suggest that Atlantic DCV and its globalscale teleconnections may originate from the mutual interaction of the oceanic Atlantic Meridional Overturning Circulation (AMOC) and the large-scale atmospheric circulation in the form of the North Atlantic Oscillation (NAO) (Delworth et al., 2016; Delworth and Zeng, 2016; Ruprich-Robert et al., 2016), although the mechanisms continue to be under investigation. Similar conclusions arise for Southern Ocean DCV (Latif et al, 2013; Latif et al., 2015; Zhang et al., 2016). Finally, Pacific DCV may reflect a combination of stochastic processes, each with a different decorrelation time scale and regional emphasis arising from dynamical and thermodynamic air-sea interaction (Clement et al., 2011; Okumura, 2013; Newman et al., 2016).

\section{Internal vs. externally-forced DCV}

As mentioned above, DCV is traditionally identified as the residual from the global mean SSTA; the latter interpreted as the secular fingerprint of human-induced climate change. However, human-induced climate change is not spatially uniform (Xie et al., 2010) and thus the removal of the global-mean SSTA may fall short of its intended purpose. The validity of this approach can be tested with large initial-condition ensembles of historical simulations with comprehensive coupled climate models, such as 40-member Community Earth System Model Large Ensemble (CESM-LE) (Kay et al., 2015). The CESM-LE has been used to isolate externally-forced and internally-generated components of simulated NATL DCV, with implications for observed NATL DCV (Tandon and Kushner, 2015; Murphy et al., 2016). These studies indicate that a significant portion of NATL DCV since 1920 may be externally-forced, and that empirical methodologies used to separate these components in the single observational record may be inadequate. Further work is needed to evaluate the efficacy of empirical approaches for separating forced and internal components of DCV, not only in the NATL but in other ocean basins as well. These approaches include linear (or other forms of) detrending, removal of the globalmean, optimal fingerprinting (Ting et al., 2009; Ting et al., 2014), pattern scaling (Hoerling et al., 2011; Bichet et al., 2015), and Empirical Ensemble Mode Decomposition (Wu et al., 2011).

\section{Concluding remarks}

We have presented a brief overview of the main phenomena of DCV based on simple analyses of observed SST over the historical record using a basin-specific approach. Our results indicate that DCV is apparent even in unfiltered seasonal data, and that DCV in the North Atlantic, North Pacific and Southern Ocean share many characteristics including their global-scale patterns and chronologies, especially since 1950. Results are more ambiguous before that time. Given the shortness of the observational record relative to the time scales of interest, we believe that DCV is best viewed in terms of a case study approach rather than as a robust and stationary statistical characterization. Long (thousands of years) model control simulations provide an effective tool for assessing the robustness and global-scale linkages of DCV, provided the model has a credible representation of the relevant processes governing DCV. Finally, an outstanding research question is the extent to which DCV is externally-forced vs. internally-generated.

\section{References}

Bichet, A., P. Kushner, L. Mudryk, L. Terray, and J. Fyfe, 2015: Estimating the Anthropogenic Sea Surface Temperature Response Using Pattern Scaling. J. Climate, 28,3751-3763, doi: 10.1175/JCLI-D-14-00604.1.

Clement, A., P. DiNezio, and C. Deser, 2011: Rethinking the 
Ocean's Role in the Southern Oscillation. J. Climate, 24, 4056-4072, doi: 10.1175/2011JCLI3973.1.

Delworth, T. L., F. Zeng, L. Zhang, R. Zhang, G. A. Vecchi1 and X. Yang, 2016: The central role of ocean dynamics in connecting the North Atlantic Oscillation to the Atlantic Multidecadal Oscillation, J. Climate, in press.

Delworth, T. L. and F. Zeng, 2016: The impact of the North Atlantic Oscillation on climate through its impact on the Atlantic Meridional Overturning Circulation. J. Climate. DOI: 10.1175/JCLI-D-15-0396.1

Deser, C., M. A. Alexander, S. -P. Xie, and A. S. Phillips, 2010: Sea surface temperature variability: patterns and mechanisms. Ann. Rev. Mar. Sci., 2010.2, 115-143, doi:10.1146/annurev-marine-120408-151453.

Dommenget, D. and M. Latif, 2008: Generation of hyper climate modes. Geophys. Res. Lett., 35, L02706, doi:10.1029/2007GL031087.

Dommenget, D., 2010: A slab ocean El Nino. Geophys. Res. Lett., 37, L20701, doi:10.1029/2010GL044888.

Fan, T., C. Deser, and D. P. Schneider, 2014: Recent Antarctic sea ice trends in the context of Southern Ocean surface climate variations since 1950 . Geophys. Res. Lett., 41, 2419-2426, doi:10.1002/2014GL059239.

Hoerling, M., J. Hurrell, A. Kumar, L. Terray, J. Eischeid, P. Pegion, T. Zhang, X. Quan, and T. Y. Xu, 2011 (August): On North American decadal climate for 2011-20. J. Climate, 24, 4519-4528.

doi:10.1175/2011JCLI4137.1

Kay, J. E., C. Deser, A. Phillips, and co-authors, 2015: The Community Earth System Model (CESM) Large Ensemble Project: A community resource for studying climate change in the presence of internal climate variability. Bull. Amer. Met. Soc., 96, 1333-1349, doi: 10.1175/ BAMS-D-13-00255.1.

Latif, M., T. Martin and W. Park, 2013: Southern Ocean sector centennial climate variability and recent decadal trends. J. Climate, 26, 7767-7782. DOI: 10.1175/ JCLI-D-12-00281.1.

Latif, M., T. Martin, W. Park, and M. Bordbar, 2015: Internal Southern Ocean Centennial Variability: Dynamics, Impacts and Implications for Global Warming. In Climate Change: Multidecadal and Beyond, pp.109-124.

DOI:10.1142/9789814579933_0007.

Mantua, N. J., S. R. Hare, Y. Zhang, J. M. Wallace, and R. C. Francis, 1997: A Pacific Interdecadal Climate Oscillation with Impacts on Salmon Production. Bull. Amer. Meteor. Soc, 78, 1069-1079.
Murphy, L. N., K. Bellomo, M. Cane and A. Clement, 2016: The Role of Historical Forcings in Simulating the Observed Atlantic Multidecadal Oscillation. Geophys. Res. Lett., in review.

Newman, M., M. A. Alexander, T. R. Ault, K. M. Cobb, C. Deser, E. Di Lorenzo, N. J. Mantua, A. J. Miller, S. Minobe, H. Nakamura, N. Schneider, D. J. Vimont, A. S. Phillips, J. D. Scott, and C. A. Smith, 2016: The Pacific decadal oscillation, revisited. J. Climate, in press. doi: 10.1175/ JCLI-D-15-0508.1.

Okumura, Y. M., 2013: Origins of tropical Pacific decadal variability: Role of stochastic atmospheric forcing from the South Pacific. J. Climate 26 (24), 9791-9796.

Power, S., T. Casey, C. Folland, A. Colman, and V. Mehta, 1999: Inter-decadal modulation of the impact of ENSO on Australia. Clim Dyn, 15, 319-324, doi:10.1007/ s003820050284.

Ruprich-Robert, Y., R. Msadek, F. Castruccio, S. Yeager, T. Delworth, and G. Danabasoglu, 2016: Assessing the Climate impacts of the observed Atlantic Mulitdecadal Variability using the GFDL CM2.1 and NCAR CESM1 Global Coupled Models. J. Climate, in press. doi: 10.1175/JCLI-D-16-0127.1.

Smith, T. M., R. W. Reynolds, T. C. Peterson, and J. Lawrimore, 2008: Improvements to NOAA's historical merged land-ocean surface temperature analysis (18802006). J. Climate, 21, 2283-2296.

DOI: $10.1175 / 2007 J C L I 2100.1$

Tandon, N.F., and P.J. Kushner, 2015: Does External Forcing Interfere with the AMOC's

Influence on North Atlantic Sea Surface Temperature? J. Climate, 28, 6309-6323. DOI:10.1175/JCLI-D-14-00664.1

Ting, M., Kushnir, Y., Seager, R., Li, C., 2009: Forced and internal twentieth-century SST in the North Atlantic. J. Climate, 22, 1469-1481.

Ting, M., Kushnir, Y., Li, C., 2014: North Atlantic Multidecadal SST Oscillation: External forcing versus internal variability, Journal of Marine Systems, 133, 2738.

Trenberth, K. E., and D. J. Shea, 2006: Atlantic hurricanes and natural variability in 2005. Geophys. Res. Lett., 33, L12704, doi:10.1029/2006GL026894.

Vimont, D. J. 2005: The contribution of the interannual ENSO cycle to the spatial pattern of decadal ENSO-like variability. J. Climate, 18, 2080-2092.

Woodruff, S. D., and co-authors, 2008: The evolving SST record from ICOADS, in Climate Variability and Extremes 
During the Past 100 Years, Adv. Global Change Res., vol. 33, edited by S. Brönnimann et al., pp. 65-83, Springer, New York.

Wu Z, Huang NE, Wallace JM, Smoliak BV, Chen X., 2011: On the time-varying trend in global-mean surface temperature. Clim Dyn 37:759-773.

Xie, S. -P., C. Deser, G. A. Vecchi, J. Ma, H. Teng, A. T. Wittenberg, 2010: Global warming pattern formation: sea surface temperature and rainfall. J. Climate, 23, 966986, doi:101175/2009JCLI3329.1.

Zhang, L., T. L. Delworth, and F. Zeng, 2016: The impact of multidecadal Atlantic meridional overturning circulation variations on the Southern Ocean. Clim. Dyn., DOI 10.1007/s00382-016-3190-8.

Zhang, Y., J. M. Wallace, and D. S. Battisti, 1997: ENSO-like interdecadal variability: 1900-93. J. Climate, 10, 10041020. 


\title{
Global impacts of the Atlantic Multidecadal Variability during the boreal winter
}

doi: $10.22498 /$ pages.25.1.7

\author{
Yohan Ruprich-Robert ${ }^{1}$, Rym Msadek ${ }^{2}$ \\ 1 Atmosphere and Ocean Sciences, Princeton University, and NOAA/GFDL, Princeton, New Jersey \\ 2 CNRS-CERFACS, Toulouse, France
}

\section{Introduction}

During the last century, the observed annual mean North Atlantic sea surface temperatures (SSTs) exhibited multidecadal fluctuations superimposed onto a longterm warming trend. This multidecadal variability has been referred to as the Atlantic Multidecadal Oscillation (AMO) or Variability (AMV). The SST anomalies that define the AMV are characterized by a basin-scale anomalous pattern that has the same sign in the whole North Atlantic, and a maximum loading in the subpolar gyre (SPG) region (Fig. 1).

Previous studies have shown that the AMV is associated with, and possibly the source of, marked climate anomalies over many areas of the globe. This includes droughts over Africa and North America (Mohino et al., 2011; Enfield et al., 2001), decline in Arctic sea ice (Mahajan et al., 2011), changes in Atlantic tropical cyclone activity (Vimont and Kossin, 2007), and recently it has been linked with the global temperature hiatus (McGregor et al., 2014; Li et al., 2015). Additionally, due to its upstream location, the North Atlantic SST is a main actor of the European climate variability. Sutton and Hodson (2005) and Sutton and Dong (2012) argue for the existence of a causal link between the warm phase of the AMV and warmer conditions than normal over Central Europe, drier conditions over the Mediterranean basin, and wetter conditions over Northern Europe during boreal summer. A number of studies suggest also that the AMV could impact the winter North Atlantic - Europe atmospheric circulation by modulating the number of blocking events and/or by driving North Atlantic Oscillation-like anomalies (Hakkinen et al., 2011; Davini et al., 2015; Peings and Magnusdottir, 2014, 2015; Omrani et al., 2014; Gastineau and Frankignoul, 2015). Furthermore, the AMV and its Pacific counterpart, the Interdecadal Pacific Oscillation (IPO), have been linked to multidecadal changes in the frequency of North American droughts (McCabe et al., 2004; Chylek et al., 2014). However, whether the concomitant forcing of the Atlantic and Pacific arise from a coincidence or reveal a causal link between Atlantic and Pacific decadal anomalies remains uncertain.

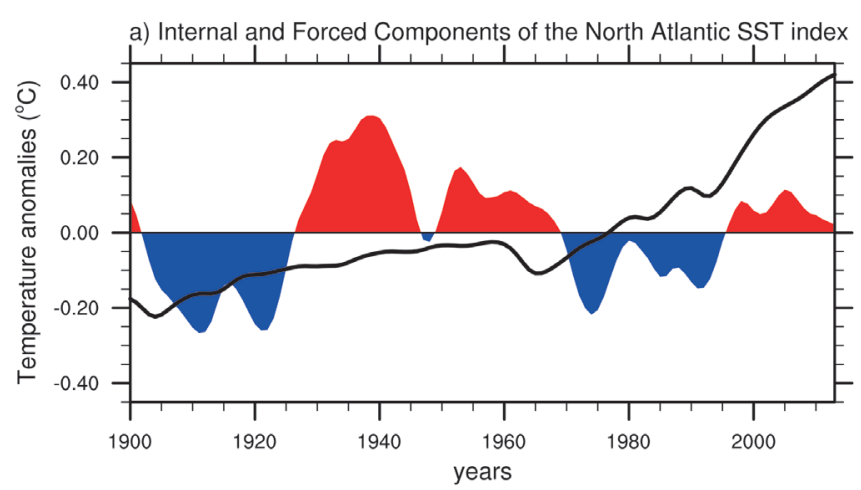

b) AMV spatial pattern

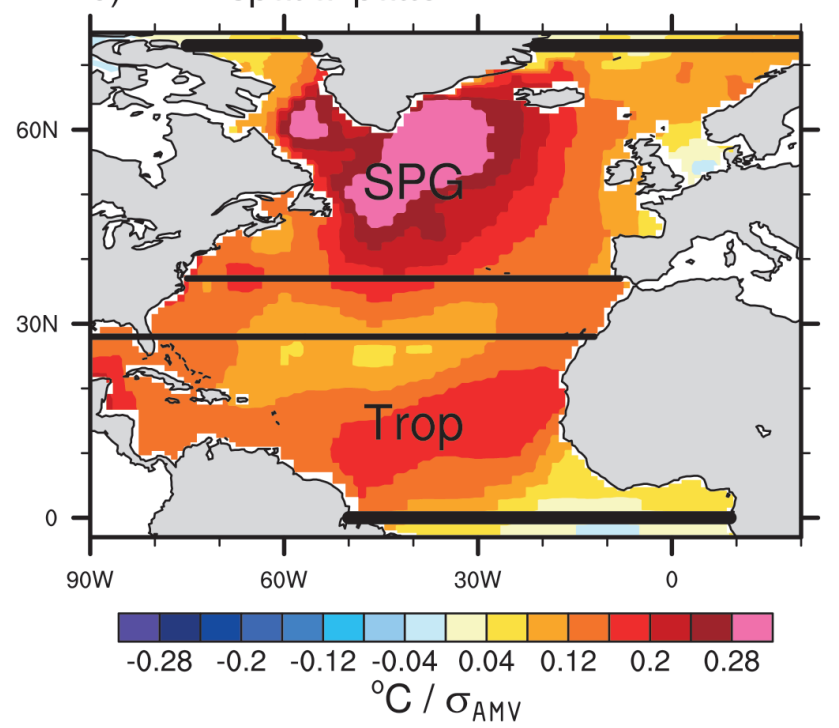

Figure 1: (a) Internal (red and blue) versus external (black) components of the observed North Atlantic SST multidecadal variability following Ting et al. (2009) definition. (b) Regression map of the observed annual mean SST (ERSSTV3; Smith et al. 2008) on the internal component of the North Atlantic SST index (i.e., the AMV index); units are ${ }^{\circ} \mathrm{C}$ per standard deviation of AMV index. Both SST field and AMV index time series have been low pass filtered prior to computing the regression, using a Lanczos filter (21 weights with a 10-yr cutoff period). The black latitudinal lines in b show the subpolar and tropical domains used for the SPG_AMV and Trop_AMV experiments (see section 2b). Figure from Ruprich-Robert et al. (2017). (C)American Meteorological Society. Used with permission. 
Given the many potential climate impacts of the AMV at decadal timescales, it is crucial to improve our knowledge of the mechanisms associated with AMV teleconnections. A better understanding of these mechanisms could help advance the prediction of AMV impacts and hence decadal climate predictions. We are providing here a short description of a recent coordinated multi-models study that investigates the global impacts of the observed $\mathrm{AMV}$, in which the respective role of the extratropical and tropical parts of the AMV have been identified.

\section{Description of model experiments}

To evaluate the AMV climate impacts, we performed idealized experiments using state-of-the art global coupled climate models, in which the North Atlantic SSTs are restored to time-invariant anomalies corresponding to an estimate of the internally driven component of the observed AMV (following Ting et al. 2009's approach; Fig. 1). The three models used in this study are the GFDLCM2.1 (Delworth et al., 2006; Wittenberg et al., 2006), the NCAR CESM1-CAM5 (hereafter CESM1; Kay et al., 2015), and the GFDL-FLOR (Vecchi et al., 2014). All three models use a nominal $1^{\circ}$ horizontal ocean resolution but employ different atmospheric resolutions. Specifically, the atmospheric resolution is about $2^{\circ}$ in CM2.1, $1^{\circ}$ in CESM1, and $0.5^{\circ}$ in FLOR.

Two experiments were performed with the three models, namely Full_AMV+ and Full_AMV-, in which SST anomalies corresponding to +1 or -1 standard deviation of the AMV index (i.e., plus or minus the AMV pattern shown in Fig. 1b) are imposed in the North Atlantic region, by restoring the model SST to the observed AMV anomalies plus the model's own SST climatology from $0^{\circ}$ to $73^{\circ} \mathrm{N}$. Outside of the restoring region, the models were let free, allowing a response of the full coupled climate system. Two additional sets of experiments similar to the Full_AMV experiments, but with the model North Atlantic SSTs restored to the observed AMV only in the North Atlantic subpolar gyre (SPG_AMV) or in the Tropical North Atlantic (Trop_AMV), were performed with CESM1 and CM2.1. For all experiments, we performed large ensemble simulations with 100 members for CM2.1, 30 members for CESM1, and 50 members for FLOR in order to robustly estimate the AMV climate impacts and the associated signal-to-noise ratio. In order to capture the potential response and adjustment of other oceanic basins to the AMV anomalies, all the simulations were integrated for 10 years with fixed external forcing conditions. In this article, we focus on the boreal winter ${ }^{1}$ climate response to AMV forcing and we discuss only the ensemble mean differences between the AMV+ and AMVsimulations. Further details regarding the experimental set-up and their results can be found in Ruprich-Robert et al. (2017) and Castruccio et al. (in revision).

\section{Results \\ a) Global impacts of the AMV}

During DJFM, restoring the three models to the observed AMV yields, as expected, a North Atlantic warming (Fig. $2 \mathrm{a}-\mathrm{c})$. The temperature pattern of the simulated anomalies shows some differences with the observed one of Fig. $1 \mathrm{~b}$. Specifically, the relative strength of the SPG anomalies compared to the tropical anomalies is much less than the observed one. This comes from our choice to keep a time and space invariant restoring timescale for the SST. By so doing, the extratropical North Atlantic SSTs are weakened due to the SPG deep mixed layers, which dilutes the imposed SST anomaly over a deeper oceanic column.

Regardless of this weakness, we find that outside of the North Atlantic, the three models simulate remarkably similar global teleconnections. We note a slight warming of the Indian Ocean and a negative phase of the IPO over the Pacific. The latter has negative SST anomalies in the Tropical Pacific that extend toward the higher latitudes in both Hemispheres along the eastern ocean boundary, in a horseshoe-like pattern, surrounding positive SST anomalies in the West. The three models show a warming of $\sim 0.3^{\circ} \mathrm{C}$ over Mexico and the Eastern part of US, a warming over East Brazil as well as over South Asia and the Mediterranean area. The models also agree on the simulated warming over Siberia and on the cooling of the northwestern part of North America. In response to $\mathrm{AMV}+$ forcing, CESM1 simulates a significant warming of the Arctic that is only found over the northeastern rim of Siberia in CM2.1 and FLOR. The models also disagree on the temperature response over Northern Europe: CM2.1 simulates a warming there whereas CESM1 and FLOR tend to simulate a cooling.

We find that AMV leads to significant changes in the atmospheric winter circulation as illustrated by precipitation and geopotential height at $500 \mathrm{hPa}$ (Z500) anomalies (Figs. 2d-f and Fig. 3b) ${ }^{2}$. There is a northward shift and a reinforcement of the Intertropical Convergence Zone all over the tropical belt as well as a southwestward shift of the South Pacific Convergence Zone. The precipitation response over the Tropical Pacific is coherent with a La Niña-like temperature pattern seen in Figs. 2a-b. We further analyzed the amplitude of the ENSO response ${ }^{3}$ and found that in all models the occurrence of La Niña events roughly doubles between the Full_AMV-and the Full_AMV+ experiments.

Over the extratropical North Pacific, the AMV leads to a weakening of the Aleutian Low (Fig. 3b) associated with an east-west dipole in the precipitation anomalies over the

\footnotetext{
${ }^{1}$ Defined as the December to March seasonal mean. ${ }^{2}$ In view of concision, only $\mathrm{Z} 500$ response from CESM1 is shown here, but we specify in the following when this response is different among the models.

${ }^{3}$ To do so, we defined an ENSO index based on the first EOF of the upper 200 $\mathrm{m}$ oceanic heat content computed over the tropical Pacific $\left(30^{\circ} \mathrm{S}-30^{\circ} \mathrm{N}\right)$.
} 

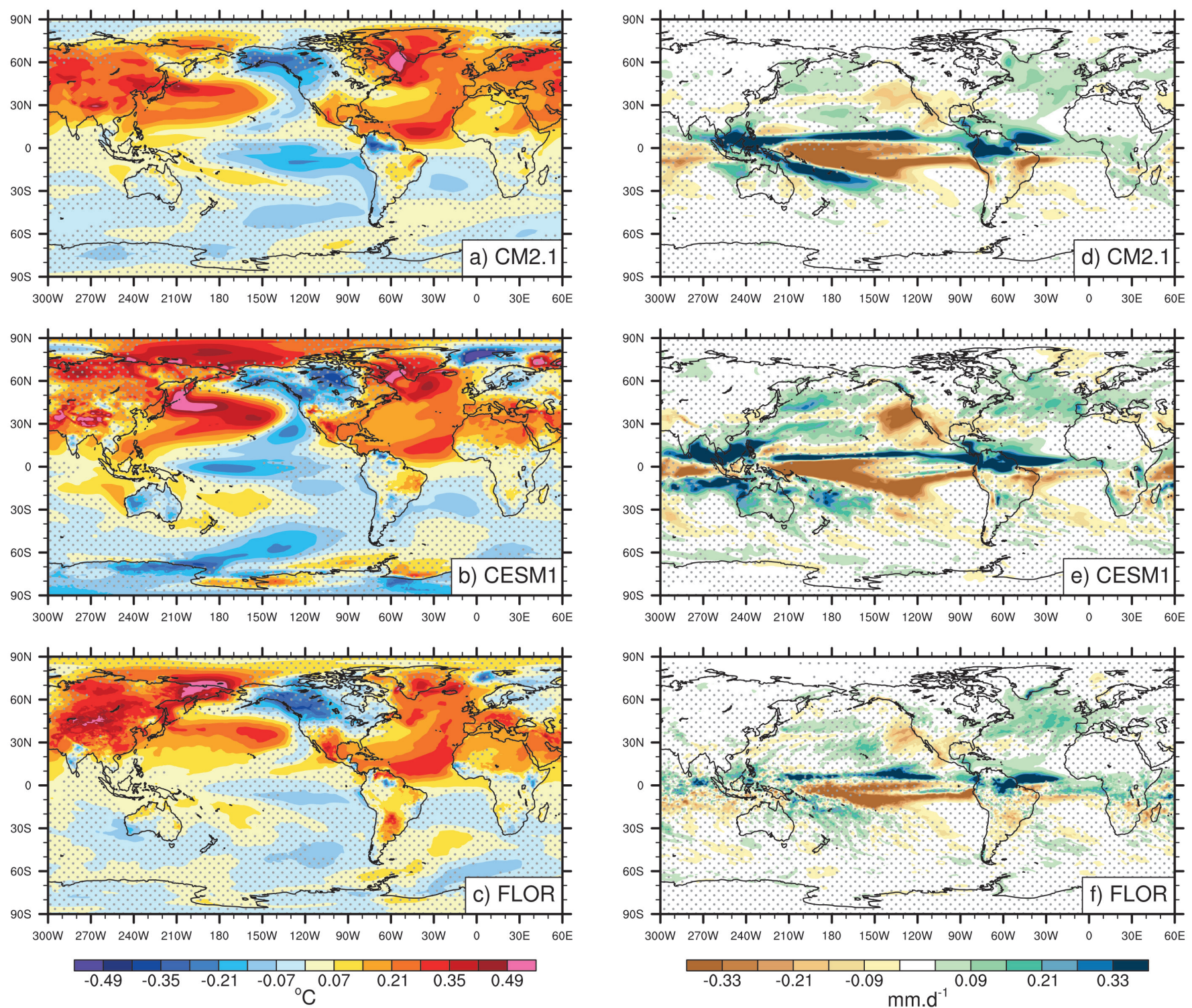

Figure 2: Differences between the 10-year average of the Full_AMV+ and the Full_AMV- ensemble simulations for December to March (DJFM) of ( $a, b, c)$ 2-meter air temperature and ( $d, e, f)$ precipitation. Results are shown from top to bottom for CM2.1, CESM1, and FLOR. Stippling indicates regions that are below the 95\% confidence level of statistical significance according to a twosided t-test. Note that the contours intervals of T2 in a, b, and c have been multiplied by 1.75 compared to Figure $\mathbf{1 b}$.

North Pacific and decrease of precipitation over the west coast of US and Mexico (Figs. 2d-f). The Z500 anomalies are reminiscent of the negative phase of the Pacific North America pattern (PNA) (Barnston and Livezey, 1987), with positive Z500 anomalies centered over the Aleutian Low and Mexico and negative anomalies over Canada and south of Hawaii. The latter center of action is more visible when looking at streamfunction anomalies at $200 \mathrm{hPa}$ (hereafter SF200; Fig. 3b).

The North Pacific SST response is also consistent with the Aleutian Low weakening as discussed by Zhang and Delworth (2015). In their study, they linked a northward shift of the westerlies to a northward shift of the oceanic gyre circulation through a Sverdrup balance and to the propagation of oceanic Rossby waves from the central Pacific to the western coast, explaining the warmer SST off Japan. Over the northeastern side of the North Pacific, the SST cooling is driven by an anomalous advection of cool air from the Arctic. Furthermore, this whole North Pacific response is reminiscent of that documented in the water hosing experiments of Zhang and Delworth (2005), Dong and Sutton (2007) and Okumura et al. (2009), although the impacts are weaker in our experiments as expected from the weaker imposed forcing.

While the North Pacific response is significant and robust among the three models, the North Atlantic - Europe (NAE) response is notably weaker. All models simulate an increase of precipitation over Southern Europe, but these 

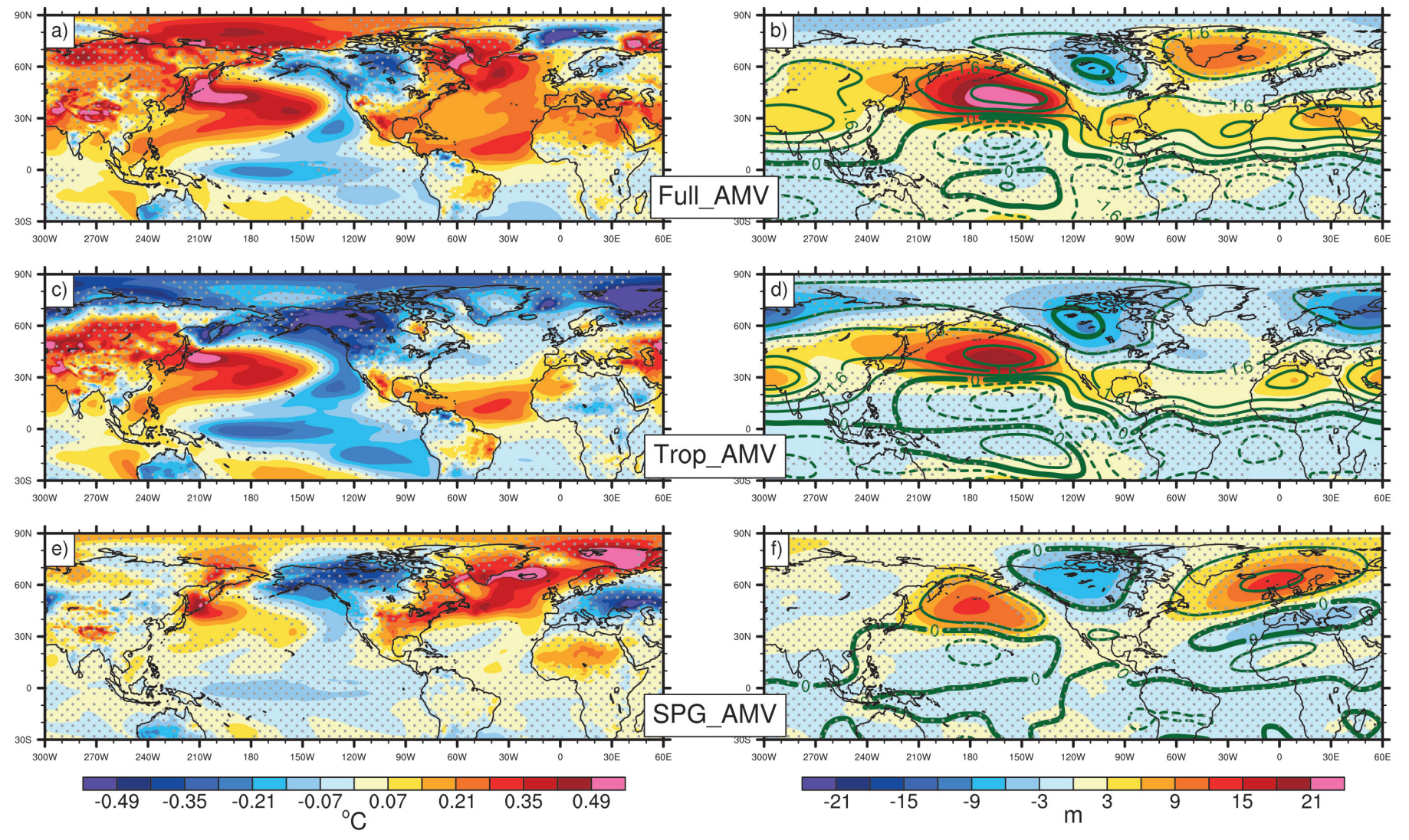

Figure 3: Difference between the 10-year average of the positive and the negative phases of (a, b) Full_AMV, (c, d) Trop_AMV, (e, f) SPG_AMV for CESM1 in DJFM. (left) 2-meter air temperature (T2m) and (right) geopotential height at 500 hPa (Z500, color) and streamfunction of the wind at $200 \mathrm{hPa}$ (SF200, contours at intervals of $0.8 \times 10^{6} \mathrm{~m}^{2} \mathrm{~s}^{-1}$ ). Stippling indicates regions that are below the 95\% confidence level of statistical significance. Figure adapted from Ruprich-Robert et al. (2017). (C)American Meteorological Society. Used with permission.

anomalies are only significant in CESM1. In CESM1 and FLOR, these precipitation anomalies are associated with a weak anomalous north-south Z500 dipole that projects on the NAO in its negative phase (hereafter NAO-). The geopotential anomalies in CM2.1 do not project strongly onto the $\mathrm{NAO}$, even though positive anomalies are present over Iceland. For CM2.1 this diagnostic suggests that the NAE atmospheric response might project onto a mix of both an NAO- and a negative phase of the East Atlantic Pattern ${ }^{4}$ (not shown). We further quantified the signalto-noise ratio of the climate response to AMV and, for all models we found that the NAE atmospheric response accounts for less than $10 \%$ of the decadal variance. The discrepancy between the models and the weak atmospheric response over the NAE region suggest that the AMV does not strongly impact the atmosphere over there. We acknowledge however that our experimental protocol may lead to an underestimation of the extratropical AMV forcing and hence potentially to an underestimation of the atmospheric response over the NAE region. Indeed, as discussed above, our choice to keep a time and spatially-invariant restoring timescale does not allow to strongly constrain the SST over a region with deep oceanic mixed layer such as the SPG.

\section{b) Tropical vs Extratropical SST contribution to the AMV climate impacts}

We investigated the respective contribution of the tropical and extratropical parts of the AMV to the climate impacts described in the previous section by performing two additional sets of experiments in which only the subpolar (SPG_AMV) or the tropical (Trop_AMV) parts of the AMV pattern were imposed. Only the results from the CESM1 experiments are shown here, but these experiments were also performed with CM2.1 and we discuss the results from both models. We find that the Pacific IPO-like and PNA-like responses are primarily driven by the tropical part of the AMV (Figs. 3c,d). This result corroborates the studies of Kucharski et al. (2015) and McGregor et al. (2014) who suggested that the tropical Pacific cooling observed during the last decades was forced by the tropical Atlantic warming through a modification of the Walker Circulation. In line with Sutton and Hodson (2005), we find that the AMV impacts over the Americas are mainly explained by the tropical part of the AMV but that they are reinforced by the subpolar part of the phenomenon (Figs. 3a,c,e).

${ }^{4}$ This mode is defined in observations as the second mode of variability of the atmosphere over the NAE region (e.g., Barnston and Livezey 1987). 
The models show marginal impacts over North Africa and Europe in terms of $\mathrm{T} 2 \mathrm{~m}$ anomalies in response to the tropical AMV anomalies only, whereas a warming of North Africa and a cooling of Europe is simulated in response to the SPG anomalies. This cooling is consistent with the Z500 dipole anomaly seen over the NAE region, which tends to decrease the atmospheric flow from the relatively warm ocean to the relatively cool European continent in winter. Further, the $\mathrm{Z} 500$ dipole response in the SPG_AMV experiment is shifted eastward compared with the NAO response seen in the Full_AMV experiment (Fig. 3b). This suggests that the subpolar part of the AMV is the primarily driver of the NAE atmospheric response but that both the tropical and the extratropical parts of the AMV contribute to the overall NAE atmospheric response.

The SPG_AMV experiment generates a strikingly larger global atmospheric response in CESM1 than in CM2.1. For the former, the subpolar gyre part of the AMV leads to impacts in T2m and Z500 over the North Pacific region that are weaker but similar in pattern to those driven by the tropical part of the AMV. This is consistent with the weak but significant warming simulated in the tropical North Atlantic in the CESM1 SPG_AMV experiment. This also suggests that part of the tropical signature of the AMV is forced by the subpolar part of the AMV as suggested by Dunstone et al. (2011) and Smirnov and Vimont (2012) but that this mechanism is model-dependent.

\section{Summary and discussion}

We investigated the climate impacts associated with the internal component of the observed Atlantic Multidecadal Variability (AMV) using the GFDL-CM2.1, the NCARCESM1, and the GFDL-FLOR coupled models, by restoring their North Atlantic SSTs to the observed anomalies. This coupled approach allowed us to determine the full climate response to the imposed North Atlantic anomalies.

Over the North Atlantic European (NAE) region, we show that, despite the large-scale warming of the Northern Hemisphere continents simulated in all models during the boreal winter (DJFM), the models disagree on the Northern Europe temperature response. They disagree also on the NAE atmospheric circulation response, which projects on the negative phase of the North Atlantic Oscillation (NAO) for CESM1 and FLOR. The disagreement between the models and the weak signalto-noise ratio of the NAE atmospheric response reveal strong uncertainties on the role played by the AMV in the decadal variations of the NAO observed during the last century. They also suggest the need to repeat such coordinated experiments with other models.

For the three models, we find that the AMV warming drives a change in the Walker Circulation that drives precipitation anomalies over the whole tropical belt. The AMV warming leads also to reduced rainfall over the western part of the US and Mexico and to a weak increase of rainfall over Europe. The Walker Circulation response is associated with broad Pacific anomalies that project onto the Interdecadal Pacific Oscillation (IPO) in its negative phase. In the three models the northern part of the IPOlike SST response is tightly linked to a negative phase of the Pacific North American teleconnection pattern (PNA). We find that both the IPO and PNA-like responses are mainly driven by the Tropical part of the AMV.

Our results stress the importance played by the North Atlantic Ocean variability associated with the AMV in driving decadal changes on a global scale, especially in the Pacific. They also indicate that the AMV has played an important role in global climate variability observed during the last century. In the present study, we specifically focus on the climate impacts associated with an estimate of the internal component of the observed AMV, which has been shown as predictable to some extent on multi-year to decadal timescale (e.g., Robson et al., 2012; Yeager et al., 2012; Msadek et al., 2014). Our results are therefore encouraging for the prospect of getting skillful decadal predictions over regions outside of the North Atlantic through the impacts of AMV. The teleconnections we highlight between the Atlantic and the Pacific are also consistent with the studies of Chikamoto et al. (2012, 2015), who showed that phase shifts of the IPO as those observed in the late 1990's might be predicted few years in advance if the sign and amplitude of the AMV are predicted.

The general impacts and mechanisms described in the present study are based on three climate models that show quite similar results despite their different atmospheric resolution. This gives confidence in the robustness of our conclusions regarding AMV impacts. However, conducting such experiments within a multimodel framework, using other coupled climate models, will be highly beneficial to strengthen our conclusions. This will be done as part of the CMIP6 Decadal Climate Prediction Project (DCPP), which calls for coordinated experiments following a protocol similar to the one proposed in this study (Boer et al., 2016).

\section{Acknowledgment}

The analysis and plots of this paper were performed with the NCAR Command Language (version 6.2.0, 2014), Boulder, Colorado (UCAR/NCAR/CISL/VETS, http:// dx.doi.org/10.5065/D6WD3XH5). NCAR is sponsored by the National Science Foundation (NSF). The CESM is supported by the NSF and the US Department of Energy. This work is supported by the NSF under the Collaborative Research EaSM2 grant OCE-1243015 to NCAR and by the NOAA Climate Program Office under the Climate Variability and Predictability Program grant NA130AR4310138 to NCAR and GFDL. 


\section{References}

Barnston, A. G., and R. E. Livezey, 1987: Classification, seasonality and persistence oflow-frequency atmospheric circulation patterns. Mon. Weather Rev., 115, 1083-1126, doi:10.1175/1520-0493(1987)115<1083:CSAPOL>2.0. CO;2.

Boer, G. J., and Coauthors, 2016: The Decadal Climate Prediction Project. Geosci. Model Dev. Discuss., 0, 1-32, doi:10.5194/gmd-2016-78. http://www.geosci-modeldev-discuss.net/gmd-2016-78/.

Castruccio, F., Y. Ruprich-Robert, S. Yeager, G. Danabasoglu, R. Msadek, T. Deloworth, 2017: Modulation of Arctic Sea Ice Loss by Atmospheric Teleconnections from Atlantic Multi-decadal Variability. Geophys. Res. Lett., in revision.

Chikamoto, Y., M. Kimoto, M. Watanabe, M. Ishii, and T. Mochizuki, 2012: Relationship between the Pacific and Atlantic stepwise climate change during the 1990s. Geophys. Res. Lett., 39, 2-7, doi:10.1029/2012GL053901.

Chikamoto, Y., and Coauthors, 2015: Skilful multi-year predictions of tropical trans-basin climate variability. Nat. Commun., 6, 6869, doi:10.1038/ncomms7869. http:// www.nature.com/doifinder/10.1038/ncomms7869.

Chylek, P., M. K. Dubey, G. Lesins, J. Li, and N. Hengartner, 2014: Imprint of the Atlantic multi-decadal oscillation and Pacific decadal oscillation on southwestern US climate: past, present, and future. Clim. Dyn., 43, 119129, doi:10.1007/s00382-013-1933-3. http://link. springer.com/10.1007/s00382-013-1933-3.

Davini, P., J. Von Hardenberg, and S. Corti, 2015: Tropical origin for the impacts of the Atlantic Multidecadal Variability on the Euro-Atlantic climate. Environ. Res. Lett., 10, 094010, doi:10.1088/17489326/10/9/094010. http://stacks.iop. org $/ 1748-9326 / 10 / \mathrm{i}=9 / \mathrm{a}=094010$ ? key=crossref. e13c7c1e10966cb8fd2a872e288a8724.

Delworth, T. L., and Coauthors, 2006: GFDL's CM2 global coupled climate models. Part I: Formulation and simulation characteristics. J. Clim., 19, 643-674, doi:10.1175/JCLI3629.1.

Dong, B., and R. T. Sutton, 2007: Enhancement of ENSO Variability by a Weakened Atlantic Thermohaline Circulation in a Coupled GCM. J. Clim., 20, 4920-4939, doi:10.1175/JCLI4284.1. http://journals.ametsoc.org/ doi/abs/10.1175/JCLI4284.1.

Dunstone, N. J., D. M. Smith, and R. Eade, 2011: Multi-year predictability of the tropical Atlantic atmosphere driven by the high latitude North Atlantic Ocean. Geophys. Res. Lett., 38, n/a - n/a, doi:10.1029/2011GL047949. http:// doi.wiley.com/10.1029/2011GL047949(Accessed
December 16, 2013).

Enfield, D. B., A. M. Mestas-Nuñez, and P. J. Trimble, 2001: The Atlantic Multidecadal Oscillation and its relation to rainfall and river flows in the continental U.S. Geophys. Res. Lett., 28, 2077.

Gastineau, G., and C. Frankignoul, 2015: Influence of the North Atlantic SST Variability on the Atmospheric Circulation during the Twentieth Century. J. Clim., 26, 2969-2972, doi:10.1029/1999GL900613.

Hakkinen, S., P. B. Rhines, and D. L. Worthen, 2011: Atmospheric Blocking and Atlantic Multidecadal Ocean Variability. Science (80-. )., 334, 655-659, doi:10.1126/ science.1205683. http://www.sciencemag.org/cgi/ doi/10.1126/science.1205683.

Hermanson, L., R. Eade, N. H. Robinson, N. J. Dunstone, M. B. Andrews, J. R. Knight, A. A. Scaife, and D. M. Smith, 2014: Forecast cooling of the Atlantic subpolar gyre and associated impacts. Geophys. Res. Lett., 41, 51675174, doi:10.1002/2014GL060420. http://doi.wiley. com/10.1002/2014GL060420.

Kay, J. E., and Coauthors, 2015: The Community Earth System Model (CESM) Large Ensemble Project: A Community Resource for Studying Climate Change in the Presence of Internal Climate Variability. Bull. Am. Meteorol. Soc., 96, 1333-1349, doi:10.1175/ BAMS-D-13-00255.1. http://journals.ametsoc.org/doi/ abs/10.1175/BAMS-D-13-00255.1.

Kucharski, F., F. S. Syed, A. Burhan, I. Farah, and A. Gohar, 2015: Tropical Atlantic influence on Pacific variability and mean state in the twentieth century in observations and CMIP5. Clim. Dyn., 44, 881-896, doi:10.1007/ s00382-014-2228-z. http://link.springer.com/10.1007/ s00382-014-2228-z.

Li, X., S.-P. Xie, S. T. Gille, and C. Yoo, 2015: Atlantic-induced pan-tropical climate change over the past three decades. Nat. Clim. Chang., 1-13, doi:10.1038/nclimate2840. http: / / www.nature.com/doifinder / 10.1038 / nclimate2840.

Mahajan, S., R. Zhang, and T. L. Delworth, 2011: Impact of the Atlantic Meridional Overturning Circulation (AMOC) on Arctic Surface Air Temperature and Sea Ice Variability. J. Clim., 24, 6573-6581, doi:10.1175/2011JCLI4002.1. http://journals.ametsoc. org/doi/abs/10.1175/2011JCLI4002.1.

McCabe, G. J., M. a Palecki, and J. L. Betancourt, 2004: Pacific and Atlantic Ocean influences on multidecadal drought frequency in the United States. Proc. Natl. Acad. Sci. U. S. A., 101, 4136-4141, doi:10.1073/pnas.0306738101. 
McGregor, S., A. Timmermann, M. F. Stuecker, M. H. England, M. Merrifield, F.-F. Jin, and Y. Chikamoto, 2014: Recent Walker circulation strengthening and Pacific cooling amplified by Atlantic warming. Nat. Clim. Chang., 4, 888-892, doi:10.1038/nclimate2330. http:// www.nature.com/nclimate/journal/v4/n10/full/ nclimate2330.html?WT.ec_id=NCLIMATE-201410.

Mohino, E., S. Janicot, and J. Bader, 2011: Sahel rainfall and decadal to multi-decadal sea surface temperature variability. Clim. Dyn., 37, 419-440, doi:10.1007/s00382010-0867-2. http://link.springer.com/10.1007/s00382010-0867-2.

Msadek, R., and Coauthors, 2014: Predicting a Decadal Shift in North Atlantic Climate Variability Using the GFDL Forecast System. J. Clim., 140707141053007, doi:10.1175/JCLI-D-13-00476.1.http: / /journals. ametsoc.org/doi/abs/10.1175/JCLI-D-13-00476.1.

Okumura, Y. M., C. Deser, A. Hu, A. Timmermann, and S.-P. Xie, 2009: North Pacific Climate Response to Freshwater Forcing in the Subarctic North Atlantic: Oceanic and Atmospheric Pathways. J. Clim., 22, 1424-1445, doi:10.1175/2008JCLI2511.1. http://journals.ametsoc. org/doi/abs/10.1175/2008JCLI2511.1 (Accessed December 16, 2013).

Omrani, N. E., N. S. Keenlyside, J. Bader, and E. Manzini, 2014: Stratosphere key for wintertime atmospheric response to warm Atlantic decadal conditions. Clim. Dyn., 42, 649-663, doi:10.1007/s00382-013-1860-3.

Ruprich-Robert, Y., R. Msadek, F. Castruccio, S. Yeager, T. Delworth, and G. Danabasoglu, 2017: Assessing the Climate Impacts of the Observed Atlantic Multidecadal Variability Using the GFDL CM2.1 and NCAR CESM1 Global Coupled Models. J. Clim., 30, 2785-2810, doi:10.1175/JCLI-D-16-0127.1. http://journals.ametsoc. org/doi/10.1175/JCLI-D-16-0127.1.

Schubert, S., and Coauthors, 2009: A US CLIVAR Project to Assess and Compare the Responses of Global Climate Models to Drought-Related SST Forcing Patterns: Overview and Results. J. Clim., 22, 52515272, doi:10.1175/2009jcli3060.1. < Go to ISI >:// WOS:000270423300018\nhttp://journals.ametsoc.org/ doi/pdf/10.1175/2009JCLI3060.1.

Smirnov, D., and D. J. Vimont, 2012: Extratropical Forcing of Tropical Atlantic Variability during Boreal Summer and Fall. J. Clim., 25, 2056-2076, doi:10.1175/ JCLI-D-11-00104.1. http://journals.ametsoc.org/doi/ abs/10.1175/JCLI-D-11-00104.1.

Sutton, R. T., and D. L. R. Hodson, 2005: North Atlantic forcing of North American and European summer climate.
Science (80-. )., 309, 115-118. papers2://publication/ doi/10.1126/science.1109496.

Sutton, R. T., and D. L. R. Hodson, 2007: Climate Response to Basin-Scale Warming and Cooling of the North Atlantic Ocean. J. Clim., 20, 891-907, doi:10.1175/JCLI4038.1. http://journals.ametsoc.org/doi/abs/10.1175/ JCLI4038.1.

Sutton, R. T., and B. Dong, 2012: Atlantic Ocean influence on a shift in European climate in the 1990s. Nat. Geosci., 5, 788-792, doi:10.1038/ngeo. http://dx.doi.org/10.1038/ ngeo 1595.

Ting, M., Y. Kushnir, R. Seager, and C. Li, 2009: Forced and Internal Twentieth-Century SST Trends in the North Atlantic*. J. Clim., 22, 1469-1481, doi:10.1175/2008JCLI2561.1. http://journals.ametsoc. org/doi/abs / 10.1175/2008JCLI2561.1(Accessed December 16, 2013).

Vecchi, G. A., and Coauthors, 2014: On the Seasonal Forecasting of Regional Tropical Cyclone Activity. J. Clim., 27, 7994-8016, doi:10.1175/JCLI-D-14-00158.1. http://journals.ametsoc.org/doi/abs/10.1175/ JCLI-D-14-00158.1.

Vimont, D. J., and J. P. Kossin, 2007: The Atlantic Meridional Mode and hurricane activity. Geophys. Res. Lett., 34, L07709, doi:10.1029/2007GL029683. http://doi.wiley. com/10.1029/2007GL029683 (Accessed December 16, 2013).

Wittenberg, A. T., A. Rosati, N. C. Lau, and J. J. Ploshay, 2006: GFDL's CM2 global coupled climate models. Part III: Tropical Pacific climate and ENSO. J. Clim., 19, 698722, doi:10.1175/JCLI3631.1.

Yeager, S., A. Karspeck, G. Danabasoglu, J. Tribbia, and H. Teng, 2012: A Decadal Prediction Case Study: Late Twentieth-Century North Atlantic Ocean Heat Content. J. Clim., 25, 5173-5189, doi:10.1175/JCLI-D-11-00595.1. http://journals.ametsoc.org/doi/abs /10.1175/ JCLI-D-11-00595.1 (Accessed December 12, 2013).

Zhang, L., and T. L. Delworth, 2015: Analysis of the Characteristics and Mechanisms of the Pacific Decadal Oscillation in a Suite of Coupled Models from the Geophysical Fluid Dynamics Laboratory. J. Clim., 28, 76787701, doi:10.1175/JCLI-D-14-00647.1. http://journals. ametsoc.org/doi/abs/10.1175/JCLI-D-14-00647.1.

Zhang, R., and T. L. Delworth, 2005: Simulated Tropical Response to a Substantial Weakening of the Atlantic Thermohaline Circulation. J. Clim., 18, 1853-1860. 


\title{
Arctic sea ice seasonal-to-decadal variability and long-term change
}

doi: 10.22498/pages.25.1.14

\section{Dirk Notz}

\author{
Max Planck Institute for Meteorology, Hamburg, Germany
}

\section{Introduction}

The large-scale loss of Arctic sea ice in recent decades is one of the most prominent indicators of the ongoing global climate change. This derives from three main reasons. First, climate change is amplified in the Arctic ("Arctic amplification", e.g. Pithan et al. (2013)), so consequences of changes in the global-mean climate are more readily observed at high latitudes compared to middle and lower latitudes. Second, while many observables change gradually with global mean climate, Arctic sea ice is among those observables that might eventually cross a binary threshold from "existing" to "non-existing", which amplifies the perception of the underlying gradual trend. And third, as a consequence, changes in "Arctic sea ice coverage" are easier to grasp and communicate to a general public than changes in more abstract metrics such as "global mean temperature".

The observed changes in Arctic sea ice are not only a clear local indicator of large-scale climate change; the ice loss also has a number of sometimes far-reaching worldwide consequences. These include physical phenomena such as the possible impact on mid-latitude weather system or the disruption of the oceanic uptake of $\mathrm{CO}_{2}$, but also societal consequences such as the opening of new shipping routes or the necessary changes in the lifelihood of the Arctic indigenous population.

The importance of sea ice loss both as an indicator and as an active player in the ongoing climate change has motivated some intense research into understanding the temporal evolution of sea ice on time scales from seasons to decades. In this contribution, I use a combined analysis of the observational record and of climate model simulations to explain and summarize some of these findings.

\section{Seasonal variability: The importance of atmospheric chaos}

Recent years have seen an increase in research activities aimed at forecasting the evolution of Arctic sea ice on time scales of a few months. There is good reason to believe that such seasonal-scale forecasts should be possible, with model studies emphasizing in particular the rather long memory of the sea ice state imprinted in the sea ice thickness fields (e.g., Blanchard-Wrigglesworth et al., 2011), and the long memory of the oceanic heat content that determines the regional evolution of Arctic sea ice (e.g., Bushuk et al., 2015).

The underlying research is in part driven by very practical applications, such as ship routing, but will also increase our fundamental understanding of air-ice-sea interactions at high latitudes. Related activities are for example coordinated by the Polar Prediction Project with its flagship Year of Polar Prediction 2017-2019 (www.polarprediction.net, under the auspices of WMO World Weather Research Programm WWRP), by the Polar Climate Predictability Initiative (www.climatecryosphere.org/wcrp/pcpi, under the auspices of the WMO World Climate Research Program WCRP), and by the Sea ice Prediction Network with its Sea ice Outlook activity (www.arcus.org/sipn).

In this latter activity, various research groups try to forecast the minimum Arctic sea ice area coverage in September based on the observed state of the sea ice cover from May onwards. The groups use a variety of methods, ranging from heuristic methods to seasonal prediction systems based on coupled climate models. An analysis of the forecast quality of the various methods has shown a mixed picture, with no single method giving significantly better results than any other (Stroeve et al., 2014).

This finding is possibly surprising in that idealised studies with seasonal prediction systems usually result in significant prediction skill of many months up to a few years in advance (Blanchard-Wrigglesworth et al., 2016). In this framework referred to as "perfect model", a single model simulation is taken as the "observed truth", while additional model simulations with slightly perturbed initial conditions are used to estimate whether this "truth" can be forecast.

The striking difference in the forecast quality of such idealised studies compared to those trying to forecast the real world might be explicable by three main factors. First, the forecast skill strongly depends on a proper knowledge of the initial state of the system. As shown by Bunzel et al. (2016), the incomplete knowledge of May sea ice concentration as reflected by the differences between different satellite data sets can cause differences 

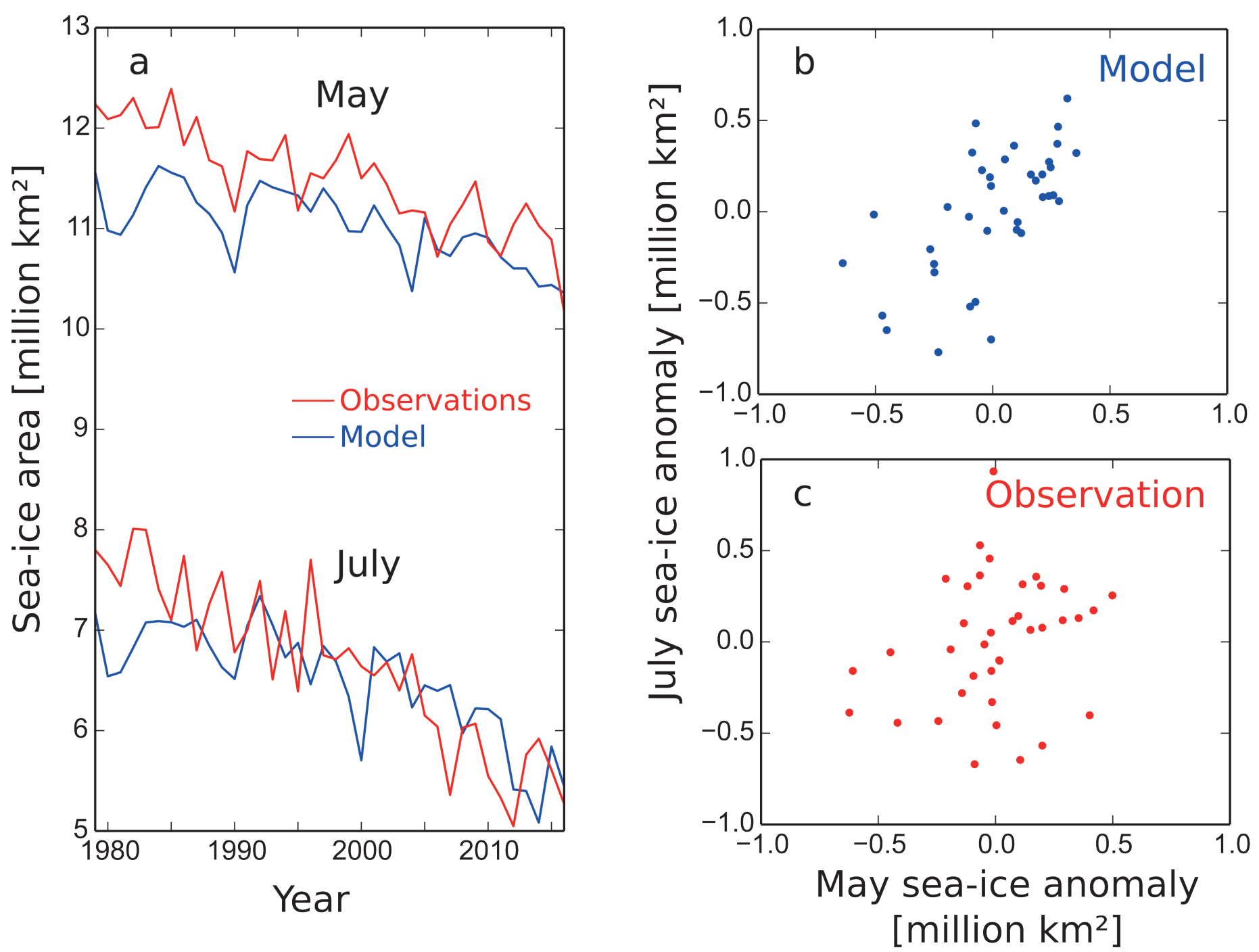

Figure 1: (a) Evolution of modeled and observed Arctic sea ice area in May and July (1979-2016). (b) Modeled Arctic sea ice area in July as a function of observed Arctic sea ice area in May of the same year. (c) Observed Arctic sea ice area in July as a function of observed Arctic sea ice area in May of the same year. Observations for all panels are based on the Arctic sea ice index (Fetterer et al., 2002, updated 2016). Model simulations for all panels are based on the first ensemble member of the CMIP5 simulations of MPI-ESM-LR (Notz et al., 2013).

in forecast mean September Arctic temperature of several degrees, and in forecast September Arctic sea ice area of 2 million $\mathrm{km}^{2}$. The incomplete knowledge of initial conditions of the sea ice cover arises because the microwave signature that is usually used to assess ice concentration reacts sensitively to snow coverage and melt-pond formation on the ice, for example. Different algorithms compensate these uncertainties in different ways, causing substantial differences of the observed sea ice area. Because of positive feedbacks such as the ice-albedo feedback, these differences in initial conditions are substantially amplified during summer and contribute to the much lower forecast quality of realworld applications compared to perfect model studies. Incomplete knowledge of the state of the underlying ocean certainly also contributes to these uncertainties.

Second, the forecast skill might be negatively affected by the initial shock and drift in the forecast runs in a real- world application. Both are absent in a perfect-model study, as its forecasts are usually started from a model state that is perfectly consistent with model physics. In contrast, the initial state for any simulation starting from a model state based on observations will usually be more or less inconsistent with model physics, possibly causing substantial drift that can quickly compensate for any added value from the assimilation of observations.

A third factor that might cause the systematically better forecast skill in idealised model studies relates to possible model errors in the simulation of the persistence of the Arctic sea ice cover. Take, for example, the relationship between Arctic sea ice area in May and Arctic sea ice area in July during the observational period 1979-2016 (Fig. 1a). The time series of these two months are highly correlated because of their underlying trend, both in the observations and in the model simulations. 
However, the detrended time series are only significantly correlated in the model simulations (Fig. 1b), with the Pearson rank coefficient of the correlations indicating a chance of far less than $1 \%$ that these time series are uncorrelated. In contrast, chances are above $30 \%$ that there is no significant correlation between the detrended observed time series of sea ice area in May and the detrended observed time series of sea ice area in July (Fig. 1c).

This suggests that at least an idealised study based on the particular model employed here (MPI-ESM-LR) will result in an unrealistically large potential forecast skill of seasonal predictions. We are currently examining whether this finding also holds for other models, and are in particular trying to investigate the underlying reasons for this different behaviour in the model compared to reality.

\section{Annual variability: The importance of negative feedbacks}

In addition to seasonal forecasts on time scales of a few months, also forecasts on time scales of a few years have made some headlines over the past decade. These headlines were usually related to claims that the Arctic would lose its remaining summer sea ice within just a few years. The underlying reasoning of such claims was often related to a discussion of a possible 'tipping point' that is related to the ice-albedo feedback. Given the substantial loss of Arctic sea ice in the past few years, the ocean could potentially absorb enough heat to rapidly melt the remainder of the sea ice cover.

However, our current understanding of the Arctic climate system strongly suggests that this reasoning is unrealistic. A first indication for this finding derived from model experiments in which all Arctic sea ice was synthetically removed from the Arctic Ocean at the onset of summer, thus maximising the possible ice-albedo feedback (Tietsche et al., 2011). Despite such maximised feedback, the ice cover recovered in these experiments within just a few years. This is because on annual time scales, negative feedbacks dominate the evolution of the Arctic sea ice cover. Three negative feedbacks are particularly important: First, the open ocean very effectively releases its heat to the atmosphere during winter, causing a rapid loss of much of the heat that was accumulated in the icefree water during summer. Second, the thin ice that forms during winter can grow much more rapidly than ice that survived the summer, because heat can more effectively be transported from the ocean to the atmosphere when the ice cover is thin (Bitz and Roe, 2004). Third, as ice forms later in the season, it will carry a thinner insolating snow cover as any snow fall occurring before ice formation simply falls into the open ocean (Notz, 2009).

The effectiveness of these negative feedbacks on an annual time scale is not only apparent in our model simulations; a) September sea-ice area

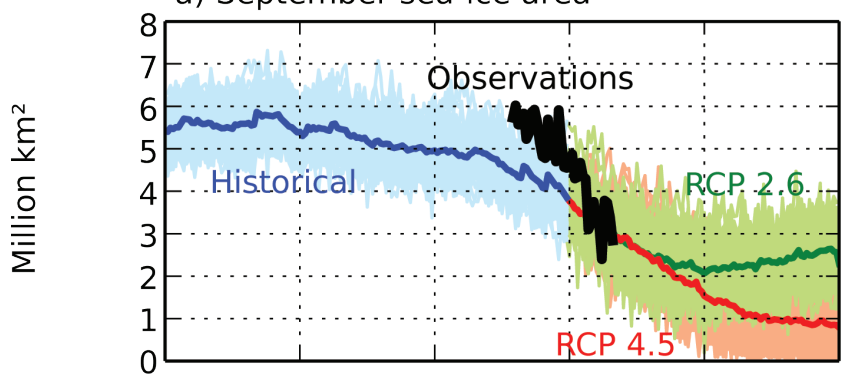

b) 10 year trend
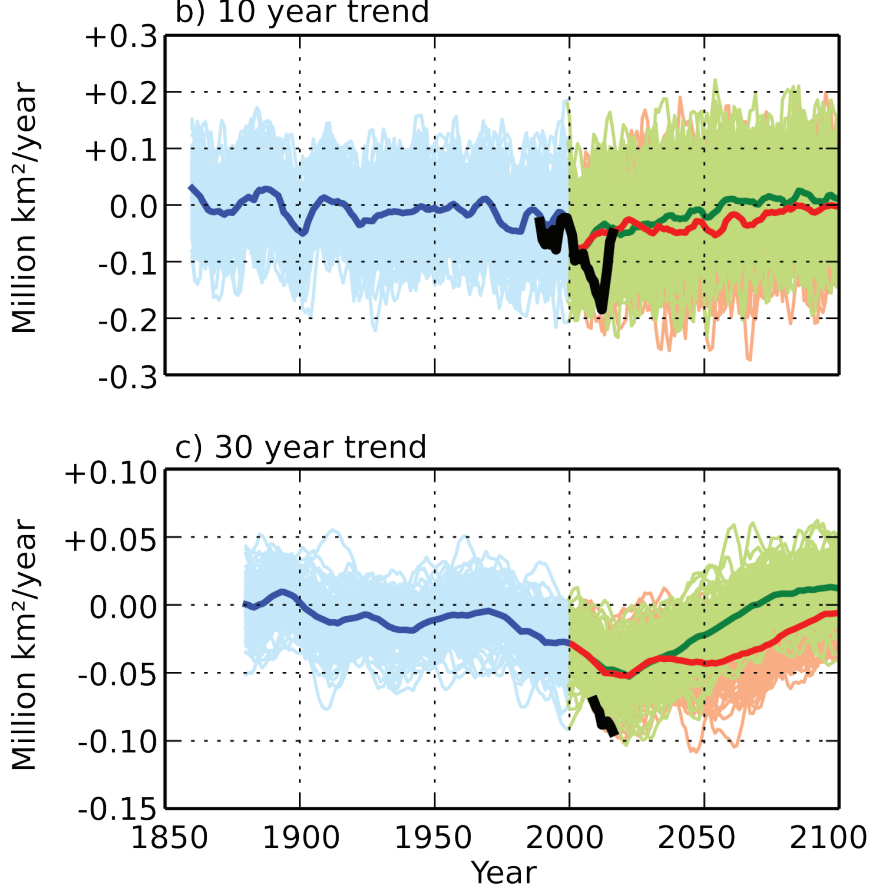

d) September sea-ice area

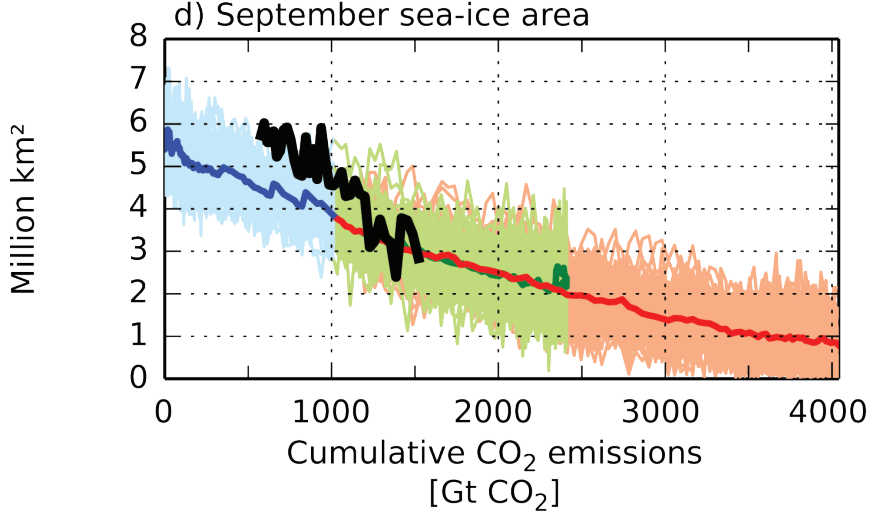

Figure 2: (a) Evolution of modeled and observed Arctic sea ice area in September (1850-2016). (b) Evolution of ten-year linear trends of Arctic sea ice area, plotted at the end point of the ten year averaging period. (c) Evolution of thirty-year linear trends of Arctic sea ice area, plotted at the end point of the thirty year averaging period. (d) Evolution of modeled and observed Arctic sea ice area in September (1850-2100) as a function of cumulative anthropogenic $\mathrm{CO}_{2}$ emissions. Observations for all panels are based on the Arctic sea ice index (Fetterer et al., 2002, updated 2016). Model simulations for all panels are based on the 100 member ensemble of MPIESM-LR. 
the observed time series of Arctic summer sea ice also carries a clear signature of such mechanisms. A year with a strong drop in ice coverage during September is usually followed by an increase in September ice coverage in the following year. More formally, the time series shows significant negative autocorrelation (Notz and Marotzke, 2012). If indeed the ice albedo feedback was as effective on annual time scales as implied by statements supporting the entire loss of Arctic summer sea ice within this decade, one would certainly expect that any year with a strong drop in ice coverage would be followed by a year with yet another drop. This is found neither in the observational record, nor in model simulation. This underpins the dominance of negative feedbacks, which stabilize the Arctic ice cover and prevent a possible "tipping point".

\section{Decadal variability: The importance of internal variability}

Internal climate variability not only governs a substantial part of the sea ice evolution on seasonal-to-interannual time scales as discussed above, but also affects the longer term trends of sea ice (Swart et al., 2015; Notz, 2015). To exemplify this, large ensembles of simulations of coupled Earth System Models are particularly helpful (Swart et al., 2015). At the Max-Planck-Institute for Meteorolgy, we have recently finished a 100 member large ensemble of simulations with our Earth System Model MPI-ESMLR for the historical period, and for two possible future emission scenarios, RCP2.6 and RCP4.5. In comparing the simulated Area sea ice area during September with the observational record 1979-2016, we find that the observed sea ice area is at the upper edge of the ensemble spread during the earlier years of the record, and approaches the mean of the ensemble in the more recent past (Fig. 2a).

Ten-year long trends within the observational record have consistenly been negative with values ranging from a mean loss of $23000 \mathrm{~km}^{2}$ per year during the period 1990-1999 to a mean loss of $180000 \mathrm{~km}^{2}$ during the period 2003-2012 (black line in Fig. 2b). This latter period includes the two record minima that have been observed in 2007 and 2012. For the most recent period 2007-2016, the average ice loss has been around $50000 \mathrm{~km}^{2}$ per year. All these numbers are well within the range simulated by individual ensemble members of MPI-ESM-LR, which show over ten year-long periods a sea ice evolution ranging from a mean loss of around $200000 \mathrm{~km}^{2}$ per year to a mean gain of around $100000 \mathrm{~km}^{2}$ per year (shaded range in Fig. 2b). In particular, it is noteworthy that the mean ten-year long trends for the first 20 years of the satellite record and for the most recent past are very close to the mean trend of the 100 member ensemble, including a slowdown of the ice loss during the 1990s and an accelaration during the early 2000s. This agreement during substantial periods of the record suggests that the rather sudden drop in observed sea ice area that occured in the year 2007 has been an extreme event compatible with internal climate variability and therefore cannot directly be compared to the ensemble mean across several models or to the ensemble mean across multiple simulations with one model. If this characterisation of this sea ice loss as an extreme event was correct, any realistic climate model should on average simulate a slower ice loss than has been observed (see also Notz (2015) for a detailed discussion).

Regarding the future evolution of sea ice, the model simulations with MPI-ESM-LR suggest a similar range of possible ten year trends than over the past few decades. Hence, in extreme cases and providing the hypothesis that the level of internal climate variability simulated is correct, the sea ice cover might in the future potentially once again lose ice as fast as during the first decade of this century, or, in contrast, gain an average of 100000 $\mathrm{km}^{2}$ per year for a decade despite the ongoing global warming (see also Swart et al., 2015).

In order to more confidently predict the near-term evolution of Arctic sea ice, the underlying reasons for internal variability must be understood better. A number of recent studies point in particular to the impact of oceanic heat transport into the Arctic for driving lowfrequency variability of the ice cover, including a possible contribution to the recent acceleration of sea ice loss (e.g., Årthun et al., 2012). These studies emphasize that a scenario with a much slower sea ice loss for the next decade is plausible if oceanic heat transport were to weaken (Zhang, 2015; Yeager et al., 2015). Such weakening of the oceanic heat transport would not only affect the sea ice cover itself, but also its future predictability on seasonal time scales (Germe et al., 2014). This then directly links the challenge of decadal forecasting of sea ice to that of its seasonal forecasting as described in the previous section.

\section{Long-term changes: The importance of the external forcing}

On longer time scales, internal variabililty also remains a substantial contributor to the evolution of Arctic sea ice area. The 100 member simulations suggest a possible spread in observed September sea ice area of around 2 million $\mathrm{km}^{2}$ for any given year (Fig. $2 \mathrm{a}$ ). In terms of trends, even long-term trends over 30 years show substantial variability (Fig. 2c). For example, the model suggests that over the past 30 years, sea ice area in the Arctic could have remained roughly constant or could have decreased roughly as quickly as observed. This large spread in 30year long trends again suggests that using these trends as metrics for the purpose of model evaluation can be misleading (Notz, 2015), in particular if the observed evolution of Arctic sea ice corresponds to a possible extreme event. 
Despite the large impact of internal variability, the dominant role of external forcing in the observed evolution of Arctic sea ice is clear (Notz and Marotzke, 2012). The weight of the external forcing becomes particularly apparent if one examines the average evolution of Arctic sea ice coverage in the 100 member ensemble as a function of cumulative anthropogenic $\mathrm{CO}_{2}$ emissions (Fig. 2d). The long-term evolution of the sea ice cover directly follows the cumulative emissions. In particular, there is no clear difference in mean sea ice coverage between RCP 2.6 and RCP 4.5 for any given cumulative $\mathrm{CO}_{2}$ emission.

We have recently been able to explain this relationship, which is largely based on the fact that the position of the outer edge of the sea ice cover is determined by the net local energy balance (Notz and Stroeve, 2016). Any rise in atmospheric $\mathrm{CO}_{2}$ concentration increases the incoming longwave radiation at the ice edge, causing the latter to move northward to a region with less incoming shortwave radiation. For geometric reasons, these combined processes lead to a roughly linear relationship between Arctic sea ice loss and anthropogenic $\mathrm{CO}_{2}$ emissions in the obervational record and in all CMIP5 model simulations. In the obervations, about $3 \mathrm{~m}^{2}$ of sea ice are lost per ton of $\mathrm{CO}_{2}$ emissions, while the models on average only simulate an ice loss of $1.7 \mathrm{~m}^{2}$ per ton of $\mathrm{CO}_{2}$ emissions.

The fact that the relationship between cumulative $\mathrm{CO}_{2}$ emissions and Arctic sea ice area is roughly linear strongly suggests a dominating role of the $\mathrm{CO}_{2}$ emissions for the evolution of sea ice area. However, other external drivers are also apparent, in particular in the mean across all simulations of our 100-member ensemble. Most striking are temporary increases in Arctic sea ice area following large volcanic eruptions during the historical period, most recently in 1991 after the Pinatubo eruption, in 1982 after the eruption of El Chichon and in 1963 after the eruption of Mount Agung (compare also Zanchettin et al., 2014). Because of the large internal variability and the relatively short-lived response, these eruptions are impossible to identify in the temporal evolution of individual simulations nor the observational record, but they apparently have contributed to a synthetic improvement of CMIP5 sea ice simulations relative to CMIP3 sea ice simulations (Rosenblum and Eisenman, 2016).

\section{Conclusions}

This short overview presents some recent work on the variability and long-term evolution of Arctic sea ice area. For space constraints, the focus was only on September sea ice coverage as this is the month with the strongest observed trends. The discussion can be summarized as follows:

- On seasonal time scales, atmospheric internal variability and its imprint on sea ice renders skillful predictions of September sea ice coverage more than two months in advance inherently difficult.

- On annual time scales, negative feedbacks stabilize the sea ice cover. There is no "tipping point" beyond which the loss of the remaining summer sea ice becomes unstoppable

- On decadal time scales, internal climate variability can cause a substantial acceleration or temporary recovery of the sea ice cover that renders the evaluation of individual model simulations based on their short-term trends impossible.

- $\quad$ On longer time scales, internal variability causes a substantial spread in possible 30-year long trends supporting for the production of large model ensembles. Nevertheless, the impact of anthropognic forcing on the long-term sea ice evolution is clear, with an average loss of $3 \mathrm{~m}^{2}$ of September sea ice cover per metric ton of anthropogenic $\mathrm{CO}_{2}$ emission.

\section{References}

Årthun, M., T. Eldevik, L. H. Smedsrud, Ø. Skagseth, and R. B. Ingvaldsen, 2012: Quantifying the influence of Atlantic heat on Barents Sea ice variability and retreat, J. Clim., 25, 4736-4743, doi:10.1175/JCLI-D-11-00466.1.

Bitz, C., and G. Roe, 2004: A mechanism for the high rate of sea ice thinning in the Arctic Ocean. J. Clim., 17 (18), 3623-3632.

Blanchard-Wrigglesworth, E., K. C. Armour, C. M. Bitz, and E. DeWeaver, 2011: Persistence and inherent predictability of Arctic sea ice in a GCM ensemble and observations, J. Climate, 24, 231-250.

Blanchard-Wrigglesworth, E., and Coauthors, 2016: Multi-model seasonal forecast of Arctic sea ice: forecast uncertainty at pan-Arctic and regional scales. Clim. Dyn., 1-12, 10.1007/s00382-016-3388-9.

Bushuk, M., D. Giannakis, and A. J. Majda, 2015: Arctic sea ice reemergence: The role of large-scale oceanic and atmospheric variability, J. Climate, 28, 5477-5509.

Bunzel, F., D. Notz, J. Baehr, W. A. Müller, and K. Fröhlich, 2016: Seasonal climate forecasts significantly affected by observational uncertainty of Arctic sea ice concentration. Geophys. Res. Lett., 43 (2), 2015GL066 928, 10.1002/2015GL066928.

Fetterer, F., K. Knowles, W. Meier, and M. Savoie, 2002, updated 2016: Sea ice index. Digital media, National Snow and Ice Data Center, Boulder, Colorado USA.

Germe, A., M. Chevallier, D. S. y Mélia, E. Sanchez Gomez, and C. Cassou,2014, Interannual predictability of Arctic sea ice in a global climate model: Regional contrasts and temporal evolution, Clim. Dyn., 43(9-10), 2519-2538.

Notz, D., 2009: The future of ice sheets and sea ice: 
Between reversible retreat and unstoppable loss. Proc. Nat. Ac. Sci., 106 (49), 20 590-20 595, doi:10.1073/ pnas.0902356 106.

Notz, D., 2015: How well must climate models agree with observations? Phil. Trans. R. Soc. A, 373 (2052), 20140 164, 10.1098/rsta.2014.0164.

Notz, D., A. Haumann, H. Haak, J. Jungclaus, and J. Marotzke, 2013: Arctic sea ice evolution as modeled by MPI-ESM. J. Adv. Model. Earth Syst., 5, 173-194, 10.1002/ jame.20016.

Notz, D., and J. Marotzke, 2012: Observations reveal external driver for arctic sea ice retreat. Geophys. Res. Lett., 39 (8), L051 094, 10.1029/2012GL051094.

Notz, D., and J. Stroeve, 2016: Observed Arctic sea ice loss directly follows anthropogenic $\mathrm{CO}_{2}$ emission. Science, aag2345, 10.1126/science.aag2345.

Pithan, F., B. Medeiros, and T. Mauritsen, 2013: Mixedphase clouds cause climate model biases in Arctic wintertime temperature inversions. Clim Dyn, 43 (1-2), 289-303, 10.1007/s00382-013-1964-9.

Rosenblum, E., and I. Eisenman, 2016: Faster Arctic Sea ice Retreat in CMIP5 than in CMIP3 due to Volcanoes. J. Climate, 29 (24), 9179-9188, 10.1175/JCLI-D-16-0391.1.

Stroeve, J., L. C. Hamilton, C. M. Bitz, and E. BlanchardWrigglesworth, 2014: Predicting September sea ice: Ensemble skill of the SEARCH Sea ice Outlook 20082013. Geophys. Res. Lett., 41 (7), 2014 GL059 388, 10.1002/2014GL059388.

Swart, N. C., J. C. Fyfe, E. Hawkins, J. E. Kay, and A. Jahn, 2015: Influence of internal variability on Arctic sea ice trends. Nature Clim. Change, 5 (2), 86-89, 10.1038/ nclimate2483.

Tietsche, S., D. Notz, J. H. Jungclaus, and J. Marotzke, 2011: Recovery mechanisms of Arctic summer sea ice. Geophys. Res. Lett., 38 (L02707), 10.1029/2010GL045698.

Yeager, S. G., A. R. Karspeck, and G. Danabasoglu, 2015: Predicted slowdown in the rate of Atlantic sea ice loss, Geophys. Res. Lett., 42, doi:10.1002/2015GL065364.

Zanchettin, D., O. Bothe, C. Timmreck, J. Bader, A. Beitsch, H. F. Graf, D. Notz, and J. H. Jungclaus, 2014: Inter-hemispheric asymmetry in the sea ice response to volcanic forcing simulated by MPI-ESM (COSMOS-Mill). Earth Syst. Dynam., 5, 223-242.

Zhang, R., 2015: Mechanisms for low-frequency variability of summer Arctic sea ice extent, Proc. Natl. Acad. Sci. 


\title{
Decadal climate variability and the global \\ energy balance
}

doi: $10.22498 /$ pages.25.1.20

\section{Richard P. Allan}

\author{
Department of Meteorology, University of Reading, UK
}

\section{Introduction}

The Earth's energy balance represents a nexus between radiative forcings which set the trajectory of climate change and feedbacks which determine the nature and magnitude of the response. Yet entwined within the observed decadal variability and trends are complex, unforced interactions within the climate system. The energy and water cycles are intimately linked and observed precipitation changes contain signals from unforced fluctuations as well as rapid adjustments to radiative forcing and responses to the longer-term heating or cooling; this is mediated by the oceans which dominate the effective heat capacity of the climate system. It is essential to monitor key indicators of climate including the evolving energy budget to interpret global change in the context of intrinsic multidecadal variability.

Fig. 1 displays variability and change in global-mean surface temperature, atmospheric moisture, precipitation and the top of atmosphere energy balance over the period 1979-2016. This includes a mixture of observationallybased estimates combined with the European Centre for Medium-range Weather Forecasts (ECMWF) interim reanalysis (ERAI) (Dee et al., 2011), which continually adjusts a numerical model by applying data assimilation to an evolving and diverse set of global observations. Also shown are atmosphere-only "AMIP" experiments from phase 5 of the Coupled Model Intercomparison Project (CMIP5) (Taylor et al., 2011) which apply realistic radiative forcing and observed surface temperature and sea ice distributions over the 1979-2008 period (an ensemble mean with a one standard deviation spread across models are displayed). The surface temperature, water vapor and precipitation variability depicted in Fig. 1a-c update Allan et al. (2014a) while Fig. 1d exploits top of atmosphere energy budget estimates from Allan et al. (2014b).

Considering deseasonalised monthly surface temperature (Ts) anomalies from HadCRUTv4.5 (Morice et al., 2012), the globe has warmed at $0.16 \mathrm{~K} /$ decade when considering the period 1988-2015 chosen to coincide with the introduction of the special sensor microwave imager (SSM/I) series of satellite instruments in 1987.
This trend is punctuated by episodic warm El Niño events (e.g. 1997/98, 2015/16) and cool La Niña episodes (e.g 1999,2011 ) which alter global monthly mean surface temperature by up to around 0.2-0.3 K. At longer timescale, increased La Niña frequency linked to multi-decadal strengthening of the Walker circulation (L'Heureux et al., 2013) suppressed decadal surface warming rates during 2000-2010 (Xie \& Kosaka, 2017). The opposite was observed during 1980-1990 characterized by recurrent and strong El Nino events, which boosted the warming trend. The Ts anomalies are well represented by AMIP

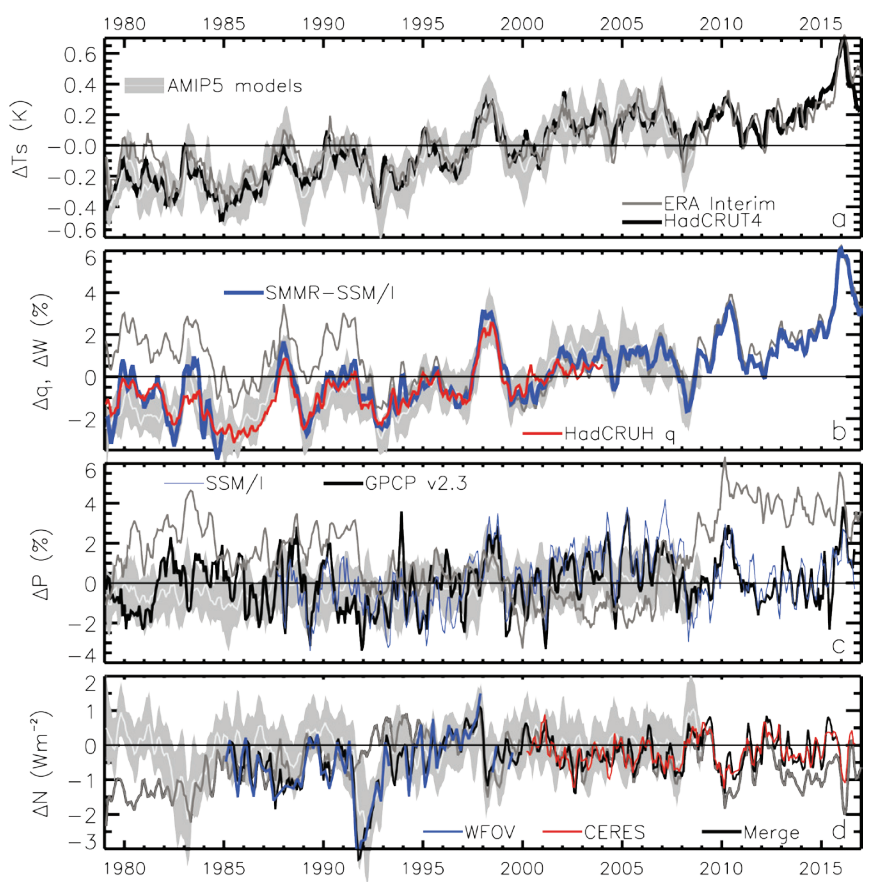

Figure 1: Deseasonalised monthly anomalies with respect to $1995-2000$ in global mean (a) surface temperature, (b) column integrated or surface water vapor, (c) precipitation and (d) top of atmosphere net radiation for a combination of satellite and surface observationally-based estimates, atmosphere-only climate models using prescribed observed sea surface temperature and sea ice (AMIP) and a the ERAI reanalysis over the period 1979-2016 (3 month smoothing is applied). 
simulations (which prescribe observed sea surface temperatures while land Ts is explicitly simulated) and ERAI (which also prescribes ocean surface temperature but land Ts is somewhat constrained by observations through data assimilation). ERAI anomalies up to $0.2 \mathrm{~K}$ higher than HadCRUT4 in late 2016 are likely due in part to the lack of interpolation of observed values over the Arctic (Cowtan and Way, 2014).

Atmospheric column integrated water vapour closely tracks the temperature changes, as expected from the strong temperature dependence of saturation vapor pressure determined by the Clausius Clapeyron equation, and there is broad agreement between the range of surface in situ observations, satellite-based datasets and AMIP simulations. The satellite estimates sample the icefree ocean (a combination of microwave measurements taken from the F08/F11/F13/F17 series of Defence Meteorological Satellite Program satellites; Wentz, 2013) and are here combined with ERAI over remaining regions: these indicate a moistening of $1.2 \% /$ decade for 1988-2015; interestingly this trend is only marginally suppressed (by about $-0.2 \%$ /decade) during the 2000 2012 period of slower surface warming.

The resultant additional water vapor continuum absorption in the more transparent window regions of the infrared spectrum cause a reduction in surface loss of clear-sky longwave radiation of $\sim 1.4 \mathrm{Wm}^{-2}$ per $\mathrm{mm}$ of precipitable water vapor (Allan, 2009) which translates to reduced clear-sky surface net longwave radiative loss of $\sim 0.4 \mathrm{Wm}^{-2}$ per decade, consistent with more detailed modelling estimates (Wild et al., 2008). Enhanced absorption of sunlight by the increasing water vapor additionally reduces net radiative energy loss by the atmosphere and contributes to solar "dimming" at the surface (Haywood et al., 2011).

Observed global mean column integrated moisture increases with $\mathrm{Ts}$ at $7.2 \pm 0.4 \% / \mathrm{K}$ based on linear regression $(r=0.87)$, in agreement with the combination of Ts and moisture trends. This is consistent with simple thermodynamics which strongly determine global low altitude water vapor although variability and change over land appears less constrained (Simmons et al. 2010). Climate model AMIP simulations capture the SSM/Ibased variability and earlier Scanning Multi-channel Microwave Radiometer (SMMR)-based microwave estimates while ERAI anomalies are in close agreement after the 1991-1993 period during which an unrealistic drop in global ocean moisture affects the reanalysis. There is a remarkable agreement in interannual variability between independent HadCRUH surface specific humidity observations (Willett et al., 2008) and the satellite-based estimates of column integrated moisture, with a consistent increasing trend over the coinciding 1988-2004 period (Allan et al., 2014a).
Low altitude moisture provides the fuel for rainfall events (Trenberth et al., 2003) yet global precipitation is determined by atmospheric energy balance, primarily attributable to net radiative energy loss (Allen and Ingram, 2002; O'Gorman et al., 2012). Given these global driving factors, combined with the heterogeneous distribution of precipitation and associated measurement limitations, it is no surprise that variability and trends in global precipitation (Fig. 1c) contrast markedly to that of water vapor and temperature (Fig. 1a-b). Global mean precipitation from the Global Precipitation Climatology Project (GPCP v2.3; Adler et al., 2017), a combination of satellite-based and land surface gauge-based estimates, appears to display greater month to month variability compared to longer time-scale changes than temperature or water vapor; co-variability with these variables and similarity to AMIP5 simulations appears less coherent (Fig. 1c) with barely significant global precipitation trends during 1988-2015 (0.3\%/decade; $r=0.19)$ and no significant trend during the period of slower surface warming 2000-2012, consistent with understanding of radiative forcing and precipitation response (Allan et al., 2014a; Saltzmann, 2016). It is reassuring but no surprise that SSM/I-based estimates agree with GPCP since SSM/I data over the ice-free ocean is used in the generation of GPCP estimates while over other regions data is identical in this merged estimate. However, the changing observing system seriously compromises the global precipitation variability depicted by ERAI as previously reported (Dee et al., 2011; Allan et al., 2014a). Interannual coupling of GPCP precipitation with HadCRUT Ts over this period is $3.0 \pm 0.7 \% / K(r=0.37)$, consistent with estimates of temperature dependent precipitation sensitivity (Andrews et al., 2010; Myhre et al., 2017). Global precipitation increases with global Ts primarily due to the enhanced radiative loss for higher surface and atmospheric temperatures, set by the thermodynamics of the coupled system (Roderick et al. 2014; Myhre et al., 2017) although this is tempered by the additional absorption of sunlight by higher water vapor loadings (Allan 2009) and modified by sensible heat flux changes. However, apparent short-term increases of 2-3\% in global precipitation during warm El Niño events (e.g. 2010 and 2016) coincide with increases in Ts of just $0.2-0.3 \mathrm{~K}$, a much greater precipitation sensitivity than anticipated from energy budget considerations and indicative of a subtler influence of spatial reorganisation of circulation systems and energy in the climate system.

Variability in net downward top of atmosphere radiation imbalance by satellites are generally well captured by the AMIP5 simulations (Allan et al., 2014b) indicating that radiative forcing and feedback response are well simulated when realistic ocean surface temperature is prescribed. ERAI also captures month to month variability in the radiation budget remarkably well given that cloud cover, which dominates these fluctuations, is not directly assimilated. However, decadal variability 
and trends are unrealistic and the reanalysis does not represent volcanic radiative forcing as evident from the lack of response to the 1991 Pinatubo eruption. Variability is dominated by cooling following the Pinatubo volcanic eruption in 1991 (up to $-3 \mathrm{Wm}^{-2}$ caused by the reflective volcanic aerosol haze in the stratosphere) and El Niño events in which a warmer atmosphere loses more energy to space through infrared emission. This reduced energy uptake is of order $1 \mathrm{Wm}^{-2}$ although an increase in energy uptake of about $0.2 \mathrm{Wm}^{-2}$ can occur as El Niño builds (Johnson and Birnbaum, 2017) and substantial reorganisation of energy in the upper $400 \mathrm{~m}$ of the ocean occurs (Roemmich et al., 2015). Recent estimates of net radiative imbalance at the top of the atmosphere of 0.6-0.8 Wm-2 for 2005-2015 (Johnson et al., 2016) are primarily determined by ocean heat content changes measured by Argo buoys; this and additional observations and assumptions are applied in anchoring the satellite records (Loeb et al., 2012) which themselves provide excellent representation of interannual variability and decadal trends. The net imbalance is remarkably stable over time with trends of just $0.02 \pm 0.01 \mathrm{Wm}^{-2}$ per decade over the period 1988-2015, substantially smaller than the expected uncertainty. This stability indicates no hiatus in anthropogenic radiative forcing despite slower global surface warming at the beginning of the 21 st century (Xie \& Kosaka, 2017) although there is intriguing evidence of distinct global energy budget response to Ts that influences interannual fluctuations, internal decadal variability and long-term climate response (Brown et al., 2014; Xie et al., 2015).

Ongoing monitoring of Earth's energy budget and other key climate indicators combining a range of observations, reanalyses and model simulations is valuable for (i) detecting unrealistic behaviour in observing systems, (ii) identifying unusual or significant climate fluctuations and trends and (iii) improving understanding of physical processes and feedbacks. Isolating internally generated interannual to decadal variability from longer term climate responses is essential for interpreting changes in the global water cycle (Gu et al., 2016; Sukhatme and Venugopal, 2017) and the fundamental driving factors involving Earth's energy balance (Palmer and McNeall, 2014; Trenbeth et al., 2016). This variability can potentially be exploited in elucidating regional feedbacks on internal decadal variability (Brown et al., 2014; Zhou et al., 2016; Xie et al., 2015) as well as in advancing understanding of how the spatial nature of climate change influences how sensitive the global climate is to radiative forcings (Gregory and Andrews, 2016). The regional manifestation of changes in the energy budget and water cycle have been identified globally (Myhre et al., 2017; Bony et al., 2013) and at hemispheric (Hwang et al., 2013; Loeb et al., 2016; Stephens et al., 2017) to continental scales (Bollasina et al., 2011; Dong and Sutton, 2015). Applying a regional energy budget perspective is informative in understanding these water cycle responses
(Muller and O'Gorman, 2011) and for tracking energy within the climate system: combining satellite radiation budget measurements with reanalysis energy transports to estimate surface fluxes can be used to identify regional decadal patterns of ocean heating (Liu et al., 2017) and potentially constrain ocean energy transports (Trenberth and Fasullo, 2017) and their changes from one decade to the next. These advances take observing systems and climate models to their limits (Desbruyères et al., 2016; Palmer, 2017; Wild, 2017). To further constrain long-term regional climate change responses to radiative forcings it is necessary to disentangle the distinct energy budget responses and feedbacks influencing internal decadal variability of the climate system.

\section{Acknowledgements}

Support was provided from the UK National Centre for Earth Observation (NCEO) and National Centre for Atmospheric Science (NCAS) and the Natural Environment Research Council SMURPHS (NE/ N006054/1) and DEEP-C (NE/K005480/1) projects. The World Climate Research Programme's Working Group on Coupled Modelling is acknowledged for developing the CMIP model archive, and we thank the climate modelling groups for producing and making available their model outputs; for CMIP, the U.S. Department of Energy's PCMDI provided coordinating support and led development of software infrastructure in partnership with the Global Organization for Earth System Science Portals. AMIP5 climate model data sets were extracted from the British Atmospheric Data Centre (http://badc.nerc.ac.uk/ home) and the Program for Climate Model Diagnosis and Intercomparison (pcmdi3.llnl.gov/esgcet). GPCP v2.3 data were extracted from http://gpcp.umd.edu. Merged radiation budget data (v3) are available from http:// www.met.reading.ac.uk/ sgs02rpa/research/DEEP-C/ GRL/ and CERES EBAF v2.8 and ERBS wide field of view (WFOV) v3 data was provided by the NASA Langley research centre. SSM/I and SSMIS v7 products were also obtained online (ftp.ssmi.com). HadCRUT4 data is available from http://www.metoffice.gov.uk/hadobs/ hadcrut4/.

\section{References}

Adler et al. (2017) An Update (Version 2.3) of the GPCP Monthly Analysis (in preparation).

Allan, R. P., C. Liu, M. Zahn, D. A. Lavers, E. Koukouvagias and A. Bodas-Salcedo (2014a) Physically consistent responses of the global atmospheric hydrological cycle in models and observations, Surv. Geophys., 35, 533-552, doi:10.1007/s10712-012-9213-z.

Allan, R. P., C. Liu, N. G. Loeb, M. D. Palmer, M. Roberts, D. Smith and P.-L. Vidale (2014b) Changes in global net radiative imbalance 1985-2012, Geophysical Research Letters, 41, 5588-559710.1002/2014GL060962 
Allen, M. R., and W. J. Ingram (2002), Constraints on future changes in climate and the hydrological cycle, Nature, 419, 224-232, doi:10.1038/nature01092.

Andrews, T., P. M. Forster, O. Boucher, N. Bellouin, and A. Jones (2010), Precipitation, radiative forcing and global temperature change, Geophys. Res. Lett., 37, L14701, doi:10.1029/2010GL043991.

Bollasina, Massimo, Yi Ming, and V Ramaswamy (2011) Anthropogenic aerosols and the weakening of the South Asian summer monsoon. Science, 334, 502-505 doi:10.1126/science.1204994.

Bony, S., G. Bellon, D. Klocke, S. Sherwood, S. Fermepinand S. Denvil (2013) Robust direct effect of carbon dioxide on tropical circulation and regional precipitation, Nature Geoscience 6, 447-451, doi:10.1038/ngeo1799

Brown, P. T., W. Li, L. Li, and Y. Ming (2014), Top-ofatmosphere radiative contribution to unforced decadal global temperature variability in climate models, Geophys. Res. Lett., 41, 5175-5183, doi:10.1002/2014GL060625.

Cowtan, K. and Way, R. G. (2014), Coverage bias in the HadCRUT4 temperature series and its impact on recent temperature trends. Q.J.R. Meteorol. Soc., 140: 19351944. doi:10.1002/qj.2297

Dee, D. P., Uppala, S. M., Simmons, A. J., Berrisford, P., Poli, P., Kobayashi, S., Andrae, U., Balmaseda, M. A., Balsamo, G., Bauer, P., Bechtold, P., Beljaars, A. C. M., van de Berg, L., Bidlot, J., Bormann, N., Delsol, C., Dragani, R., Fuentes, M., Geer, A. J., Haimberger, L., Healy, S. B., Hersbach, H., Hólm, E. V., Isaksen, L., Kållberg, P., Köhler, M., Matricardi, M., McNally, A. P., Monge-Sanz, B. M., Morcrette, J.-J., Park, B.-K., Peubey, C., de Rosnay, P., Tavolato, C., Thépaut, J.N. and Vitart, F. (2011), The ERA-Interim reanalysis: configuration and performance of the data assimilation system. Q.J.R. Meteorol. Soc., 137: 553-597. doi:10.1002/ qj.828

Desbruyères, D., McDonagh, E.L. \& King, B.A. (2016) Observational Advances in Estimates of Oceanic Heating, Curr Clim Change Rep, 2, 127-134, doi:10.1007/s40641016-0037-7

Dong, B. and R. Sutton (2015) Dominant role of greenhouse-gas forcing in the recovery of Sahel rainfall, Nature Clim. Ch., doi: 10.1038/nclimate2664

Gregory, J. M., and T. Andrews (2016), Variation in climate sensitivity and feedback parameters during the historical period, Geophys. Res. Lett., 43, 3911-3920, doi:10.1002/2016GL068406.

Gu, G., Adler, R.F. \& Huffman, G.J. Clim Dyn (2016) 46: 1091. doi:10.1007/s00382-015-2634-x
Haywood, J. M., N. Bellouin, A. Jones, O. Boucher, M. Wild, and K. P. Shine (2011), The roles of aerosol, water vapor and cloud in future global dimming/brightening, J. Geophys. Res., 116, D20203, doi:10.1029/2011JD016000. Hwang, Y-T., Frierson, D. M. W. \& Kang, S. M. Anthropogenic sulfate aerosol and the southward shift of tropical precipitation in the 20th century. Geophys. Res. Lett. 40, 1-6 (2013).

Johnson, G. C., and A. N. Birnbaum (2017), As El Niño builds, Pacific Warm Pool expands, ocean gains more heat, Geophys. Res. Lett., 44, 438-445, doi:10.1002/2016GL071767.

L'Heureux, M.L., S. Lee \& B. Lyon (2013), Recent multidecadal strengthening of the Walker circulation across the tropical Pacific, Nature Clim. Ch., 3, 571-576, doi:10.1038/nclimate 1840

Liu, C. Allan, R.P., M. Mayer, P. Hyder, N.G. Loeb , C.D. Roberts, M. Valdivieso, J. Edwards, P.-L. Vidale (2017) Evaluation of satellite and reanalysis-based global net surface energy flux and uncertainty estimates, J. Geophysical Research, doi: 10.1002/2017JD026616

Loeb, N. G., J. M. Lyman, G. C. Johnson, R. P. Allan, D. R. Doelling, T. Wong, B. J. Soden and G. L. Stephens (2012), Observed changes in top-of-the-atmosphere radiation and upper-ocean heating consistent within uncertainty, Nature Geoscience, 5, 110-113, doi:10.1038/ngeo1375

Loeb, N.G., H. Wang, A. Cheng, S. Kato, J.T. Fasullo, K.M. Xu and R.P. Allan (2016) Observational Constraints on Atmospheric and Oceanic Cross-Equatorial Heat Transports: Revisiting the Precipitation Asymmetry Problem in Climate Models, Climate Dynamics, 46, 32393257, 10.1007/s00382-015-2766-z.

Morice, C. P., J. J. Kennedy, N. A. Rayner, and P. D. Jones (2012), Quantifying uncertainties in global and regional temperature change using an ensemble of observational estimates: The HadCRUT4 dataset, J. Geophys. Res., 117, D08101, doi:10.1029/2011JD017187.

Muller CJ, O'Gorman PA (2011) An energetic perspective on the regional response of precipitation to climate change. Nat Clim Change 1:266-271

Myhre, G., P. Forster, B. Samset, Ø. Hodnebrog, J. Sillmann, S. Aalbergsjø, T. Andrews, 0. Boucher, G. Faluvegi, D. Flaeschner, T. Iversen, M. Kasoar, S. Kharin, A. Kirkevåg, J. Lamarque, D. Olivié, T. Richardson, D. Shindell, K. Shine, C. Stjern, T. Takemura, A. Voulgarakis, and F. Zwiers, 2017: PDRMIP: A Precipitation Driver and Response Model Intercomparison Project, Protocol and preliminary results. Bull. Amer. Meteor. Soc. doi:10.1175/ BAMS-D-16-0019.1, in press. 
O'Gorman, P. A., R. P. Allan, M. P. Byrne and M. Previdi (2012) Energetic constraints on precipitation under climate change, Surv. Geophys., 33, 585-608, doi: 10.1007/s10712-011-9159-6

Palmer, M. D., and D. J. McNeall (2014), Internal variability of Earth's energy budget simulated by CMIP5 climate models, Environ. Res. Lett., 9, 034016, doi:10.1088/17489326/9/3/034016.

Palmer, M.D. (2017) Reconciling Estimates of Ocean Heating and Earth's Radiation Budget, Curr Clim Change Rep, doi:10.1007/s40641-016-0053-7

Roderick, M. L., F. Sun, W. H. Lim, and G. D. Farquhar (2014), A general framework for understanding the response of the water cycle to global warming over land and ocean, Hydrol. Earth Syst. Sci., 18(5), 1575-1589, doi:10.5194/hess-18-1575-2014

Roemmich, D., J. Church, J. Gilson, D. Monselesan, P . Sutton and S. Wijffels (2015) Nature Clim. Change, 5, 240-245, doi:10.1038/nclimate2513.

Salzmann, M. (2016) Global warming without global mean precipitation increase? Science Advances, 2, doi:10.1126/sciadv.1501572

Simmons, A. J., K. M. Willett, P. D. Jones, P. W. Thorne, and D. P. Dee (2010), Low-frequency variations in surface atmospheric humidity, temperature, and precipitation: Inferences from reanalyses and monthly gridded observational data sets, J. Geophys. Res., 115, D01110, doi:10.1029/2009JD012442.

Stephens, G.L., Hakuba, M.Z., Hawcroft, M. J. M. Haywood, A. Behrangi, J. E. Kay, P. J Webster (2016) The Curious Nature of the Hemispheric Symmetry of the Earth's Water and Energy Balances, Curr Clim Change Rep, 2, 135-147, doi:10.1007/s40641-016-0043-9

Sukhatme, J. and Venugopal, V. (2017), Waxing and waning of observed extreme annual tropical rainfall. Q.J.R. Meteorol. Soc., 142: 102-107. doi:10.1002/qj.2633 Taylor KE, Stouffer RJ, Meehl GA (2011) An overview of CMIP5 and the experiment design. Bull Am Meteorol Soc 93:485-498. doi:10.1175/BAMS-D-11-00094.1

Trenberth KE, Dai A, Rasmussen RM, Parsons DB (2003) The changing character of precipitation. Bull Am Meteorol Soc 84:1205-1217

Trenberth, K., J. Fasullo, K. von Schuckmann, and L. Cheng (2016) Insights into Earth's Energy Imbalance from Multiple Sources. J. Climate, 29, 7495-7505, doi: 10.1175/JCLI-D-16-0339.1.
Wentz, F. J., (2013), SSM/I Version-7 Calibration Report, report number 011012, Remote Sensing Systems, Santa Rosa, CA, 46pp.

Wild, M. (2017) Towards Global Estimates of the Surface Energy Budget, Curr Clim Change Rep, doi:10.1007/ s40641-017-0058-x

Wild, M., J. Grieser, and C. Schär, 2008: Combined surface solar brightening and increasing greenhouse effect favour recent intensification of the hydrological cycle. Geophys. Res. Lett., doi:10.1029/2008GL034842

Willett, K.W., P.D. Jones, N.P. Gillett and P. W. Thorne, 2008: Recent changes in surface humidity: development of the HadCRUH dataset. J. Clim..21, 5364:5383

Xie, S.-P., Y. Kosaka, Y. M. Okumura (2016) Distinct energy budgets for anthropogenic and natural changes during global warming hiatus, Nature Geoscience 9, 29-33 (2016) doi:10.1038/ngeo2581, L17706.

Xie, SP. \& Kosaka, Y. (2017) What Caused the Global Surface Warming Hiatus of 1998-2013? Curr Clim Change Rep, 3, 128, doi:10.1007/s40641-017-0063-0

Zhou, C., M. D. Zelinka and S. A. Klein (2016), Impact of decadal cloud variations on the Earth's energy budget, Nature Geosci., 9, 871-874, doi:10.1038/NGE02828 


\title{
Toward predicting volcanically-forced decadal \\ climate variability
}

doi: $10.22498 /$ pages.25.1.25

\section{Davide Zanchettin ${ }^{1}$, Francesco S.R. Pausata ${ }^{2,3}$, Myriam Khodri4, Claudia Timmreck ${ }^{5}$, Hans Graf ${ }^{6}$, Johann H. Jungclaus ${ }^{5}$, Alan Robock ${ }^{7}$, Angelo Rubino', Vikki Thompson ${ }^{8}$}

\author{
1 Department of Environmental Sciences, Informatics and Statistics, \\ University Ca'Foscari of Venice, Italy \\ 2 Department of Meteorology (MISU), Stockholm University, Sweden \\ 3 Department of Earth and Atmospheric Sciences, \\ University of Quebec in Montreal (UQÀM), Montreal (QC), Canada \\ 4 IRD/IPSL/Laboratoire d'Océanographie et du Climat, Paris, France \\ 5 Max Planck Institute for Meteorology, Hamburg, Germany \\ 6 University of Cambridge, Cambridge, UK \\ 7 Department of Environmental Sciences, Rutgers University, New Brunswick, USA \\ 8 Met Office Hadley Centre, Exeter, UK
}

\section{Volcanic forcing and climate}

Strong volcanic eruptions inject into the stratosphere massive amounts of chemically and microphysically active gases that lead to the formation of aerosol particles, affecting the Earth's radiative balance and climate (Robock, 2000; Timmreck, 2012; LeGrande et al., 2016). Sulfate aerosol particles scatter solar radiation back to space, which results in global surface cooling and slowdown of the global hydrological cycle. The particles also absorb radiation in the infrared and near-infrared bands, causing local warming of the lower stratosphere. Both direct radiative forcing effects are temporary, their time scale being set by the persistence of the volcanic aerosol cloud in the lower stratosphere. This amounts to a couple of years in the case of the strongest recent tropical eruptions, such as the 1815 eruption of $\mathrm{Mt}$ Tambora in Indonesia (Fig. 1a). However, the climatic impact of strong volcanic eruptions can last well beyond the timescale of the direct radiative perturbation through the dynamic alterations it induces in the entire coupled climate system. These include "feedbacks" in their classic definition of amplification and dampening loops related to changes in climatic variables that operate through changes in global-mean surface temperature (Boucher et al., 2013). For instance, the so-called "polar amplification" of climate signals - mainly a consequence of positive feedbacks involving snow cover and sea ice provides one element of inter-hemispheric asymmetry to the decadal climate response to volcanic eruptions through global radiative cooling (Zanchettin et al., 2014). Dynamical impacts further stem from the spatially heterogeneous structure of volcanic forcing. In the case of tropical eruptions, for which the bulk of the volcanic aerosol cloud remains largely constrained in the tropical stratosphere, simple theoretical arguments indicate that the aerosol radiative heating enhances the upper-level equator-to-pole temperature gradients that, by thermal wind balance, can force a strengthened stratospheric polar vortex in both hemispheres, as diagnosed from climate models (e.g., Stenchikov et al., 2002; Zanchettin et al., 2014). The consequent downward penetration of the westerly wind anomalies at the edge of the polar vortex and their interaction with topography provide further elements of a top-down atmospheric mechanism of volcanic forcing. In the Northern Hemisphere, its tropospheric effects during the first post-eruption winter typically project on a positive anomaly of the North Atlantic Oscillation/Arctic Oscillation (NAO/AO) and associated continental warming (Stenchikov et al., 2006; Graf et al., 2014; Zambri and Robock, 2016). This is a key component of a major recognized general pathway of volcanically-forced decadal climate signals (Otterå et al., 2010; Zanchettin et al., 2012).

Specifically, the NAO-related post-eruption modifications to the wind field modify the circulation in the upper North Atlantic Ocean and locally enhance oceanic convective mixing through anomalous turbulent heat and freshwater fluxes. These superpose on the extensive buoyancy effects of the post-eruption radiative cooling, leading to strengthened deep water formation. The slow propagation of so-formed water masses in the ocean abyss is expected to protract the fast oceanic response 

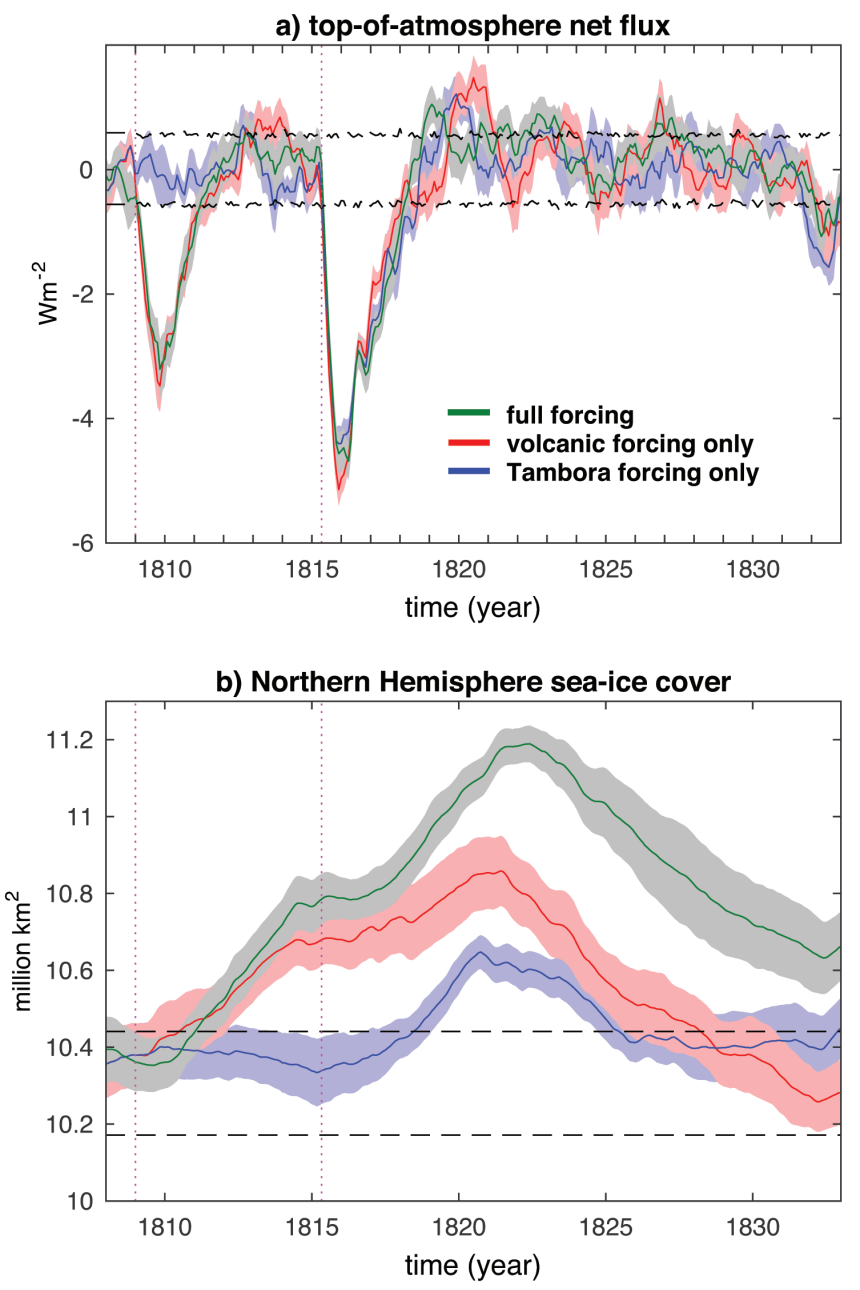

Figure 1: Simulated global-average top-of-atmosphere net radiative anomalies (a: 3 -month smoothing) and simulated Arctic sea ice cover evolution (b: 61-month smoothing) around the 1815 Tambora eruption in three climate simulation ensembles with the ECHAM5/MPIOM coupled climate model, differing in the ensemble-mean initial state and in the applied forcing. Dark green: full-forcing conditions (including the Dalton Minimum of solar activity); Red: volcanic forcing-only conditions, including both the 1809 and 1815 eruptions; Blue: volcanic forcing-only conditions, without the 1809 eruption. Lines (shading): mean (1- $\sigma$ standard error of the mean). Black dashed lines: $5^{\text {th }}-95^{\text {th }}$ percentile intervals for signal occurrence in the control run. Vertical dotted lines indicate the 1809 and Tambora eruptions. Each ensemble consists of 10 simulations differing in the initial state. Note that the Arctic sea ice response is significantly different in the three ensembles whereas the applied forcing, in terms of anomalous top-of-atmosphere net flux, is practically indistinguishable. For details see: Zanchettin et al. (2013a).

to decadal time scales through the tendency for reinvigoration of the oceanic meridional overturning circulation that culminates several years - up to a decade or so - after major eruptions, as diagnosed from models. Implications for meridional ocean heat transports and sea ice dynamics contribute to regional characterization of the signal, and hence to recognizable traces of volcanic signals especially in extratropical and polar regional climates (Zanchettin et al., 2012, 2013b; Sicre et al., 2013). Lacking further external excitation (e.g., by a successive eruption), negative feedbacks eventually become predominant and the near-surface system relaxes back to the mean pre-eruption state as part of a roughly bi-decadal fluctuation. The feedback loop thus sets the phase of internal modes of interdecadal climate variability (Otterå et al., 2010), whose effects can be protracted, with dampening intensity, beyond one fluctuation (Swingedouw et al., 2015). In the latter case, deep ocean anomalies may remain significant for much longer (Gleckler et al., 2006; Gregory, 2010). A similar interdecadal general oceanic response is also found for high-latitude eruptions, for which it is the direct radiative surface cooling at subpolar latitudes linked to the confinement of the volcanic aerosol cloud to the eruption's hemisphere that typically leads to enhanced oceanic deep convection (Fig. 2, see also Pausata et al., 2015).

\section{Knowledge gaps}

The general framework outlined above is useful to identify the core dynamics involved in post-eruption decadal climate variability. However, several caveats must be taken into consideration. Above of all, direct observations of strong volcanic eruptions are very few - only five in the instrumental period - which does not allow robust statistics of their climate impact, and hence attribution. Therefore, large part of our knowledge builds on climate model simulations and proxy-based climate reconstructions, both of which have large uncertainties and deficiencies (e.g., Zanchettin, 2017). Incessant improvement in both tools brings old evidence back into the discussion. For instance, the mechanisms leading to a preferred enhanced stratospheric polar vortex in post-eruption winters have been questioned by recent studies suggesting that the mechanism based on the thermal wind balance and outlined above does not always hold (e.g., Bittner et al., 2016), possibly as the zonal wind response to direct aerosol radiative heating may be dominated by other effects, such as the residual circulation response to anomalous wave activity (Toohey et al., 2014). Accordingly, obvious implications for the polar vortex response stem from the tropical Pacific, a known critical source of tropospheric wave disturbances affecting stratospheric dynamics (e.g., Graf et al., 2014). Instrumental observations and climate proxy-based reconstructions indicate that volcanic eruptions tend to be followed by an El Niño event. A newly discovered causal mechanism is initiated by cooling over Africa (the largest tropical landmass), which reduces precipitation and forces an atmospheric Kelvin wave response that couples with western Pacific convection to trigger westerly wind anomalies and a Pacific El Niño. While modulated by the seasonal cycle of convection, the effect of volcanism onwind forcing over the Pacific persists during the year after the eruption, implying that the Pacific El Niño-like response involves more external forcing than traditional, 
a)

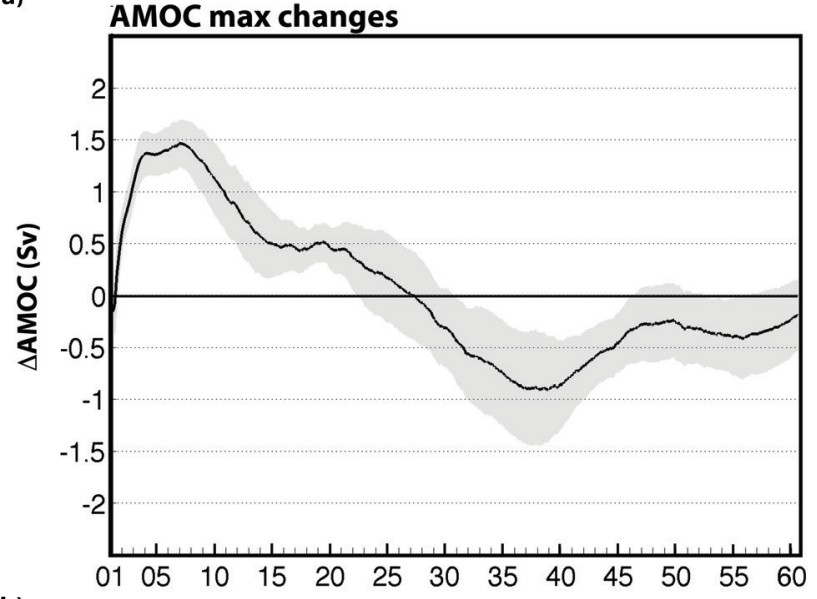

b)

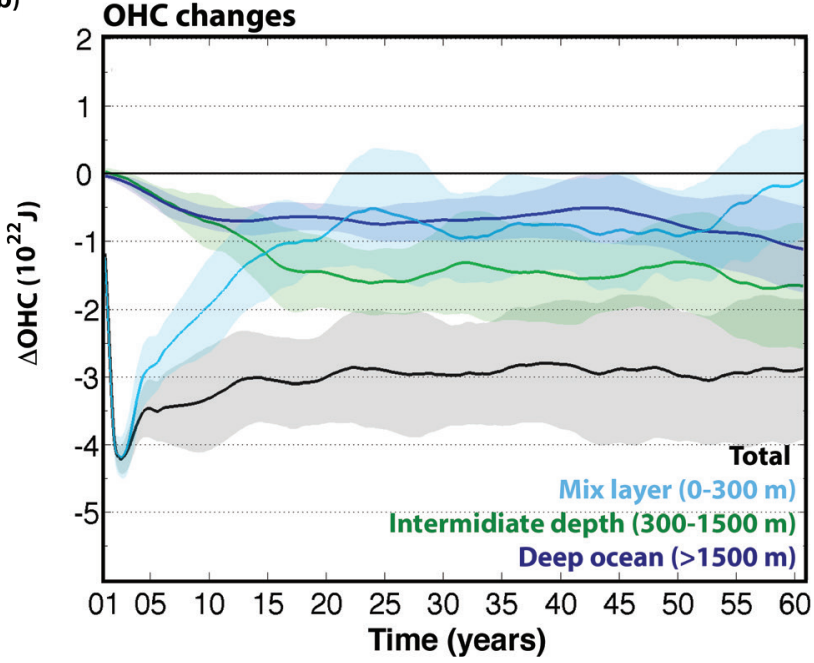

Figure 2: Decadal oceanic response to a high-latitude eruption resembling the multistage 1783 eruption of Laki (Iceland) simulate by the NorESM coupled climate model. a) Changes in the strength of the Atlantic Meridional Overturning Circulation (AMOC) estimated as the maximum of the zonally-integrated overturning stream function in the Atlantic. b) Changes in Ocean Heat Content $(\mathrm{OHC})$ averaged from the surface to selected depths for the global ocean. In both panels the solid lines denote the ensemble average changes and shadings represent the confidence intervals at approximate 95\% level (twice the standard error of the mean) of the difference in all pairs of experiments that comprise the ensembles. The ensemble consists of 10 simulations differing for the initial state. Anomalies are calculated with respect to a control simulation. The figure has been adapted from Pausata et al. (2015).

internally generated events (Khodri et al., 2017). However, there are stratospheric (e.g., Scaife et al., 2009) and tropospheric (e.g., Graf and Zanchettin, 2012) pathways of El Niño forcing on the atmospheric circulation over the North Atlantic that project on a negative NAO; this would counteract the NAO+ tendency above described. In addition, sampling issues in simulation ensembles (Lehner et al., 2016) and uncertainty linked to the eruption's season (Stevenson et al., 2017) are recently proposed explanations for reconstructions-simulations discrepancies in the estimated post-eruption cooling. This outlines the complexity of competing influences on the top-down mechanism of volcanic forcing, hence on the post-eruption positive NAO anomaly for moderate or small tropical eruptions, whose uncertainty cascades on the decadal oceanic response. Ocean dynamics simulated by coupled models are another major source of uncertainty to be understood considering the different time scales of simulated oceanic responses (Otterå et al., 2010; Mignot et al., 2011; Zanchettin et al., 2012). Furthermore, the fact that a climate model spontaneously generates bi-decadal variability in the overturning circulation strength seems to determine its excitability to the general response mechanism outlined above (Swingedouw et al., 2015).

\section{Inherent sources of uncertainty}

The climatic response to a given volcanic eruption is highly specific. First, the general response mechanism strongly depends on the characteristics of the forcing. An obvious determinant factor is the magnitude of the eruption, whose potential control can be, for instance, estimated looking at the sea ice response. For a very strong eruption, polar amplification of the global cooling signal may lead sea ice to cover regions of strong oceanic deep convection, thereby hampering deep water formation through insulation of the ocean-atmosphere boundary. Associated increased freshwater export from the Arctic also contributes to stabilize the ocean water column. These will lead ultimately to a tendency for weakening - instead of strengthening - of the thermohaline circulation (e.g., Zhong et al., 2010; Mignot et al., 2011). Second, the way the volcanic aerosol cloud distributes in the stratosphere influences both the direct radiative and dynamic atmospheric responses (e.g., Toohey et al., 2014; Colose et al., 2016). In this regard, the latitudinal position of the erupting volcano is an obvious determinant factor, but similar uncertainty on the spatial structure of the volcanic aerosol cloud can be originated by the season of the eruption (Stevenson et al., 2017).

A milestone in our understanding of volcanically forced decadal climate variability was the recent recognition that the mean climate state, the phase and amplitude of ongoing internal variability at the time of an eruption, such as that associated with major climatic modes including, e.g., El Niño Southern Oscillation (ENSO) or the Quasi-Biennial Oscillation (QBO), and the presence of additional forcing factors crucially determine how the climate system responds to the volcanic forcing (Zhong et al., 2010; Zanchettin et al., 2012, 2013a; Berdahl and Robock, 2013; Swingedouw et al., 2015; Pausata et al., 2016). Fig. 1 (after Zanchettin et al., 2013a) shows the role of background conditions for the case of Arctic sea ice response to the 1815 Tambora eruption simulated in three ensembles in which the volcanic forcing is the same but background climate state and histories are different. Results show that a significant increase in Arctic sea 
ice cover is consistently diagnosed after the eruption in all ensembles but the average anomalies differ in both magnitude and duration. The inter-ensemble differences in the Arctic sea ice response reflect substantial differences in the decadal feedback mechanisms activated in the coupled atmosphere-ocean-sea-ice system after the eruption.

This dependency on the background climate state can partly explain the different, often contrasting, results found for simulated and reconstructed post-eruption decadal variability from different volcanic eruptions (Zanchettin et al., 2013a,b). This concept also allows understanding how the timing between subsequent volcanic eruptions can deterministically influence the response in the case of a volcanic cluster. Specifically, if two eruptions are roughly paced at one period of the above-mentioned decadal mechanism (roughly two decades), they will interfere constructively, as they will occur around the same phase of internal modes of oceanic variability. In contrast, if they are paced at half the period of the mechanism (a decade or so), they will interfere destructively (Swingedouw et al., 2015). Intriguingly, both cases apply to the most recent strong volcanic eruptions: Agung in 1963 and El Chichón in 1982 are paced at roughly two decades (constructive interference), while El Chichón and Pinatubo in 1991 were paced at roughly one decade (destructive interference). This finding widens margins for long-term predictability of decadal climate impacts by strong volcanic eruptions.

\section{Opportunities for progress}

A series of research initiatives are currently contributing to building the scientific basis for reaching such an ambitious objective by filling major gaps of understanding. A first goal of current research is robust characterization, by means of climate models with interactive stratospheric aerosols, of the forcing generated by a given eruption based on the estimated amount of gaseous sulphur species it injects in the stratosphere. The WCRP/SPARC Stratospheric Sulfur and its Role in Climate (SSiRC) initiative (http://sparc-ssirc.org/ssirc.html, Timmreck et al., 2016b) coordinates the international activities on stratospheric aerosol research aiming at better understanding and hence modeling of the stratospheric aerosol layers and their controls. SSiRC will help study why the characterization of the volcanic aerosol cloud and the radiative forcing generated by state-of-the-art global aerosol models for a certain sulphur injection remain highly uncertain (e.g., SPARC, 2006; Zanchettin et al., 2016). Focus will be in particular on model inconsistencies related to the treatment of aerosol microphysics and climate physical processes, such as stratospheric circulation and stratosphere-troposphere coupling.

In addition, unpredictability of timing and magnitude of volcanic eruptions is a major source of uncertainty and the climate community should be prepared for such an eventuality. Therefore, a new SSiRC initiative called VolRes ("Volcano Response Plan after the next major eruption") has been launched aiming at developing a scientific plan to prepare observational and modelling tools and strategies to be readily applied for the next major volcanic eruption. Characterization of the potential climatic impact of an eruption in the more distant future (such as envisaged for end-of-the-century warming scenarios) bears additional uncertainties related to the dependence of dynamics of the eruption plume on the atmospheric stratification and tropopause height, in turn subject to global temperature changes (Aubry etal., 2016).

Finally, the "Model Intercomparison Project on the climatic response to Volcanic forcing" (VolMIP) (Zanchettin et al., 2016) has been created as part of the Coupled Model Intercomparison Project phase 6 (CMIP6), to define a coordinated protocol for idealized volcanicperturbation experiments to improve comparability of results across different climate models. Interest is on various aspects of volcanically-forced climate variability, with specific sets of experiments designed to investigate both the seasonal-to-interannual atmospheric response and the interannual-to-decadal response of the coupled ocean-atmosphere-sea-ice system. Through systematic and consistent (across the different models) sampling of internal variability (e.g., ENSO, QBO), VolMIP will allow the identification of robust response mechanisms to volcanic forcing or explain the lack thereof.

VolMIP will also foster investigation of simulated Southern Hemispheric responses to volcanic forcing, currently an overlooked topic due to the known severe climate model biases in the Southern Hemisphere (e.g., Simpson et al., 2012; Salleé et al., 2013; Turner et al., 2013). More generally, if volcanically-forced decadal climate variability can be understood through the excitation by volcanic forcing of internal modes of climate variability, confidence must be built on the accurate and robust simulation of such modes. Current climate models, however, have difficulties in reproducing the observed spatial pattern, time scales and teleconnections of dominant modes such as ENSO (e.g., Zou et al., 2014) or the Atlantic Multidecadal Oscillation (Kavvada et al., 2013).

Only a few studies specifically focused on the quantitative assessment of volcanic forcing impacts on decadal climate predictions and potential predictability (Collins, 2003; Shiogama et al., 2010; Timmreck et al., 2016a). Overall, in the presence of strong natural climate variability on the one hand and because of different magnitude and frequency of volcanic eruptions on the other hand, it is difficult to assess the potential predictability from volcanoes of regional climates. Improvements of decadal climate prediction systems concerning implementationof volcanic forcing (e.g., LeGrande et al., 2016) and bias estimation and correction (e.g., Hawkins et al., 2014) are milestones toward robust prediction of volcanically- 
forced decadal climate variability. Along this long-term goal, within CMIP6, a joint decadal climate prediction experiment between VolMIP and the Decadal Climate Prediction Panel (Boer et al., 2016) will be conducted to address the climatic implications if a Pinatubo-like eruption would have occurred in 2015.

In conclusion, there is emerging evidence that volcanic forcing can significantly affect decadal climate variability through mechanisms that are increasingly better understood. Milestones on the road toward robust prediction of volcanically-forced decadal variability include improved understanding and implementation of aerosol forcing in decadal prediction systems and improved simulated representation and estimation of internal decadal climate variability.

\section{References}

Aubry, T. J., A. M. Jellinek, W. Degruyter, C. Bonadonna, V. Radić, M. Clyne, A. Quainoo, 2016: Impact of global warming on the rise of volcanic plumes and implications for future volcanic aerosol forcing, J. Geophys. Res. Atmos. 121, 13,326-13,351, doi:10.1002/2016JD025405

Berdahl, M., and A. Robock, 2013: Northern Hemispheric cryosphere response to volcanic eruptions in the Paleoclimate Modeling Intercomparison Project 3 last millennium simulations, J. Geophys. Res. Atmos., 118, 12,359-12,370, doi:10.1002/2013JD019914

Boucher, O., D. Randall, P. Artaxo, C. Bretherton, G. Feingold, P. Forster, V.-M. Kerminen, Y. Kondo, H. Liao, U. Lohmann, P. Rasch, S.K. Satheesh, S. Sherwood, B. Stevens and X.Y. Zhang, 2013: Clouds and Aerosols. In: Climate Change 2013: The Physical Science Basis. Contribution of Working Group I to the Fifth Assessment Report of the Intergovernmental Panel on Climate Change [Stocker, T.F., D. Qin, G.-K. Plattner, M. Tignor, S.K. Allen, J. Boschung, A. Nauels, Y. Xia, V. Bex and P.M. Midgley (eds.)], Cambridge University Press, Cambridge, United Kingdom and New York, NY, USA

Boer, G. J., D. M. Smith, C. Cassou, F. Doblas-Reyes, G. Danabasoglu, B. Kirtman, Y. Kushnir, M. Kimoto, G. A. Meehl, R. Msadek, W. A. Mueller, K. E. Taylor, F. Zwiers, M. Rixen, Y. Ruprich-Robert, and R. Eade, 2016: The Decadal Climate Prediction Project (DCPP) contribution to CMIP6, Geosci. Model Dev., 9, 3751-3777, doi:10.5194/ gmd-9-3751-2016

Bittner, M., H. Schmidt, C. Timmreck, and F. Sienz, 2016: Using a large ensemble of simulations to assess the Northern Hemisphere stratospheric dynamical response to tropical volcanic eruptions and its uncertainty, Geophys. Res. Lett., 43(17), 9324-9332.

Collins, M., 2003: Predictions of climate following volcanic eruptions, In: Robock A., Oppenheimer C. (eds) Volcanism and the Earth's atmosphere,Washington,DC:AGU;283-300

Colose, C.M., A. N. LeGrande, A.N., and M. Vuille, 2016: Hemispherically asymmetric volcanic forcing of tropical hydroclimate during the last millennium, Earth Sys. Dyn., 7(3): 681-696, doi:10.5194/esd-7-681-2016

Gleckler, P. J., K. AchutaRao, J. M. Gregory, B. D. Santer, K. E. Taylor, and T.M. L. Wigley, 2006: Krakatoa lives: the effect of volcanic eruptions on ocean heat content and thermal expansion, Geophys. Res. Lett., 33(17):L17702

Graf, H.-F., and D. Zanchettin, 2012: Central Pacific El Nino, the subtropical bridge, and Eurasian climate, J. Geophys. Res., 117, doi:10.1029/2011JD016493

Graf, H.-F., D. Zanchettin, C. Timmreck, and M. Bittner, 2014: Observational constraints on the tropospheric and near-surface winter signature of the Northern Hemisphere stratospheric polar vortex, Clim. Dyn., 43: 3245, doi:10.1007/s00382-014-2101-0

Gregory, J. M., 2010: Long-term effect of volcanic forcing on ocean heat content, Geophys. Res. Lett., 37, L22701, doi:10.1029/2010GL045507

Hawkins, E., B. Dong, J. Robson, R. Sutton, and D. Smith, 2014: The interpretation and use of biases in decadal climate predictions. J. Climate, 27:2931-2947, doi:http:// dx.doi.org/10.1175/JCLI-D-13-00473.1

Ineson, S., and A. A. Scaife, 2009: The role of the stratosphere in the European climate response to El Niño, Nature Geosci., 2, 32-36

Kavvada, A., A. Ruiz-Barradas, A., and S. Nigam, 2013: AMO's structure and climate footprint in observations and IPCC AR5 climate simulations, Clim. Dyn., doi:10.1007/ s00382-013-1712-12013.

Khodri, M., T. Izumo, J. Vialard, C. Cassou, M. Lengaigne, J. Mignot, E. Guilyardi, N. Lebas, Y. Ruprich-Robert, A., Robock, and M. J. McPhaden, 2017: How tropical explosive volcanic eruptions trigger El Niño events, Nature Comm., in press.

LeGrande, A. N., K. Tsigaridis, and S. E. Bauer, 2016: Role of atmospheric chemistry in the climate impacts of stratospheric volcanic injections, Nature Geosci., 9, 652655, doi:10.1038/ngeo2771

Lehner, F., A. P. Schurer, G. C. Hegerl, C. Deser, and T. L. Frölicher, 2016: The importance of ENSO phase during volcanic eruptions for detection and attribution, Geophys. Res. Lett., 43, 2851-2858, doi:10.1002/2016GL067935

Mignot, J., M. Khodri, C. Frankignoul, and J., Servonnat, 2011: Volcanic impact on the Atlantic Ocean over the last 
millennium, Clim. Past, 7, 1439-1455, doi:10.5194/cp-71439-2011

Otterå, O.H., M. Bentsen, H. Drange, and L. Suo, 2010: External forcing as a metronome for Atlantic multidecadal variability, Nature Geosci., doi:10.1038/NGE0995

Pausata, F. S. R., L. Chafik, R. Caballero, R., and D. S. Battisti, 2015: Impacts of high-latitude volcanic eruptions on ENSO and AMOC, P. Natl. Acad. Sci. USA, 112, 1378413788, doi:10.1073/pnas.1509153112

Pausata, F. S. R., C. Karamperidou, R. Caballero, and D. S. Battisti, 2016: ENSO response to high-latitude volcanic eruptions in the Northern Hemisphere: the role of initial conditions, Geophys. Res. Lett., doi:10.1002/2016GL069575

Robock, A., 2000: Volcanic eruptions and climate, Rev. Geophys., 38, 2: 191-219

Sallée, J.-B., E. Shuckburgh, N. Bruneau, A. J. S. Meijers, T. J. Bracegirdle, and Z. Wang, 2013: Assessment of Southern Ocean mixed layer depths in CMIP5 models: Historical bias and forcing response, J. Geophys. Res.-Oceans, 118, 1845-1862, doi:10.1002/jgrc.20157

Shiogama, H., S. Emori, T. Mochizuki, S. Yasunaka, T. Yokohata, M. Ishii, T. Nozawa, M. Kimoto, 2010: Possible Influence of Volcanic Activity on the Decadal Potential Predictability of the Natural Variability in Near-Term Climate Predictions, Adv. Meteorol., 657318, doi:10.1155/2010/657318

Sicre M. A., M. Khodri, J. Mignot, J. Eiriksson, K. L. Knudsen, U. Ezat, I. Closset, P. Nogues, and G. Massé, 2013: Sea surface temperature and sea ice variability in the subpolar North Atlantic from explosive volcanism of the late thirteenth century, Geophys. Res. Lett., 40 (20), 5526-5530. doi: 10.1002/2013GL057282.

Simpson, I., P. Hitchcock, T. Shepherd, and J. Scinocca, 2012: Southern Annular Mode Dynamics in Observations and Models. Part 1: the Influence of Climatological Zonal Wind Biases in a Comprehensive GCM, J. Clim., 26, 39533967, doi:10.1175/JCLI-D-12-00348.1

SPARC, 2006: SPARC Assessment of Stratospheric Aerosol Properties (ASAP), L. Thomason and Th. Peter (Eds.), SPARC Report No. 4, WCRP-124, WMO/TD - No. 1295, available at www.sparc-climate.org/publications/sparcreports/

Stenchikov, G., A. Robock, V. Ramaswamy, M. D. Schwarzkopf, K. Hamilton, and S. Ramachandran, 2002: Arctic Oscillation response to the 1991 Mount Pinatubo eruption: effects of volcanic aerosols and ozone depletion, J. Geophys. Res., 107(D24): 4803, doi:10.1029/2002JD002090

Stenchikov, G., K. Hamilton, R. J. Stouffer, A. Robock, V. Ramaswamy, B. Santer, and H.-F. Graf, 2006: Arctic oscillation response to volcanic eruptions in the IPCC AR4 climate models, J. Geophys. Res., 111: D07107, doi:10.1029/2005JD006286

Stevenson, S., J. T. Fasullo, B. L. Otto-Bliesner, R. A. Tomas, and C. Gao, 2017: Role of eruption season in reconciling model and proxy responses to tropical volcanism, P. Natl. Acad. Sci. USA, doi:10.1073/pnas.1612505114

Swingedouw, D., P. Ortega, J. Mignot, E. Guilyardi, V. Masson-Delmotte, P. G. Butler, M. Khodri, and R. Seferian, 2015: Bidecadal North Atlantic ocean circulation variability controlled by timing of volcanic eruptions, Nature Comm., 6, 6545, doi:10.1038/ncomms7545

Timmreck, C., 2012: Modeling the climatic effects of large volcanic eruptions, WIREs Clim. Change, 3: 545-564, doi:10.1002/wcc. 192

Timmreck, C., G. W. Mann, V. Aquila, C. Brühl, M. Chin, S. S. Dhomse, J. M. English, R. Hommel, L. A. Lee, M. J. Mills, R. Neely, A. Schmidt, J.-X. Sheng, M. Toohey and D. Weisenstein, 2016b: ISA-MIP: A co-ordinated intercomparison of Interactive Stratospheric Aerosol models, Geophys. Res. Abstr., 18, EGU2016-13766, EGU General Assembly 2016

Timmreck, C., H. Pohlmann, S. Illing, and C. Kadow, 2016a: The impact of stratospheric volcanic aerosol on decadalscale climate predictions, Geophys. Res. Lett., 43, 834-842, doi:10.1002/2015GL067431

Toohey, M., K. Krüger, M. Bittner, M., C. Timmreck, and H. Schmidt, 2014: The impact of volcanic aerosol on the Northern Hemisphere stratospheric polar vortex: mechanisms and sensitivity to forcing structure, Atmos. Chem. Phys., 14, 13063-13079, doi:10.5194/acp-1413063-2014

Turner, J., T. J. Bracegirdle, T. Phillips, G. J. Marshall, and J. S. Hosking, 2013: An initial assessment of Antarctic Sea ice extent in the CMIP5 models, J. Clim., 26: 1473-1484

Zambri, B., and A. Robock, 2016: Winter warming and summer monsoon reduction after volcanic eruptions in Coupled Model Intercomparison Project 5 (CMIP5) simulations, Geophys. Res. Lett., 43, 10,920-10,928, doi:10.1002/2016GL070460

Zanchettin, D., 2017: Aerosol and solar irradiance effects on decadal climate variability and predictability, Curr. Clim. Ch. Rep., 3: 150, doi:10.1007/s40641-017-0065-y 
Zanchettin, D., O. Bothe, C. Timmreck, J. Bader, A. Beitsch, H.-F. Graf, D. Notz, and J. H. Jungclaus, 2014: Interhemispheric asymmetry in the sea-ice response to volcanic forcing simulated by MPI-ESM (COSMOS-Mill), Earth Syst. Dynam., 5, 223-242, doi:10.5194/esd-5-2232014

Zanchettin, D., C. Timmreck, H.-F. Graf, A. Rubino, S. Lorenz, K. Lohmann, K. Krueger, and J. H. Jungclaus, 2012: Bi-decadal variability excited in the coupled oceanatmosphere system by strong tropical volcanic eruptions, Clim. Dyn., 39:1-2, 419-444, DOI:10.1007/s00382-0111167-1

Zanchettin, D., O. Bothe, H.-F. Graf, S. J. Lorenz, J. Luterbacher, C. Timmreck, and J. H. Jungclaus, 2013a: Background conditions influence the decadal climate response to strong volcanic eruptions, J. Geophys. Res. Atm., 118(10): 4090-4106, doi:10.1002/jgrd.50229

Zanchettin D., C. Timmreck, O. Bothe, S.J. Lorenz, G. Hegerl, H.-F. Graf, J. Luterbacher, and J.H. Jungclaus, 2013b: Delayed winter warming: a robust decadal response to strong tropical volcanic eruptions?, Geophys. Res. Lett. 40, 204-209 doi:10.1029/2012GL054403

Zanchettin, D., M. Khodri, C. Timmreck, M. Toohey, A. Schmidt, E. P. Gerber, G. Hegerl, A. Robock, F. S. R. Pausata, W. T. Ball, S. Bauer, S. Bekki, S. S. Dhomse, A. N. LeGrande, G. W. Mann, L. Marshall, M. Mills, M. Marchand, U. Niemeier, V. Poulain, E. Rozanov, A. Rubino, A. Stenke, K. Tsigaridis, and F. Tummon, 2016: The Model Intercomparison Project on the climatic response to Volcanic forcing (VolMIP): experimental design and forcing input data for CMIP6, Geosci. Model Dev., 9, 2701-2719, doi:10.5194/ gmd-9-2701-2016

Zhong, Y., G. H. Miller, B. L. Otto-Bliesner, M. M. Holland, D. A. Bailey, D. P. Schneider, and A. Geirsdottir, 2010: Centennial-scale climate change from decadally-paced explosive volcanism: a coupled sea ice-ocean mechanism, Clim. Dyn. 23:5-7, doi:10.1007/s00382-010-0967-z

Zou, Y., J.-Y. Yu, T. Lee, M.-M. Lu, and S. T. Kim, 2014: CMIP5 model simulations of the impacts of the two types of El Niño on the U.S. winter temperature, J. Geophys. Res. -Atmos., 119(6):3076-3092. doi:10.1002/2013JD021064 


\title{
Towards the prediction of multi-year to decadal climate variability in the Southern Hemisphere
}

doi: $10.22498 /$ pages.25.1.32

\section{Scott Power ${ }^{1}$, Ramiro Saurral ${ }^{2}$, Christine Chung ${ }^{1}$, Rob Colman ${ }^{1}$, Viatcheslav Kharin ${ }^{3}$, George Boer ${ }^{3}$, Joelle Gergis ${ }^{4}$, Benjamin Henley ${ }^{4}$, Shayne McGregor ${ }^{5}$, Julie Arblaster ${ }^{5}$, Neil Holbrook ${ }^{6}$, Giovanni Liguori ${ }^{7}$}

\author{
1 Bureau of Meteorology, Australia \\ 2 CIMA, Ciudad Universitaria, Argentina \\ 3 Environment and Climate Change, Canada \\ 4 University of Melbourne, Australia \\ 5 Monash University, Australia \\ 6 University of Tasmania, Australia \\ 7 Georgia Institute of Technology, USA
}

\section{Introduction}

Multi-year (2-7 years) and decadal climate variability (MDCV) can have a profound influence on lives, livelihoods and economies. Consequently, learning more about the causes of this variability, the extent to which it can be predicted, and the greater the clarity that we can provide on the climatic conditions that will unfold over coming years and decades is a high priority for the research community. This importance is reflected in new initiatives by WCRP, CLIVAR, and in the Decadal Climate Prediction Project (Boer et al., 2016) that target this area of research. Here we briefly examine some of the things we know, and have recently learnt, about the causes and predictability of Southern Hemisphere MDCV (SH MDCV), and current skill in its prediction.

\section{Causes of SH MDCV}

As with other parts of the globe, internally generated climate variability is a major element of SH MDCV (Kirtman et al., 2013). Major components of internal variability for the Southern Hemisphere are decadal variations in ENSO, the Interdecadal Pacific Oscillation (IPO, Garreaud and Battisti, 1999; Power et al., 1999; Salinger et al., 2001; Folland et al., 2002; Wu and Hsieh, 2003; Holbrook et al., 2011; Christensen et al., 2013; Kosaka and Xie, 2013; England et al., 2014; Holbrook et al., 2014; Watanabe et al., 2014; Henley et al., 2015; Meehl et al., 2016), the Southern Annular Mode (SAM (Shiotani, 1990; Thompson et al., 2000; Watterson, 2009; Pohl et al., 2009; Yuan and Yonekura, 2011; Jones et al., 2016), and the Indian Ocean Dipole.

North Pacific decadal variability has recently been described by Di Lorenzo et al. (2015) as a seasonallybased red noise process involving the interaction between extratropical atmospheric variability and
ENSO via the North Pacific Meridional Modes (Chiang and Vimont, 2004). Although a similar mechanism has not yet been proposed for the South Pacific DCV, tropical-extratropical interactions, including via both the ocean and atmosphere, are thought to be at least partly responsible for inducing decadal to multidecadal variability in the South Pacific too (e.g., McGregor et al., 2007, 2008, 2009a and b; Farneti et al., 2014; Zhang et al., 2014; Ding et al., 2015). Inter-basin interactions are also thought to play a role in driving Pacific Ocean decadal and multi-decadal variability (e.g., McGregor et al., 2014; Kucharski et al., 2016, Chikamoto et al., 2016). Palaeoclimate reconstructions of MDCV in the Pacific vary significantly in their spectral characteristics, likely due to spectral biases in the different proxy records, nonstationarity of teleconnections and the use of various statistical reconstructions methods (Bateup et al., 2015).

External forcing, both natural and anthropogenic, can also drive decadal and longer-term variability in the $\mathrm{SH}$ (e.g., Bindoff et al., 2013 and references therein). Natural drivers include volcanic eruptions (e.g. Church et al., 2005), while anthropogenic external drivers include changes in greenhouse gas concentrations, aerosols (Cai et al., 2010) and stratospheric ozone (Kirtman et al., 2013; Arblaster et al., 2014; Eyring et al., 2013).

\section{How well do climate models simulate MDCV in the} SH?

The ability of climate models to simulate Earth's climate was assessed in the IPCC Fifth Assessment Report (Flato et al., 2013). They concluded that models reproduce many important modes of variability. This includes modes of relevance to the SH: ENSO, the Indian-Ocean Dipole and the Quasi-Biennial Oscillation. Models have improved in 
some respects since the last generation although, in the case of ENSO, some of this improvement might not be entirely for the right reasons.

While models are extremely valuable tools that enable us to improve our understanding of SH MDCV, they are not without their limitations. For example, while CMIP5 models tend to capture the spatial pattern of the IPO, models tend to underestimate the magnitude of SST variability associated with the IPO (Power et al., 2016; Henley et al., 2017), and both the magnitude of DCV in trade winds (England et al., 2014; McGregor et al., 2014) and multidecadal changes in the strength of the Walker Circulation (Kociuba and Power, 2015). These deficiencies appear to be due, at least in part, to modeled ENSOs that tend to be too oscillatory on too short a time-scale. This makes it hard for the models to maintain multi-year and longer-term anomalies (Kociuba and Power, 2015; Power et al., 2016).

A further illustration of the limitations of CMIP5 models in simulating SH MDCV is seen in Fig. 1. It shows timeseries of the decadal variability in SH surface air temperature from pre-industrial runs of CMIP5 models. The model-to-model range in the magnitude and character of the variability is remarkable. Some models exhibit variability that has a range of a few tenths of a degree, while the range of some other models is three or more times larger. The character of the variability also differs markedly among models. In some models there is pronounced multi-decadal variability, whereas in other models variability occurs on much shorter time-scales. While further research is needed to ascertain which of these simulations more realistically captures SH MDCV. Clearly, given the large model to model differences evident in Fig.1, care is needed in assigning confidence to conclusions drawn on the basis of SH MDCV simulated in the current generation of climate models.

There have been other studies investigating SH MDCV of the past 1000 years in climate model simulations and reconstructions For example, a recent study by Hope et al. (2016) examined the decadal characteristics of ENSO spectra based on seven published ENSO reconstructions, and indices of Nino 3.4 SSTs and the Southern Oscillation Index calculated from six CMIP5-PMIP3 last millennium simulations. The post-1850 spectrum of each modelled or reconstructed ENSO series captures the observed spectrum to varying degrees. However, no single model or ENSO reconstruction completely reproduces the instrumental spectral characteristics across the multiyear or decadal bands.

Appreciable changes in the level of decadal ENSO variability is observed in the reconstructions and simulations of the pre-1850 period. While much of this represents internally generated variability (see e.g. Power et al., 2006), some of the variability may be linked to intermittent major volcanic eruptions (Hope et al., 2016). Nevertheless, Hope et al. (2016) report inconsistencies between reconstructions, models and instrumental indices used to evaluate changes over past centuries, reflecting the complexity of reconstructing and simulating past changes of a highly variable coupled system. In the reconstructions, variability arises from internal climate processes, different forced responses, or non-climatic proxy processes that are still not well understood (Ault et al., 2013).

Improving the simulation of SH MDCV would be greatly assisted by the availability of additional data from high latitude regions. The palaeoclimate reconstruction of the SAM by Abram et al. (2014) displays good agreement with CMIP5-PMIP3 last millennium simulations. Although the reconstruction shows a progressive shift towards SAM's positive phase as early as the fifteenth century, the positive trend in the SAM since 1940 is reproduced by multi-model climate simulations forced with rising greenhouse gas levels and ozone depletion (Abram et al.. 2014). These results are likely to reflect the brevity of the instrumental data from high latitudes, and associated deficiencies in model representation of SH climate (Jones et al., 2016).

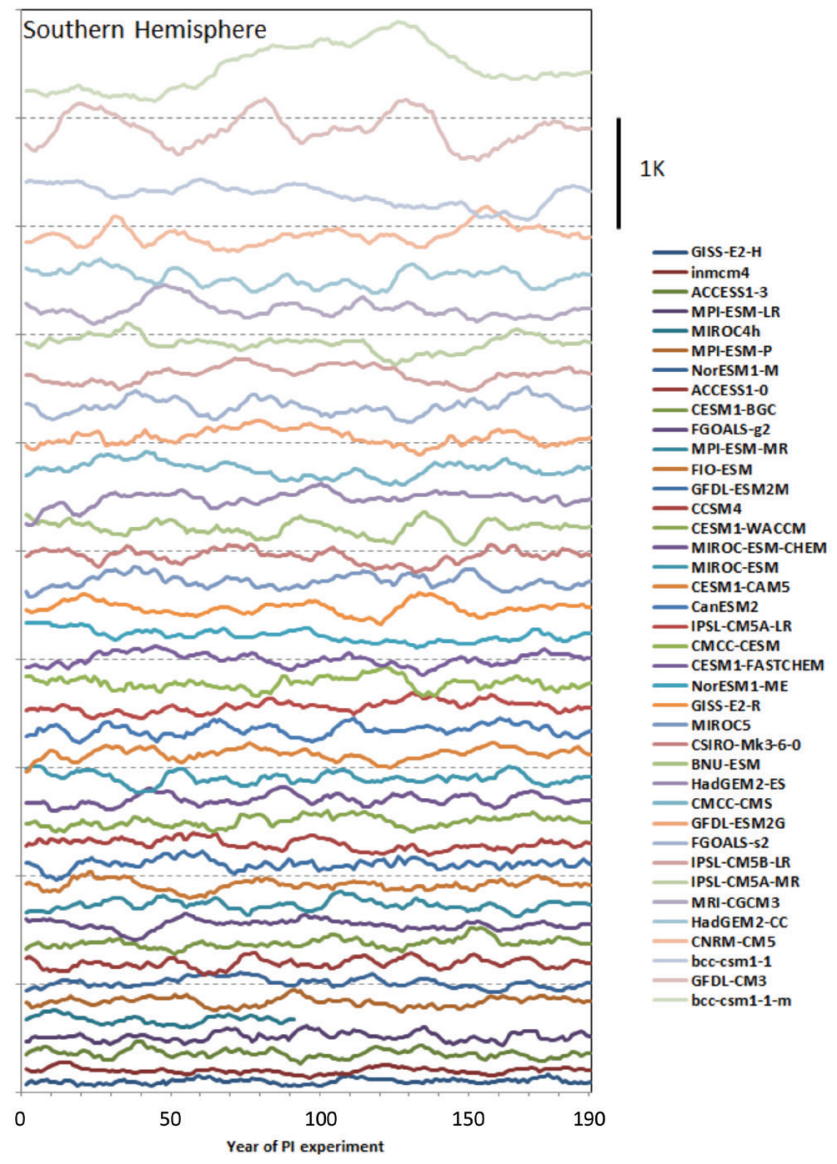

Figure 1: Time series of the (detrended) 10-year running annual mean surface air temperature, averaged over the $\mathrm{SH}$ from the CMIP5 models (K), ordered from smallest to largest. Values calculated from the first 200 years of pre-industrial experiments offsets for display purposes. 


\section{Predictability of MDCV in the SH}

In climate science the term "predictability" has a different meaning to "predictive skill". Predictability provides an estimate of the upper limit to predictive skill, in the absence of technical problems - apart from uncertainty in initial conditions. Predicability is usually estimated from a model's ability to predict its own evolution given imperfect initial conditions. The presumption is that the results from a well-behaved climate model can provide information on the predictability of the actual climate system. Predictability arises from internal variability, external forcing (e.g. increasing greenhouse gas concentrations), and interactions between them. One estimate of the relative importance of initial conditions and external forcing for the predictability of timeaveraged temperature in the Southern Hemisphere is depicted in Fig. 2 (dashed lines). Initialisation provides additional potential skill on average over the southern hemisphere on all time-scales, from one month to 10 years. The relative contribution of initialisation to the potential skill tends to diminish the longer the timescale, as the relative contribution from external forcing increases.

The estimated potential predictability of five-year means across the SH is dominated by the contribution of external forcing, with internal variability making comparatively little contribution (Kirtman et al., 2013, Fig. 11.1). This is consistent with the findings of Meehl and Hu (2010), with the possible exception of the east Antarctic region south of Africa. Whether or not this represents a robust exception remains unclear.

Additional studies have examined the regional predictability of MDCV in the $\mathrm{SH}$ using idealised experiments in which model conditions are perturbed at a particular point in time in an integration and the degree to which the ensuing variability is affected is assessed. Power and Colman (2006) used this strategy to assess the predictability on internally generated variability in their climate model. They found that off-equatorial regions in the South Pacific exhibited variability that was a delayed, low pass-filtered version of preceding ENSO variability. The ocean had acted as a low pass filter on the wind-stress and heat flux forcing it received, in an ENSO-modified Frankignoul and Hasselmann process (Hasselmann, 1976; Frankignoul and Hasselmann, 1977). At ocean depths of $300 \mathrm{~m}$, this gave rise to highly predictable multi-year variability. This is consistent with the findings of Shakun and Shaman (2009), who showed that the leading mode of SST variability in the South Pacific could be reasonably well-simulated as a response to preceding ENSO-driven heat flux forcing, in analogy with the Pacific Decadal Oscillation in the North Pacific (Newman et al., 2003; 2016).

Power et al. (2006) used the same strategy and concluded that there is limited predictability in interdecadal changes in ENSO activity and its associated teleconnections to Australian climate. More recently, Wittenberg et al. (2014) concluded that potential predictability was evident in ENSO variability in their model several years ahead, but not on decadal time-scales. Power and Colman (2006) also concluded that the relative influence of decadal variability on ocean variability as a whole tended to be weak in the tropical Pacific and more pronounced as depth and latitude increased. This general pattern is consistent with the more recent analysis of predictability in SST (Frederiksen et al. 2016).

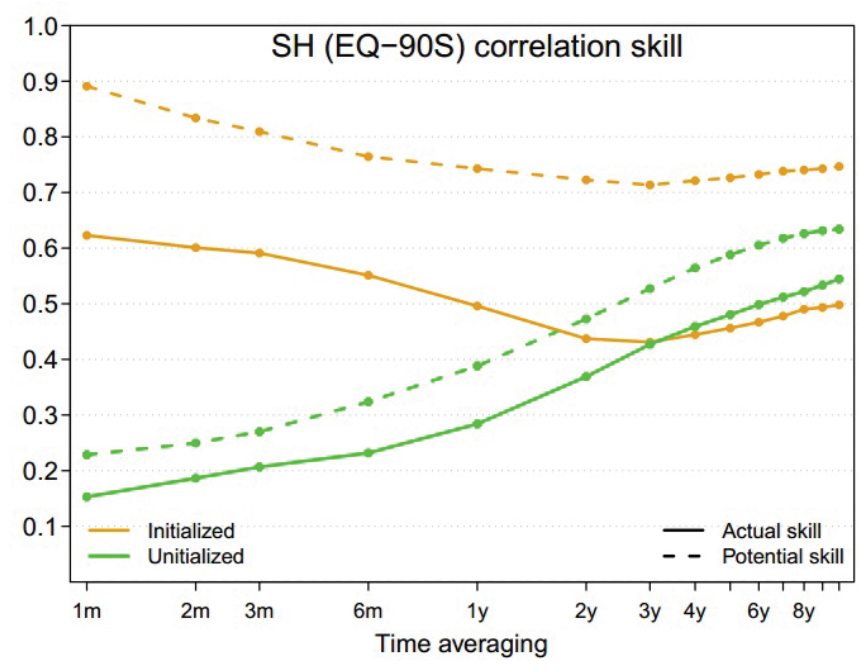

Figure 2: The relative importance of initial conditions and external forcing for the climate prediction and predictability of time-averaged temperature in the $\mathrm{SH}$. The correlation skill scores for the ensemble mean of initialized temperature forecasts, and the model-based "potential" correlation skill scores, area averaged over the $\mathrm{SH}$, are presented as orange lines. The same quantities, but for uninitialized climate simulations, are plotted as green lines. All lines represent area-averaged SH values. Solid lines: hindcast skill; Dashed lines: potential skill. Results are for temperature averaged over periods from a month to a decade. (Figure prepared by $V . V$. Kharin based on the results reported in Boer et al. (2013))

The excitation of Rossby waves from ENSO-driven windstresses also drives subsequent and therefore predictable sea-level variability (e.g., Luo, 2003; Qiu and Chen, 2006; Holbrook et al., 2011; 2014). Other studies have examined lagged associations with extra-tropical regions and the tropics, with results suggesting that South Pacific driven changes in both the ocean and atmosphere may provide a source of predictability for multi-year variability in the tropics (McGregor et al., 2007, 2008, 2009a and b; Luo et al., 2003; Tatebe et al., 2013; Zhang et al., 2014). For example, Zhang et al. (2014) identified a South Pacific meridional mode in idealised climate simulations, in which wind variability in the South Pacific underpins a sub-component of subsequent climatic variability in the tropics, while the studies of McGregor et al. highlight ocean links between the extra-tropics and the tropics and their role in driving climate variability in the tropics. 
More recently, the re-emergence of remnant mixed layers to the surface has been identified as a possible source of predictability for SH MDCV (D. Dommenget, pers. comm.).

Finally, predictability may arise in the Pacific, including the South Pacific, via atmospheric teleconnections driven by partially predictable Atlantic surface temperature variability (e.g. Rashid et al., 2010).

\section{Prediction of SH MDCV}

Unlike "predictability" assessment, a "prediction" is an estimate or collection of estimates of the future state of the real world. Research on decadal climate prediction (Smith et al., 2007; Meehl et al., 2009; Meehl et al., 2016) aims to provide forecasts of MDCV. Part of the scientific basis for producing such predictions is given by the predictability that exists in some areas and for some variables, as discussed in the previous section. MDCV prediction research was an important element of the Fifth Phase of the Coupled Model Intercomparison Project (CMIP5) (Taylor et al., 2012) and was a subject assessed in the Fifth Assessment Report of the IPCC (Kirtman et al., 2013). CMIP5 provided a new set of forecasts that were initialized using the observed state of the climate system. This allowed an assessment of the benefit of initialization by comparison with parallel experiments where no information on the initial state of the climate system was provided. The quantification of such changes is important since near-term climate predictions are affected by the initial conditions as well as by changes in the external forcing (Meehl et al., 2009; Kirtman et al., 2013; Meehl and Teng 2016).

Initialization, which is accomplished using a range of different techniques (e.g. Hawkins and Sutton, 2009, 2011; Mochizuki et al. 2010; Doblas-Reyes et al., 2011), produce ensembles of simulations which are intended to account for uncertainties in the initial conditions. As with any other forecast, a set of skill scores is usually computed to quantify the quality of such predictions for previous years (i.e. prediction of past years or hindcasts), providing a quantitative assessment of the performance of the different forecast systems.

In spite of the relative youth of this research area, there are a growing number of papers that address predictability and prediction skill over areas of the Northern Hemisphere (e.g. Griffies and Bryan, 1997; Boer, 2000; Collins, 2002; Hawkins and Sutton, 2009; Smith et al., 2010; Zanna, 2012; García-Serrano and Doblas-Reyes, 2012; Boer et al., 2013; Guémas et al., 2013; among many others). However, considerably less attention has been paid to the SH. Part of the explanation is likely related to the smaller scientific community that exists in the $\mathrm{SH}$ compared to the northern hemisphere. Most importantly, there is a relative lack of in situ climate records in most of the SH, with the exception of some ship routes in the Indian and Atlantic Oceans. Limited in situ data poses a difficulty for the assessment of SST variability and prediction skill. The advent of the satellite era increased the amount of available information, but since that source of data only exists since the late 1970 s or early 1980 s, most of the SST hindcasts prior to the 1970 s cannot be validated against ground truth, thus decreasing the sample size and significance of most of the statistical tests applied therein. In an assessment of the decadal climate prediction skill over southern Africa, Reason et al. (2006) had already noticed how the lack of data and the decrease in density and quality of the information in several regions in Africa was a major concern.

The relative importance of initial conditions and external forcing for the skill of existing hindcasts of time-averaged temperature in the Southern Hemisphere is depicted in Fig. 2 (solid lines). Initialisation provides additional hindcast skill over the Southern Hemisphere for averages of up to three years, beyond which initialisation in current systems appears to have little impact. The difference between the actual skill scores (solid lines) and the potential skill scores (dashed lines) suggests that greater skill may be achieved as the technical issues associated with MDCV prediction are overcome.

Among other recent contributions to this topic, Rea et al., (2016) quantified prediction quality over high SH latitudes, concluding that a proper representation of the stratospheric processes and the stratospheretroposphere coupling is crucial in order to obtain skillful predictions. Saurral et al., (2016) analyzed the influence of initialization and climate drift on hindcasts of SST in the South Pacific in a set of coupled GCMs. They noticed differences in the hindcast skill depending upon initialization under strong or weak ENSO conditions. Overall, their results showed lower skill in decadal predictions than that found for the North Pacific basin (Lienert and Doblas-Reyes, 2013).

The increased number of observations that are being made in the SH, particularly of the ocean's surface and subsurface through e.g. the Global Temperature and Salinity Profile Programme, ARGO, and other critical elements of the global observing network, will provide invaluable data for the assessment of predictability and prediction skill in coming years. At the same time, modelling efforts focused on improving the representation of processes underpinning decadal variability and initial conditions are also of great importance for the field. The prediction of SH MDCV could benefit from the improvements in sea ice concentration and thickness reanalysis and the ingestion of those data into the GCMs. For instance, the upcoming Year of Polar Prediction could prove a very interesting opportunity to gather new information on sea ice in order to improve understanding of high-to-mid latitude linkages and to see how these new observations impact the skill of MDCV predictions. 


\section{Making further progress}

Our understanding of the causes and predictability of MDCV in the Southern Hemisphere and our ability to predict its behavior could be increased by improving, e.g., :

- the documentation, quality controlling and analysis of MDCV evident in instrumental records, other historical records (see, e.g. Callaghan and Power, 2011; 2014), and paleo records

- the quality and increasing the range of relevant instrumental, historical and paleoclimate records.

- our understanding of the impact/sensitivity of methods used for multi-proxy paleoclimate records in order to develop methods that are not sensitive to the non-stationarity of teleconnections.

- climate models and their simulation of observed SH MDCV, including the underlying dynamical processes and statistics of SH MDCV and particular important events (e.g., strengthening the of Walker circulation over the past few decades and the rate of warming in the Pacific over the past half-century)

- understanding of the causes of SH MDCV through e.g. process studies, by continuing to develop theoretical understanding of the relevant processes involving both observations and model simulations, using a hierarchy of modelling approaches

- understanding of MDC predictability and its underlying dynamics in models, through further experimentation and further analysis of experiments already conducted

- initialisation methods, and predictive systems more broadly

- our ability to reliably determine hindcast skill.

These objectives can be assisted by, e.g., :

- participation in CMIP6, the Decadal Climate Prediction Project and other relevant international initiatives

- maintaining and expanding observing networks to better monitor SH MDCV

- continuing to foster links between paleoclimate, climate modelling and model analysis communities

- digitising and quality controlling early instrumental records from SH locations (Allan et al., 2016; Freeman et al., 2016), and by

- collecting critical palaeoclimate data in key regions (e.g. Abram et al., 2015).

\section{References}

Abram, N. J., Dixon, B. C., Rosevear, M. G., Plunkett, B., Gagan, M. K., Hantoro, W. S. and Phipps, S. J., 2015: Optimized coral reconstructions of the Indian Ocean Dipole: An assessment of location and length considerations. Paleoceanography, 30 (10), 2015PA002810.

Abram, N. J., Mulvaney, R., Vimeux, F., Phipps, S. J., Turner, J. and England, M. H., 2014: Evolution of the Southern Annular Mode during the past millennium. Nature
Climate Change, 4, 564-569.

Allan, R., Endfield, G., Damodaran, V., Adamson, G., Hannaford, M., Carroll, F., Macdonald, N., Groom, N., Jones, J., Williamson, F., Hendy, E., Holper, P., Arroyo-Mora, J. P., Hughes, L., Bickers, R. and Bliuc, A.-M., 2016: Toward integrated historical climate research: the example of Atmospheric Circulation Reconstructions over the Earth. WIREs Climate Change, 7, 164-174, doi: 10.1002/ wcc.379.

Arblaster, J.M., and N.P Gillett (Lead Authors), N. Calvo, P.M. Forster, L.M. Polvani, S.-W. Son, D.W. Waugh, and P.J. Young, 2014: Stratospheric ozone changes and climate, Chapter 4. Scientific Assessment of Ozone Depletion: 2014, Global Ozone Research and Monitoring Project - Report No. 55, World Meteorological Organization, Geneva, Switzerland.

Ault, T. R., C. Deser, M. Newman, J. Emile-Geay, 2013: Characterizing decadal to centennial variability in the equatorial Pacific during the last millennium. Geophysical Research Letters, 40, 3450-3456.

Bateup, R., S. McGregor and A. J. E. Gallant, 2015: The influence of non-stationary teleconnections on palaeoclimate reconstructions of ENSO variance using a pseudoproxy framework, Clim. Past, 11, 1733-1749, doi:10.5194/cp-11-1733-2015.

Bindoff, N.L., P.A. Stott, K.M. AchutaRao, M.R. Allen, N. Gillett, D. Gutzler, K. Hansingo, G. Hegerl, Y. Hu, S. Jain, I.I. Mokhov, J. Overland, J. Perlwitz, R. Sebbari and X. Zhang, 2013: Detection and Attribution of Climate Change: from Global to Regional. In: Climate Change 2013: The Physical Science Basis. Contribution of Working Group I to the Fifth Assessment Report of the Intergovernmental Panel on Climate Change [Stocker, T.F., D. Qin, G.-K. Plattner, M. Tignor, S.K. Allen, J. Boschung, A. Nauels, Y. Xia, V. Bex and P.M. Midgley (eds.)]. Cambridge University Press, Cambridge, United Kingdom and New York, NY, USA.

Boer, G. J., 2000: A study of atmosphere-ocean predictability on long time scales. Climate Dyn., 16, 469477.

Boer, G. J., V. V. Kharin, and W. J. Merryfield, 2013: Decadal predictability and forecast skill. Clim. Dyn., 41, 18141833, doi:10.1007/s00382-013-1705-0.

Boer, G., and Coauthors, 2016: The Decadal Climate Prediction Project (DCPP) contribution to CMIP6. Geosci. Model Dev., 9, 3751-3777.

Cai, W., T. Cowan, J. M. Arblaster, and S. Wijffels, 2010: On potential causes for an under-estimated global ocean heat content trend in CMIP3 models, Geophys. Res. Lett., 37, L17709, doi:10.1029/2010GL044399. 
Callaghan, J., and S. B. Power, 2014: Major coastal flooding in southeastern Australia 1860-2012, associated deaths and weather systems. Aust. Meteor. Oceanogr. J., 64, 183213.

Christensen, J.H., K. Krishna Kumar, E. Aldrian, S.-I. An, I.F.A. Cavalcanti, M. de Castro, W. Dong, P. Goswami, A. Hall, J.K. Kanyanga, A. Kitoh, J. Kossin, N.-C. Lau, J. Renwick, D.B. Stephenson, S.-P. Xie and T. Zhou, 2013: Climate Phenomena and their Relevance for Future Regional Climate Change. In: Climate Change 2013: The Physical Science Basis. Contribution of Working Group I to the Fifth Assessment Report of the Intergovernmental Panel on Climate Change [Stocker, T.F., D. Qin, G.-K. Plattner, M. Tignor, S.K. Allen, J. Boschung, A. Nauels, Y. Xia, V. Bex and P.M. Midgley (eds.)]. Cambridge University Press, Cambridge, United Kingdom and New York, NY, USA.

Church, J., N.J. White and J.M. Arblaster, 2005: Significant decadal-scale impact of volcanic eruptions on sea level and ocean heat content. Nature, 438, 74-77, doi:10.1038/ nature 04237.

Collins, M., 2002: Climate predictability on interannual to decadal time scales: The initial value problem. Clim. Dyn., 19, 671-692.

CSIRO, Australian Bureau of Meteorology and SPREP, 2015: Climate in the Pacific: a regional summary of new science and management tools, Pacific-Australia Climate Change Science and Adaptation Planning Program Summary Report. Commonwealth Scientific and Industrial Research Organisation, Melbourne, Australia.

Di Lorenzo, E., G. Liguori, N. Schneider, J. C. Furtado, B. T. Anderson, and M. A. Alexander, 2015: ENSO and meridional modes A null hypothesis for Pacific Climate Variability. Geophys. Res. Lett., 42, 9440-9448, doi: 10.1002/2015GL066281.

Ding, R., J. Li, and Y. Tseng, 2015: The impact of South Pacific extratropical forcing on ENO abnd comparisons with the North Pacific. Climate Dynamics, 44, DOI: 10.1007/s00382-014-2303-5.

Doblas-Reyes, F. J., M. A. Balmaseda, A. Weisheimer, and T. N. Palmer, 2011: Decadal climate prediction with the ECMWF coupled forecast system: Impact of ocean observations. J. Geophys. Res., 116, D19111.

Dong L., T. Zhou, A. Dai, F. Song, B. Wu, X. Chen, 2016: The Footprint of the Inter-decadal Pacific Oscillation in Indian Ocean Sea Surface Temperatures. Scientific Reports, 6, 21251, doi:10.1038/srep21251.

England, M. H., S. McGregor, P. Spence, G. A. Meehl, A. Timmermann, W. Cai, A. Sen Gupta, M. J. McPhaden, A. Purich and A. Santoso, 2014: Recent intensification of wind-driven circulation in the Pacific and the ongoing warming hiatus. Nature Climate Change, 4, 222-227, doi: 10.1038/nclimate2106

Eyring, V., J. M. Arblaster, I. Cionni, J. Sedláček, J. Perlwitz, P. J. Young, S. Bekki, D. Bergmann, P. Cameron-Smith, W. J. Collins, G. Faluvegi, K.-D. Gottschaldt, L. W. Horowitz, D. E. Kinnison, J.-F. Lamarque, D. R. Marsh, D. Saint-Martin, D. T. Shindell, K. Sudo, S. Szopa and S. Watanabe, 2013: Long-term ozone changes and associated climate impacts in CMIP5 simulations, J. Geophys. Res. Atmos., 118, 50295060, doi:10.1002/jgrd.50316.

Farneti, R., F. Molteni, and F. Kucharski, 2014: Pacific interdecadal variability driven by tropical-extratropical interactions. Climate Dynamics, 42(11-12), 3337-3355.

Folland, C. K., J. A. Renwick, M. J. Salinger, and A. B. Mullan, 2002: Relative influences of the Interdecadal Pacific Oscillation and ENSO on the South Pacific Convergence Zone. Geophys. Res. Lett., 29, 1643-1647.

Frankignoul, C., and K. Hasselmann, 1977: Stochastic climate models, Part II Application to sea-surface temperature anomalies and thermocline variability. Tellus, 29, 10.1111/j.2153-3490.1977.tb00740.x.

Frederiksen, C.S., X. Zheng, and S. Grainger, 2016: Simulated modes of inter-decadal predictability in sea surface temperature. Climate Dynamics, 46, 2231-2245. DOI 10.1007/s00382-015-2699-6.

Freeman, E., Woodruff, S. D., Worley, S. J., Lubker, S. J., Kent, E. C., Angel, W. E., Berry, D. I., Brohan, P., Eastman, R., Gates, L., Gloeden, W., Ji, Z., Lawrimore, J., Rayner, N. A., Rosenhagen, G. and Smith, S. R., 2016: ICOADS Release 3.0: a major update to the historical marine climate record. International Journal of Climatology: doi:10.1002/joc.4775.

Garreaud, R.D. and D.S. Battisti, 1999: Interannual ENSO and Interdecadal ENSO-like Variability in the Southern Hemisphere Tropospheric Circulation. J. Climate, 12, 2113-2123

Garcia-Serrano, J., F. J. Doblas-Reyes, and C. A. S. Coelho, 2012: Understanding Atlantic multi-decadal variability prediction skill. Geophys. Res. Lett., 39, L18708, doi:10.1029/2012GL053283.

Griffies, S. M., and K. Bryan, 1997: A predictability study of simulated North Atlantic multidecadal variability. Clim. Dyn., 13, 459-487.

Guémas, V., F. J. Doblas-Reyes, I. Andreu-Burillo, and M. Asif, 2013: Retrospective prediction of the global warming slowdown in the last decade. Nature Clim. Change, 3, 649-653, doi:10.1038/nclimate1863. 
Hasselmann, K., 1976: Stochastic climate models. Part I. Theory. Tellus, 6, 473-485, 10.1111/j.2153-3490.1976. tb00696.x.

Han, W., J. Vialard, M. J. McPhaden, W. P. M. de Ruitjer, 2014: Indian Ocean Decadal Variability: A Review. Bull. American Meteorol. Soc., 95, 1679-1703.

Hawkins, E., and R. Sutton, 2009: The potential to narrow uncertainty in regional climate predictions. Bull. Am. Meteorol. Soc., 90, 1095-1107, doi: 10.1175/2009BAMS2607.1.

Henley, B.J. and Coauthors, 2015: A Tripole Index for the Interdecadal Pacific Oscillation. Climate Dynamics, 45(11-12), 3077-3090.

Henley, B.J. and Coauthors, 2017. Spatial and Temporal Agreement in Climate Model Simulations of the Interdecadal Pacific Oscillation. Environmental Research Letters, in press, 1-33.

Holbrook N. J., I. D. Goodwin, S. McGregor, E. Molina, S. B. Power, 2011: ENSO to multi-decadal time scale changes in East Australian Current transports and Fort Denison sea level: Oceanic Rossby waves as the connecting mechanism. Deep Sea Research, Part II,, 58, 547-558, doi:10.1016/j.dsr2.2010.06.007.

Holbrook NJ, J Li, M Collins, E Di Lorenzo, F-F Jin, T Knutson, M Latif, C Li, SB Power, R Huang and G Wu, 2014: Decadal climate variability and cross-scale interactions: ICCL 2013 Expert Assessment Workshop. Bulletin of the American Meteorological Society, 95, ES155-ES158. doi: 10.1175/BAMS-D-13-00201.1.

Hope, P., Henley, B. J., Gergis, J., Brown, J. and Ye, H., 2016: Time-varying spectral characteristics of ENSO over the Last Millennium. Climate Dynamics: DOI: 10.1007/ s00382-016-3393-z.

Jones, J. M., S. T. Gille, H. Goosse, N. J. Abram, P. O. Canziani, D. J. Charman, K. R. Clem, X. Crosta, C. de Lavergne, I. Eisenman, M. H. England, R. L. Fogt, L. M. Frankcombe, G. J. Marshall, V. Masson-Delmotte, A. K. Morrison, A. J. Orsi, M. N. Raphael, J. A. Renwick, D. P. Schneider, G. R. Simpkins, E. J. Steig, B. Stenni, D. Swingedouw, T. R. Vance, 2016: Assessing recent trends in high-latitude Southern Hemisphere surface climate. Nature Climate Change, 6, 917-926.

Kirtman, B., S.B. Power, J.A. Adedoyin, G.J. Boer, R. Bojariu, I. Camilloni, F.J. Doblas-Reyes, A.M. Fiore, M. Kimoto, G.A. Meehl, M. Prather, A. Sarr, C. Schär, R. Sutton, G.J. van Oldenborgh, G. Vecchi and H.J. Wang, 2013: Near-term Climate Change: Projections and Predictability. In: Climate Change 2013: The Physical Science Basis. Contribution of Working Group I to the Fifth Assessment Report of the
Intergovernmental Panel on Climate Change [Stocker, T.F., D. Qin, G.-K. Plattner, M. Tignor, S.K. Allen, J. Boschung, A. Nauels, Y. Xia, V. Bex and P.M. Midgley (eds.)]. Cambridge University Press, Cambridge, United Kingdom and New York, NY, USA.

Kociuba G. and S. B. Power, 2015: Inability of CMIP5 Models to Simulate Recent Strengthening of the Walker Circulation: Implications for Projections. J. Clim., 28, 2035.

Kosaka, Y. and S.-P. Xie, 2013: Recent global-warming hiatus tied to equatorial Pacific surface cooling. Nature, 501(7467), 403-7.

Kucharski, F., Ikram, F., Molteni, F. et al., 2016: Atlantic forcing of Pacific decadal variability, Clim Dyn, 46: 2337. doi:10.1007/s00382-015-2705-z

Lienert F., F. J. Doblas-Reyes, 2013: Decadal prediction of interannual tropical and North Pacific sea surface temperature. J. Geophys. Res. Atmospheres, 118, 59135922.

Luo, J.-J., S. Masson, S. Behera, P. Delecluse, S. Gualdi, A. Navarra, T. Yamagata, 2003: South Pacific origin of the decadal ENSO-like variation as simulated by a coupled GCM. Geophys. Res. Lett., 30 (24), 2250, doi:10.1029/2003GL018649.

McGregor, S., A. Sen Gupta, N. J. Holbrook and S. B. Power, 2009: The Modulation of ENSO Variability in CCSM3 by Extratropical Rossby Waves. J. Climate, 22, 5839-5383.

McGregor, S., N. J. Holbrook and S. B. Power, 2009: The response of a stochastically forced ENSO model to observed off-equatorial wind-stress forcing. J. Climate. 2512-2525.

McGregor, S., N. J. Holbrook, and S. B. Power, 2007: Interdecadal sea surface temperature variability in the equatorial Pacific Ocean. Part I: The role of off-equatorial wind stresses and oceanic Rossby waves. J. Clim., 20 (11), 2643-2658

McGregor, S., N. J. Holbrook, and S. B. Power, 2008: Interdecadal sea surface temperature variability in the equatorial Pacific Ocean. Part II: the role of equatorial/ off-equatorial wind stresses in a hybrid coupled model. J. Clim., 21 (17), 4242-4256.

McGregor, S., A. Timmermann, M. F. Stuecker, M. H. England, M. Merrifield, F.-F. Jin, Y. Chikamoto, 2014: Recent Walker Circulation strengthening and Pacific cooling amplified by Atlantic warming, Nature Climate Change, 4, 888-892, doi:10.1038/NCLIMATE2330. 
Meehl, G. A., J. M. Arblaster, C. M. Bitz, C. T. Y. Chung, and H. Teng, 2016: Antarctic sea-ice expansion between 2000 and 2014 driven by tropical Pacific decadal climate variability. Nature Geoscience, doi:10.1038/ngeo2751.

Meehl, G.A., A Hu, H Teng, 2016: Initialized decadal prediction for transition to positive phase of the Interdecadal Pacific Oscillation, Nature Communications, 7, doi:10.1038/ncomms11718.

Mochizuki, T., et al., 2010: Pacific decadal oscillation hindcasts relevant to near-term climate prediction. Proc, Natl. Acad. Sci., 107, 1833-1837.

Newman, M., G. P. Compo, and M. A. Alexander, 2003: ENSO-forced variability of the Pacific Decadal Oscillation, J. Climate, 16, 3853-3857, doi:10.1175/1520-0442.

Newman, M., et al. 2016: The Pacific Decadal Oscillation, revisited. J. Climate, 29, 4399-4427, DOI: http://dx.doi. org/10.1175/JCLI-D-15-0508.1

Palmer, J., Cook, E., Turney, C., Allen, K., Fenwick, P., Cook, B., O’Donnell, A., Lough, J., Grierson, P. and Baker, P., 2015: Drought variability in the eastern Australia and New Zealand summer drought atlas (ANZDA, CE 15002012) modulated by the Interdecadal Pacific Oscillation. Environmental Research Letters, 10 (12), 124002.

Power, S. B., T. Casey, C. Folland, A. Colman and V. Mehta, 1999: Inter-decadal modulation of the impact of ENSO on Australia. Climate Dynamics, 15, 319-324.

Power, S. B. and R. Colman, 2006: Multi-year predictability in a coupled general circulation

model. Climate Dynamics, 2, 247-272.

Power, S., M. Haylock, R. Colman, and X. Wang, 2006: The predictability of interdecadal changes in ENSO and ENSO teleconnections. J. Climate, 8, 2161-2180.

Power, S., F. Delage, G. Wang, and G. Kocuiba, 2016: Inability of climate models to simulate recent multidecadal change in Pacific surface temperature: implications for global temperature projections. Climate Dynamics, doi:10.1007/s00382-016-3326-x.

Power, S. B. and J. Callaghan, 2016: Variability in Severe Coastal Flooding, Associated Storms, and Death Tolls in Southeastern Australia since the Mid-Nineteenth Century. Journal of Applied Meteorology and Climatology, 55, 1139-1149.

Qiu, B., and S. Chen, 2006: Decadal Variability in the Large-Scale Sea Surface Height Field of the South Pacific Ocean: Observations and Causes. J. Phys. Oceanogr., 36, 1751-1762.
Rashid, H., S.B. Power, and J. Knight, 2010: Impact of multi-decadal fluctuations in the Atlantic thermohaline circulation on Indo-Pacific climate variability in a coupled GCM. J. Climate, 23, 4038-4044.

Rea G, C. Cagnazzo, A. Riccio, F. Fierli, and F. Cairo, 2016: Multi-decadal changes and predictions over the Southern Hemisphere region: role of the stratospheric representation in CMIP5 models. EGU General Assembly Conference Abstracts, Vienna, Austria, European Geosciences Union.

Reason CJ, W Landman, and W Tennant, 2006: Southern African climate and its links with variability of the Atlantic Ocean. Bull. Amer. Meteor. Soc., 87, 941-955.

Salinger, M.J, J.A. Renwick, and A. B. Mullan, 2001: Interdecadal Pacific Oscillation and South Pacific Climate. Int. J. Climatol., 21, 1705-1721.

Saurral R. I., F. J. Doblas-Reyes, and J. García-Serrano, 2016: Initial shock, drift and trends in decadal climate predictions in the South Pacific region upon different phases of ENSO. SPECS/PREFACE/WCRP Workshop on initial shock, drift and bias adjustment. 9-13 May 2016, Barcelona, Spain.

Shakun, J.D., and J. Shaman, 2009: Tropical origins of North and South Pacific decadal variability. Geophys. Res. Lett., 36, L19711, doi:10.1029/2009GL040313.

Shiotani, M., 1990: Low-frequency variations of the zonal mean state of the Southern Hemisphere troposphere, J. Meteorol. Soc. Jpn., 68, 461-471.

Smith, D. M., S. Cusack, A. W. Colman, C. K. Folland, G. R. Harris, and J. M. Murphy, 2007: Improved surface temperature prediction for the coming decade from a global climate model. Science, 317, 796-799.

Smith, D. M., R. Eade, N. J. Dunstone, D. Fereday, J. M. Murphy, H. Pohlmann, and A. A. Scaife, 2010: Skilful multi-year predictions of Atlantic hurricane frequency. Nature Geosci., 3, 846-849.

Taylor, K. E., R. J. Stouffer, and G. A. Meehl, 2012: An overview of CMIP5 and the experiment design. Bull. Am. Meteorol. Soc., 93, 485-498.

Tierney, J. E., Abram, N. J., Anchukaitis, K. J., Evans, M. N., Giry, C., Halimeda Kilbourne, K., Saenger, C. P., Wu, H. C. and Zinke, J., 2015: Tropical sea-surface temperatures for the past four centuries reconstructed from coral archives. Paleoceanography, 30, 226-252, doi:10.1002/2014PA002717.

Thompson, D. W. J., J. M. Wallace, and G. C. Hegerl, 2000: Annular modes in the extratropical circulation, part 2, 
Trends, J. Clim., 13, 1018-1036.

Tozer, C. R., T. R. Vance, J. L. Roberts, A. S. Kiem, M. A. J. Curran, and A. D. Moy, 2016: An ice core derived 1013year catchment-scale annual rainfall reconstruction in subtropical eastern Australia. Hydrology and Earth System Science, 20 (5), 1703-1717.

Vera, C., 2003: Interannual and interdecadal variability of atmospheric synoptic-scale activity in the Southern Hemisphere. J. Geophys. Res: Oceans, 108 (C4), 8077, doi:10.1029/2000JC000406.

Watanabe, M., H. Shiogama, H. Tatabe, M. Hayashi, M. Ishii, and M. Kimoto, 2014: Nature Climate Change, 4, 893-897.

Watterson, I. G., 2009: Components of precipitation and temperature anomalies and change associated with modes of the Southern Hemisphere. Int. J. Climatol., 29: 809-826. doi:10.1002/joc.1772.

Waugh, D.W., F. Primeau, T. DeVries, and M. Holzer, Recent changes in the ventilation of the southern oceans, Science, 339 (6119), 568-570, doi: 10.1126/science.1225411, 2013

Wittenberg, A.T., A. Rosati, T.L. Delworth, G.A. Vecchi, F. Zeng, 2014: ENSO Modulation: Is it decadally predictable? J. Climate, 27, 2667-2681, doi: http://dx.doi. org/10.1175/JCLI-D-13-00577.1.

Wu, A., and W. W. Hsieh, 2003: Nonlinear interdecadal changes of the El Nino-Southern Oscillation. Climate Dynamics, 21, 719-730.

Yuan X. and E. Yonekura, 2011: Decadal variability in the Southern Hemisphere, J. Geophys. Res., 116, D19115, doi:10.1029/2011JD015673.

Zanna, L., 2012: Forecast skill and predictability of observed Atlantic sea surface temperatures. J. Climate., 25, 5047-5056.

Zhang, H., A. Clement and P. Di Nezio, 2014: The South Pacific Meridional Mode: A Mechanism for ENSO-like Variability. J. Climate, 27, 769-783. 
doi: $10.22498 /$ pages.25.1.41

\title{
Haiyan Teng, Gerald A. Meehl, Grant Branstator, Stephen Yeager, Alicia Karspeck
}

\author{
National Center for Atmospheric Research, Boulder, USA
}

\section{Introduction}

Initialized predictions tend to drift away from the initial states towards the model's imperfect climatology. If all predictions drift in a coherent manner that is independent of an initial state, the drift to a large extent can be removed during the posterior bias correction. However, lack of continuous global ocean observations poses a serious challenge to the quality of ocean initial states that span several decades. Furthermore, incoherent initial errors especially in the Tropics can be amplified by air-sea coupling as a prediction evolves and can impact the entire globe through atmospheric teleconnections. Consequently the effect of such initial shocks on predictions are difficult to remove by simple bias correction methods and can overwhelm the relatively small decadal signals that we seek to predict. Here, we describe the initialization shock in a set of decadal prediction experiments with the Community Climate System Model version 4 (CCSM4) and discuss the challenges they cause to near-term hindcasts, in particular of the Interdecadal Pacific Oscillation (IPO).

\section{CCSM4 decadal prediction experiments}

CCSM4 is a fully coupled general circulation model consisting of atmosphere, ocean, land, and sea ice that are linked via a flux coupler and no flux corrections are employed (Gent et al., 2011). The atmosphere model uses a finite volume dynamical core with a nominal horizontal resolution of $1^{\circ}$ and 26 layers in the vertical. The ocean is a version of the Parallel Ocean Program (POP) with a nominal latitude-longitude resolution of $1^{\circ}$ (tapering down to $1 / 4^{\circ}$ in latitude in the equatorial tropics) and 60 levels in the vertical. The land and sea ice components share the same horizontal grids as the atmosphere and ocean models, respectively.

The CCSM4 decadal prediction experiments (also referred to as initialized hindcasts, or hindcasts) analyzed here are an expansion of a previously documented set (Yeager et al., 2012) that was submitted to the Coupled Model Intercomparison Project phase 5 (CMIP5) (Taylor et al., 2012). The ocean/sea ice initial conditions are obtained from a CCSM4 ocean/sea ice stand-alone simulation forced with atmospheric variables, such as surface winds, air temperature, precipitation, surface fluxes, sea level pressure, humidity etc. from the NCEP/NCAR reanalysis
(Kalnay et al., 1996). This forced ocean/ice simulation represents the NCAR contribution to the

Coordinated Ocean-ice Reference Experiments phase II (CORE II) (Danabasoglu et al., 2014). The initial states for atmosphere/land are taken from CCSM4 CMIP5 uninitialized historical/RCP4.5 runs. For each January $1^{\text {st }}$ during 1955-2014, we ran a 10-member ensemble of initialized hindcast experiments with the ensemble spread created by perturbing the atmosphere (or both atmosphere and land in the earlier set as documented by Yeager et al., 2012) initial conditions.

There exists a large variety of bias correction methods and they are designed to reduce errors and add skills to the forecasts. To avoid complexities that can arise in assessing the source of improvements in calibrated initialized hindcasts compared to the traditional climate change projection experiments without initialization (also referred to as the uninitialized simulations), here we examine interannual anomalies with respect to a hindcast climatology that is only a function of prediction range; no observations are taken into account in our calculation of anomalies (as in Doblas-Reyes et al., 2013). That is, at lead $t(t=$ Month1, 2, ... 120) from a start year $j$ (j=year 1955, ... 2014), the interannual anomalies

$$
Y_{j t}^{\prime}=Y_{j t}-\sum_{k=1}^{N} Y_{k t} / N,
$$

where $Y_{j t}$ is the raw hindcast, and $\mathrm{N}$ is the total number of start years. By using this methodologv, the reference model hindcast climatology $\sum_{k=1}^{N} Y_{k t} / N$ already includes most model systematic errors (including systemic errors in the forced response, assuming the forced response is independent to the initial states). Presuming initial errors are the same for different start years, computing differences on the right hand side of (1) will leave mostly the signal in the hindcasts. A caveat is that the initial errors often vary with start years, which is even more true for decadal predictions than for seasonal predictions, as the former covers decades with limited ocean observations.

\section{Warm shocks in the Nino3.4 SST}

First, we focus on sea surface temperature (SST) in the Nino3.4 region for the hindcast behavior. Fig. 1a shows the time evolution of raw Nino3.4 SST during the 10-year 
hindcast period; with each colored thin line representing a raw 10-member ensemble mean hindcast from a start year indicated by the label bar, and the thick black line representing the observed climatology (http://www. esrl.noaa.gov/psd/gcos_wgsp/Timeseries/Data/nino34. long.data). Strikingly, the Nino3.4 SSTs from hindcasts initialized during the early decades (1955-1970, dark blue) tend to produce a $2^{\circ} \mathrm{C}$ warm spike relative to the observed climatology in the first two or three years. By contrast there are no obvious warm spikes in the later start years, and a number of hindcasts initialized around year 2000 produce cold spikes of roughly $-2^{\circ} \mathrm{C}$ in the first three years.

We further examine the hindcasts of Nino3.4 SST at three different lead times by comparing predicted interannual anomalies defined by (1) to observed anomalies derived by subtracting the observed climatological mean. In Month1 (Fig.1b), the hindcast anomalies (red) generally match the observations (black). This reflects the consistency of the initial states with the observations. Because we cannot effectively remove the initial shock that is most pronounced in Year 2 with the calculation in (1), the Year 2 annual mean Nino3.4 SST hindcast anomalies show a pronounced multidecadal shift, with more than $1^{\circ} \mathrm{C}$ anomalies in the early two decades and $-1^{\circ} \mathrm{C}$ anomalies in late 1990 s and the early 2000s (Fig. 1c). The observed anomalies do not have these multidecadal variations suggesting that the variations are examples of impacts from initialization shocks that cannot be removed by simple bias correction techniques.
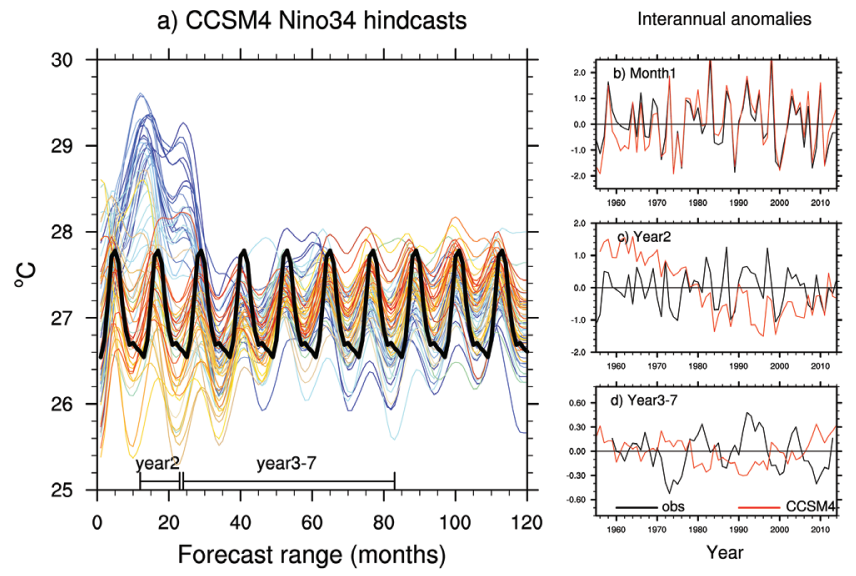

Start year

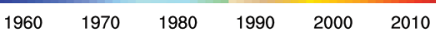

Figure 1: (a) Time evolution of raw Nino3.4 SST during the 10year hindcast period, with each colored thin line representing a 10-member ensemble mean hindcast from a start year indicated by the label bar, and the thick black line representing the observed climatology. The hindcast SSTs are smoothed by an unweighted 6-month running average. b-d) interannual Nino3.4 SST anomalies from the CCSM4 hindcasts (red) and observations (black) at three different forecast ranges: (b) Month 1, (c) Year 2 and (d) Year 3-7.
Year 3-7 is the forecast range that some current decadal prediction experiments aim to target (Meehl et al., 2014a, 2014b, 2016; Meehl and Teng, 2012, 2014a, 2014 b). The tropical Pacific, which is a pace-maker of global climate (Kosaka and Xie, 2013), has limited initialvalue predictability for all initial states at this range of 3-7 years based on a "perfect model" assessment (Branstator and Teng, 2010). When we calculate the Nino3.4 SST interannual anomalies at the Year 3-7 range (Fig.1d), we still find secular multidecadal variability, with a downward trend until about 1980, and then stable or somewhat upward after that. In some ways this is reminiscent of the Year 2 drifts (Fig. 1c). Note there is a change in the range of the y-axis from Fig.1bc to Fig.1d; the amplitude of the Year 3-7 anomalies is much weaker.

\section{What caused the shock?}

First, we examine how closely the ocean initial conditions reflect observations by comparing the Month1 hindcasts and the corresponding January observations. We focus on SST and subsurface temperature measured by the thermocline depth $\left(20^{\circ} \mathrm{C}\right.$ isotherm, $\left.\mathrm{Z20}\right)$ in the equatorial Pacific, with the observed SST obtained from HadISST (Rayner et al., 2003) and the Z20 observations calculated from the 2009 World Ocean Database (Levitus et al., 2009). Our main focus is not climatological meanbiases but a possible change in either the strength or distribution of the initial errors occurring at about 1980 that might explain why the positive initial shock only occurs for start years between roughly 1955-1970.
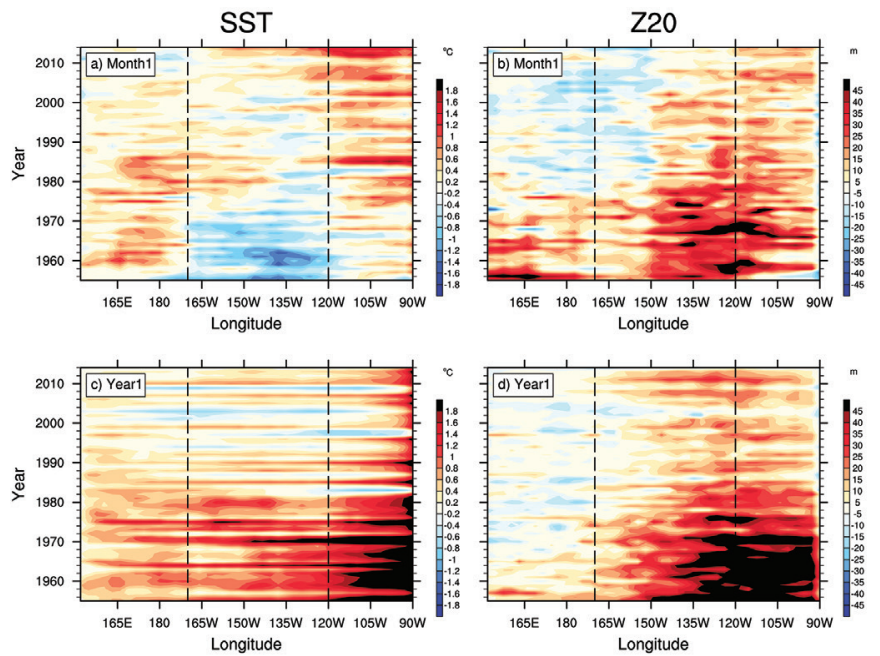

Figure 2: Start year vs. longitude distribution of Month1 (top) and Yearl (bottom) errors in equatorial SST $\left(5^{\circ} \mathrm{S}-5^{\circ} \mathrm{N}\right)$ and $20^{\circ} \mathrm{C}$ isotherm depth $\left(\mathrm{Z2O}, 2^{\circ} \mathrm{S}-2^{\circ} \mathrm{N}\right)$. Boundaries for the Nino3.4 region are outlined by the two vertical dashed lines. The observed SST and Z20 are obtained from HadISST (Rayner et al. 2003) and 2009 World Ocean Database. 
The warm spikes in the Nino3.4 region in the early hindcast period do not seem to be directly caused in any obvious way by the SST initial errors, for those initial errors are generally negative $\left(\sim-1^{\circ} \mathrm{C}\right)$ during 1950-1970 and are actually cooler than the errors in start years after 1980 (Fig. 2a). However, the Z20 errors are much deeper in the pre-1980 initial conditions compared with the later period (Fig. 2b), indicating that the early start years have a much warmer subsurface temperature bias (hence deeper Z20). This subsurface warm bias is further amplified during Year 1 (Fig. 2d) and appears to have propagated to the surface (Fig. 2c).

We further diagnose the interannual temperature tendency budget in the upper $100 \mathrm{~m}$ in the Nino3.4 region:

$\frac{\partial T^{\prime}}{\partial t}=-\frac{Q_{n e t}^{\prime}}{\rho_{0} C_{p} H}+U E T_{w-E}^{\prime}+V N T_{S-N}^{\prime}+W T T_{100 m}^{\prime}+$ residual

where $T$ is the depth averaged temperature anomaly, $\mathrm{Q}_{\text {net }}$ is the net air-sea surface flux. $H, \rho_{0}$, and $\mathrm{C}_{\mathrm{p}}$ are three constants that denote the layer thickness $(=100 \mathrm{~m}$, and consistent results are found for $\mathrm{H}=60 \mathrm{~m}$ ), water density, and heat capacity, respectively. $\mathrm{UET}_{\mathrm{W}-\mathrm{E}}$ and $\mathrm{VNT}_{\mathrm{S}-\mathrm{N}}$ denote horizontal and meridional convergence (differential at the west and east boundary, or the south and north boundary of the Nino3.4 region) of temperature flux respectively, and WTT $_{100 \mathrm{~m}}$ is the vertical temperature flux at the $100 \mathrm{~m}$ depth. Prime represents the interannual anomalies (1). The residual term includes tendencies from the diffusive temperature fluxes and fluxes from the subgrid scale.

During the first three months, the positive interannual temperature tendency (Fig. 3a, red), which is contributing to the warm spikes seen in Fig.1a, can be well explained by the first four terms on the right hand side of the tendency equation. (In Fig. 3a, the sum of the four terms is represented by the black dashed line). Both the vertical temperature flux at the bottom of the layer (purple, Fig. $3 a$ ) and the meridional temperature flux convergence (green, Fig. 3a) make positive contributions to the positive temperature tendency anomalies during the 1955-1975 start years, which are partially compensated by a large negative zonal temperature flux convergence (blue, Fig. 3a).

More specifically, interannual anomalies in both vertical velocity and temperature at the $100 \mathrm{~m}$ depth contribute to the anomalously large $W T T^{\prime}{ }_{100 \mathrm{~m}}$ during 1955-1975 in each of the first three months (not shown). Although we don't have reliable ocean observations to quantify the observed decadal change in the equatorial upwelling velocities, the domain averaged vertical velocity at $100 \mathrm{~m}$ depth in the Nino3.4 region in Month 1 of the hindcasts is significantly higher (at the 99\% confidence level) during the first two decades (1955-1974) compared to the last two decades (1995-2014), with the 20-year mean equal to $0.51 \mathrm{~m} /$ day and $0.38 \mathrm{~m} /$ day, respectively.

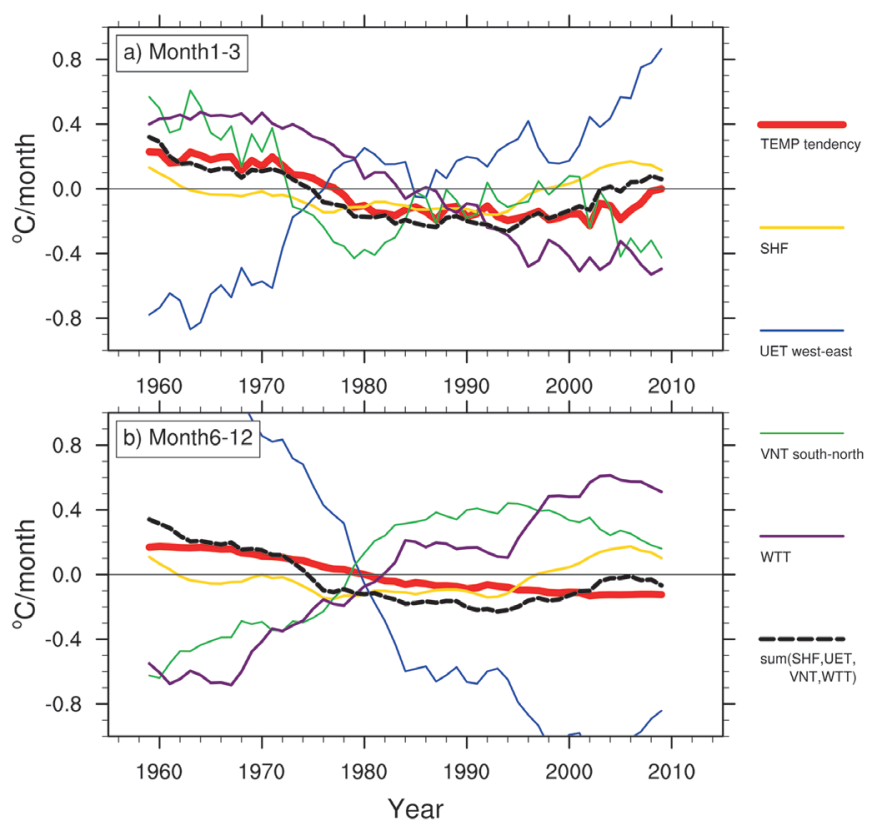

Figure 3: Budget analysis for the mixed layer temperature tendency anomalies in the Nino3.4 region averaged in a) Month1-3 and b) Month 6-12 hindcasts. All terms are shown as interannual anomalies, including temperature tendency (red), surface flux (orange), horizontal (UET, blue) and meridional (VNT, green) convergence of temperature flux, temperature flux at the 100m depth (WTT, purple), and sum of SHF, UET, VNT and WTT (black dashed). All curves are smoothed by the 10-year running averages.

Meanwhile, the corresponding $100 \mathrm{~m}$ depth temperature during the two periods is $25.0^{\circ} \mathrm{C}$ and $24.2^{\circ} \mathrm{C}$, respectively; the former period is significantly warmer at the $98 \%$ confidence level than the later period.

Once the warm subsurface temperature anomalies are advected into the mixed layer and the surface warming is fully established for all start years during 1955-1975 by Month 6 (not shown), the mixed layer warming is further amplified through atmosphere-ocean coupling. This is indicated by the Month 6-12 anomalous temperature tendency during 1955-1975 being mainly produced by the $U E T^{\prime}{ }_{\text {w-E }}$ term, which is partially compensated by the other four terms on the right hand side of the temperature tendency equation (Fig. 3b). Positive $U E T^{\prime}{ }_{\text {w-E }}$ is expected from westerly wind anomalies induced by the warm SST anomalies, and in a figure not shown we find the climatological zonal temperature gradient advected by the anomalous zonal current can explain a large portion of the positive temperature tendency anomalies during 1955-1975 (red, Fig. 3b). Associated with westerly surface wind anomalies are equatorial downwelling anomalies and meridional temperature divergence which make $W T T^{\prime}{ }_{100 \mathrm{~m}}$ and $V N T^{\prime}{ }_{\mathrm{S}-\mathrm{N}}$ negative.

While the budget analysis can explain how the warm spikes in the pre-1975 hindcasts are triggered and 
amplified, it does not single out which atmospheric forcing from the NCEP/NCAR reanalysis has played a key role in producing these ocean initial conditions. Among more than a dozen models that participated in the CMIP5 decadal prediction experiments (Kirtman et al., 2013), the Max Planck Institute Earth System Model (MPI-ESM) has a similar initial shock problem to that found in CCSM4. Their ocean initial conditions were also produced by forcing the ocean-only model with the NCEP/NCAR reanalysis. Pohlmann et al. (2016) further pin down the origins of the shock in this model to a spurious change in the NCEP/NCAR surface wind stress over $150^{\circ} \mathrm{W}-120^{\circ} \mathrm{W}, 10^{\circ} \mathrm{S}-10^{\circ} \mathrm{N}$, which is strongly westward before the 1970 s and eastward after 1980 compared to other reanalyses. The anomalous trade wind trend in the NCEP/NCAR reanalysis may help to explain the CCSM4 initialization shock because: a) through Ekman transport, the anomalously strong equatorial trade wind stress before the 1970s in the NCEP/NCAR reanalysis can directly induce anomalous equatorial upwelling in the CCSM4 initial states; b) in an investigation at NCAR parallel to that done at MPI, a new set of decadal prediction experiments were produced from an ocean state reconstruction generated using a different wind field $\left(20^{\text {th }}\right.$ Century Reanalysis, Compo et al. 2006) than the prior CORE-II simulation. We find no spurious pre-1975 subsurface warming in the new ocean initial conditions. Therefore, it is likely that those especially warm subsurface initial conditions pre-1975 in CCSM4 are also caused by the NCEP/NCAR spurious wind stress. More importantly, our preliminary analysis of new hindcast experiments initialized from the ocean states produced by the $20^{\text {th }}$ Century Reanalysis winds indicates no big initialization shock.

\section{Impacts on the IPO hindcast}

One might hope the model can adjust quickly to the initialization shock in the equatorial Pacific so that for the near-term forecast range (e.g. 3-5 years) it is still possible to harvest some skill from modes or patterns that have long predictability. Indeed, the CCSM4 experiments show considerable skill in predicting North Atlantic upper-ocean heat content and surface temperature up to a decade in advance (Yeager et al., 2012; Karspeck et al., 2015), which is consistent with other models' CMIP5 near-term climate predictions (Doblas-Reyes et al., 2013; Kirtman et al., 2013). There also is skill in hindcast simulations of the IPO SST pattern in terms of model anomalies computed from observations (Meehl et al., 2014; Meehl et al., 2016). However, also consistent with other models, Fig. 1d indicates prediction skill is low in the year 3-5 equatorial Pacific SST in CCSM4, raising the issue of how hindcast skill is evaluated for the Interdecadal Pacific Oscillation (IPO) (Power et al., 1999) on the near-term time scales.

The observed IPO pattern is often defined as the second empirical orthogonal function (EOF) of low-pass filtered
Pacific SSTs at $40^{\circ} \mathrm{S}-60^{\circ} \mathrm{N}, 120^{\circ} \mathrm{E}-70^{\circ} \mathrm{W}$ (Fig. $4 \mathrm{a}$ ). While the spatial pattern closely resembles the El Nino composite (Zhang et al., 1997), the IPO time series has much lower frequency. It shows a negative-to-positive transition in the mid 1970s, and a positive-to-negative transition in the late 1990s and early 2000s (black line in Figs. 4de). The latter has been regarded as the main cause for the recent slow-down in observed global warming (Easterling and Wehner, 2009, Meehl et al., 2011, 2013). Motivated by the IPO's strong impact on global climate, and by the fact that it contains a midlatitude component (the Pacific Decadal Oscillation, PDO) (Mantua et al., 1997) that is more predictable than the tropical SSTs (Teng and Branstator, 2011; Branstator and Teng, 2010, 2012; Branstator et al., 2011), predicting the IPO has become a goal for the decadal prediction efforts.
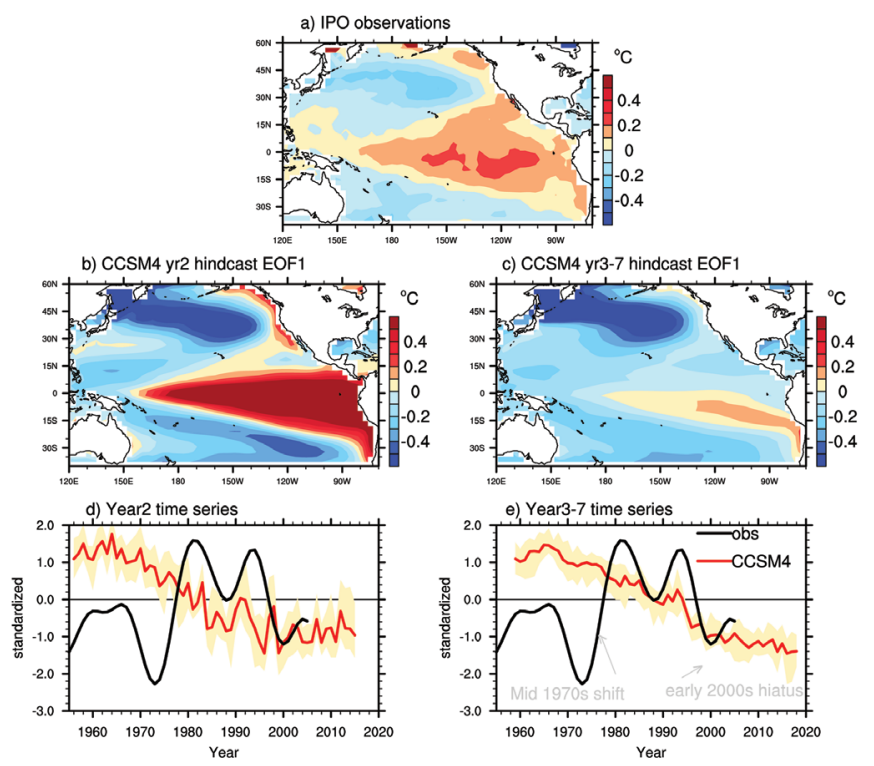

Figure 4: (a) The observed IPO: SST anomalies regressed upon the IPO index (second EOF of 10-year low-pass filtered HadISST during 1870-2016, time series shown as the black line in (d) and (e). (b) and (c) regressed EOF1 SST anomalies from CCSM4 Year 2 (b) and Year3-7 (c) hindcasts and the corresponding time series are represented by red thick line (ensemble mean) and orange shading (spread) in d) and e).

The initialization shock has an impact on Year 2 hindcasts of the IPO in CCSM4. This is shown by an EOF analysis of the Year 2 annual mean SST anomalies over the Pacific Ocean from all start years and all ensemble members. The time series of EOF1 (ensemble average and spread is shown by the red thick line and orange shading in Fig. $4 \mathrm{~d}$ respectively, and it accounts for $54 \%$ of the total variance) shows a downward trend, crossing from positive to negative near year 1980 . While both the timing of the cross-over from positive to negative (Fig. 4d) and the amplitude of the regressed SST anomalies (Fig. 4b) in the Nino3.4 region resemble the time series of the Year 2 Nino3.4 interannual anomalies shown in Fig. 1c, the regressed SST anomalies (Fig. 4b) 
trend, crossing from positive to negative near year 1980. While both the timing of the cross-over from positive to negative (Fig. 4d) and the amplitude of the regressed SST anomalies (Fig. 4b) in the Nino3.4 region resemble the time series of the Year 2 Nino3.4 interannual anomalies shown in Fig. 1c, the regressed SST anomalies (Fig. 4b) further demonstrate that the equatorial SST shock is associated mainly with a trend in the PC time series with a basin-wide IPO-like (or ENSO-like) pattern. Since we don't find such large cold temperature anomalies in the mixed layer temperature along the Kuroshio extension region in the Month1 hindcasts from 1955-1970, these cold anomalies are likely induced by the initialization shock in the equatorial Pacific through atmospheric teleconnections.

We repeat the EOF analysis for the Year 3-7 annual mean SST anomalies (Figs. 4c and e) and the PC1 also represents a downward trend and a somewhat different timing of the positive to negative change compared to Year 2, with the change occurring somewhat later around 1990-95 (Fig. 4e). This could be due to multiyear smoothing and the longer hindcast range (since the $\mathrm{x}$-axis represents the central prediction year of the five year average range rather than initialization year, e.g. a hind cast for 1986-1990 is represented on the plot as 1988 and was initialized in 1984). At this longer range, the SST anomalies associated with EOF1, representing the trend in the initialized hindcasts, have damped greatly in the equatorial Pacific, but almost no damping is found in the SST anomalies in the North Pacific, possibly due to long persistence resulting from a deeper mixed layer. Thus, despite the fast adjustment in the tropical Pacific, the initialization shock represented by a trend that in some ways resembles an IPO/PDO pattern may persist in the higher latitude oceans. Thus, while the high persistence of midlatitude anomalies has the potential to give longer predictability to anomalies present in the midlatitude initial conditions, it may also degrade predictive skill as it enhances the persistence of anomalies produced by initialization shock.

Our results and those in other investigations (SanchezGomez et al., 2016; Pohlmann et al., 2016) indicate that initialization shock can degrade forecasts and sometimes even produce negative skill. For example, when trying to predict the negative IPO prior to the mid-1970s, the initialization shock shown as a trend in EOF1 of both the Year 2 and Year 3-7 interannual anomalies (Figs. 4d,e) suggests the initial shock would contribute to positive values of the IPO for that time period. Therefore, skill in the positive IPO SST pattern in the CCSM4 hindcasts for this time period relative to observations (Meehl et al., $2014 ; 2016$ ) could conceivably have been higher if positive values of the initialization shock trend were taken into account. There are also occasions such as in the 1990s when the trends in the Year 3-7 anomalies, which to a large extent may be caused by the initialization shock, are in phase with the observed IPO such that those negative trend values could artificially contribute some skill in hindcasts for the negative phase of the IPO. A better understating of the time-dependent characterization of initialization shock in CCSM4 is thus necessary in order to correctly interpret the model skill.

\section{Acknowledgment}

We thank Dr. Holger Pohlmann for valuable comments. Portions of this study were supported by the regional and Global Climate Modeling Program (RGCM) of the U. S. Department of Energy's, Office of Science (BER), Cooperative Agreement DE-FC02-97ER62402, and the National Science Foundation. SY acknowledges support from the National Oceanic and Atmospheric Administration (NOAA) Climate Program Office under Climate Variability and Predictability Program grants NA090AR4310163 and NA130AR4310138, and both SY and AK are partly funded by the National Science Foundation (NSF) Collaborative Research EaSM2 grant OCE-1243015. Computing resources were provided by National Center for Atmospheric Research (NCAR)'s Computational and Information Systems Laboratory (CISL), and by the National Energy Research Scientific Computing Center (NERSC) under Contract No. DEAC02-05CH11231and Oak Ridge Leadership Computing Facility located in the National Center for Computational Sciences (NCCS) at Oak Ridge National Laboratory under Contract DE-AC05-000R22725, which are supported by BER of the U.S. Department of Energy. NCAR is sponsored by the National Science Foundation.

\section{References}

Branstator, G. and H. Teng, 2010: Two limits of initialvalue decadal predictability in a CGCM. J. Climate, 23, 6292-6311.

Branstator, G. and coauthors, 2011: Systematic estimates of initial-value decadal predictability for six AOGCMs. J. Climate, 25, 1827-1846.

Branstator, G. and H. Teng, 2012: Potential impact of initialization on decadal predictions as assessed for CMIP5 models. Geophys. Res. Lett., doi:10.1029/2012GL051974

Compo, G. P., J. S. Whitaker, and P. D. Sardeshmukh, 2006: Feasibility of a 100-year reanalysis using only surface pressure data. Bull. Am. Meteorol. Soc., 87, 175-190.

CLIVAR, 2011: Data and bias correction for decadal climate prediction. CLIVAR Publication Series 150, International CLIVAR Project Office, 4pp.

Danabasoglu, G. and coauthors, 2014: North Atlantic simulations in coordinated ocean-ice reference experiments phase II (CORE-II). Part I: mean states. Ocean Modelling, 73, 76-107. 
Doblas-Reyes F. J. and coauthors, 2013: Initialized nearterm regional climate change prediction. Nature Comms, doi:10.1038/ncomms2704

Easterling, D. R., and M. F. Wehner, 2009: Is the climate warming or cooling? Geophys. Res. Lett., 36, doi:10.1029/2009GL037810.

Gent, P. and coauthors, 2011: The Community Climate System Model version 4. J. Climate, 24, 4973-4991.

Kalnay, E and coauthors, 1996: The NCEP/NCAR 40-year reanalysis project. Bull. Am. Meteorol. Soc., 77, 437-471.

Karspeck, A. and coauthors, 2015: An evaluation of experimental decadal predictions using CCSM4, Climate Dyn, 44, 907-923.

Kirtman, B. and coauthors, 2013: Near-term climate change: projections and predictions. In: Stocker T.F. et al. (eds) Climate Change 2013: the physical science basis, contribution of working group 1 to the fifth assessment report of the intergovernmental panel on climate change, Cambridge University Press, Cambridge, pp 953-1028.

Kosaka, Y. and S.-P. Xie, 2013: Recent global-warming hiatus tied to equatorial Pacific surface cooling. Nature, 501, 403-407.

Levitus, S. and coauthors, 2009: Global ocean heat content 1955-2008 in light of recently revealed instrumentation problem. Geophys. Res. Lett., doi: 10.1029/2008GL037155

Mantua, N. J and coauthors, 1997: A Pacific Interdecadal Climate Oscillation with impacts on salmon production. Bull. Amer. Meteor. Soc., 78, 1069-1079.

Meehl, G. A. and coauthors, 2011: Model-based evidence of deep-ocean heat uptake during surface-temperature hiatus periods. Nat. Climate Change, 1, 360-364.

Meehl G. A. and coauthors, 2013: Externally forced and internally generated decadal climate variability associated with the Interdecadal Pacific Oscillation. J. Climate, 26, 7298-7310.

Meehl G. A. and H. Teng, 2012: Case studies for initialized decadal hindcasts and predictions for the Pacific region. Geophys. Res. Lett., doi: 10.1029/2012GL053423.

Meehl, G. A. and coauthors, 2014a: Decadal climate prediction: an update from the trenches. Bull. Am. Meteorol. Soc., 95, 243-267.

Meehl, G. A., H. Teng, and J. M. Arblaster, 2014b: Climate model simulations of the observed early-2000s hiatus of global warming. Nat. Climate Change, 4, 898-902.
Meehl G. A. and H. Teng, 2014a: CMIP5 multi-model hindcasts for the mid-1970s shift and early 2000s hiatus and predictions for 2016-2035. Geophys. Res. Lett., doi: 10.1002/2014GL059256.

Meehl G. A. and H. Teng, 2014b: regional precipitation simulations for the mid-1970s shift and early-2000s hiatus. Geophys. Res. Lett., doi: 10.1102/2014GL061778.

Meehl, G. A., A. Hu and H. Teng, 2016: Initialized decadal prediction for transition to positive phase of the Interdecadal Pacific Oscillation. Nature Comm, doi: 10.1038/ncomms11718.

Pohlmann, H. and coauthors, 2016: Initialization shock in decadal hindcasts due to errors in wind stress over the tropical Pacific. Clim Dyn, doi: 10.1007/s00382-0163486-8.

Power, S. and coauthors, 1999: Interdecadal modulation of the impact of ENSO on Australia. Climate. Dyn., 15, 319-324.

Rayner, N. A. and coauthors, 2003: Global analysis of sea surface temperature, sea ice, and night marine air temperature since the late nineteenth century. J. Geophys. Res., 108:4407, doi: 10.1029/2002JD002670.

Sanchez-Gomez, E. and coauthors, 2016: Drift dynamics in a coupled model initialized for decadal forecasts. Climate Dyn., 46, 1819-1840.

Teng H. and G. Branstator, 2011: Initial-value predictability of prominent modes of North Pacific subsurface temperature in a CGCM, J. Climate, 36, 18131834.

Taylor, K.E., R.J. Stouffer and G.A. Meehl, 2012: An overview of CMIP5 and the experiment design. Bull Am Meteorol Soc, 93, 485-498.

Yeager, S, and coauthors, 2012: A decadal prediction case study: late twentieth-century North Atlantic ocean heat content. J. Climate, 25, 5173-5189.

Zhang, Y., J. M. Wallace, and D. S. Battisti, 1997: ENSO-like interdecadal variability: 1900-1993. J. Climate, 10, 10041020. 


\title{
Internal and forced decadal variability: lessons from the past millennium
}

doi: 10.22498/pages.25.1.47

\section{Hugues Goosse ${ }^{1}$, François Klein ${ }^{1}$, Didier Swingedouw², Pablo Ortega ${ }^{3}$}

\author{
1 ELIC/TECLIM Université catholique de Louvain, Belgium \\ 2 Environnements et Paléoenvironnements Océaniques et Continentaux (EPOC), UMR CNRS 5805 \\ EPOC-OASU-Université de Bordeaux, Allée Geoffroy Saint-Hilaire, Pessac 33615, France \\ 3 NCAS-Climate, Meteorology Department, University of Reading, UK
}

\section{Introduction}

The climatic observations over the instrumental era as commonly defined (from roughly C.E. 1850 to present) cover a period too short to document the full range of climate variability. The study of paleoclimates provides a longer perspective allowing to explore the behavior of the climate system in a wider range of conditions and forcings. The most recent millennium is characterized by a climate very close to the present one and offers a large amount of long paleo-climatic time series. This allows multiple applications, such as to characterize more precisely the decadal to centennial climate variations, to test the robustness of potential mechanisms, or to estimate the exact probability and return period of some specific events. It can also be used to define a baseline climate on which the anthropogenic forcing has imposed its imprint. Fortunately, the last millennium is a period for which we have a relatively large amount of paleo data, with generally a low uncertainty on the dating of the records, and reasonable estimates of the changes in external forcing. Consequently, it has received a lot of attention over the last 20 years, allowing to obtain some crucial results for our understanding of the climate system.

Paleoclimatology requires collaboration between communities as the records are coming from diverse natural archives such as corals, tree rings, ocean and ice cores, speleothems, and others. Deciphering the climate signal in those archives requires a deep understanding of the physical, chemical and biological processes resulting in the formation of those archives. This knowledge is essential for paleoclimate reconstructions but, in turn, gives precious evidence of the impact of climate on natural systems. Furthermore, multi-proxy studies are always desirable so that inherent biases to each of the different archives can be partly canceled out. Studying the last millennium is thus a good opportunity to strengthen the link between the groups focusing on climate changes and the ones working on systems influenced by climate. In this short note, we briefly present a few illustrations focusing first on the relative contributions of anthropogenic forcing, natural forcing and internal variability in the estimated temperature changes over the last millennium. Specific points about the role of oceanic circulation in the variability at decadal to centennial time scale and the impact of the forcing on climatic modes are then presented. We conclude with some perspectives for future developments.

\section{The warming during the $20^{\text {th }}$ century compared to} the pre-industrial climate

A first clear conclusion from the analysis of the last millennium is that at the global scale climate was relatively stable before the industrial era (especially as compared to abrupt climate variations during glacial period), although reconstructions for the last millennium display some significant regional fluctuations. In many regions, the first centuries of the second millennium were relatively warm (the so-called medieval climate anomaly around 950-1250), followed by a colder period (the little ice age, around roughly 1450-1850) (Mann et al., 2009; PAGES 2k consortium, 2013). Those warm conditions during the medieval climate anomaly were less homogenous than during the $20^{\text {th }}$ century, which appears as the only one over the past centuries characterized by a clear warming over all the continents, except Antarctica (Mann et al., 2009; PAGES 2k consortium, 2013). Model results agree with this conclusion and reproduce relatively well the main characteristics of reconstructed changes (MassonDelmotte et al., 2013; PAGES 2k-PMIP3, 2015). This reinforces our confidence in their ability to reproduce the dominant processes responsible for the continental and global-scale temperature fluctuations at interannual to centennial timescales.

\section{Role of internal variability}

An emerging point from the analysis of last millennium climate is the dominant contribution of the internal variability (defined here simply as the one occurring even in the absence of natural or anthropogenic forcing) in the recorded fluctuations. Indeed, internal climate variability often overwhelms completely the influence of the natural external forcing (solar variations, volcanic eruptions) at the local to regional scales in climate model simulations (Goosse et al., 2005; Jungclaus et al., 2010). 
Due to this important contribution of internal climate variability, ensembles of simulations, driven by the same external forcing but using different initial conditions, are required for meaningful comparisons between the results of one model and reconstructions and to disentangle the forced and unforced components of the simulated response (Goosse et al., 2005; Jungclaus et al., 2010; Otto-Bliesner et al., 2016).

A commonly used metric to quantify the relative contribution of forced and internal variability in an ensemble of simulations is the ratio of the standard deviation of the ensemble mean over the mean standard deviation of the individual departures around this ensemble mean. The forced signal dominates in regions where this ratio is larger than 1 , and the internally-driven signal when it is lower. These relative contributions can change depending on the timescale considered, as illustrated in Fig. 1 for the 2-meter air temperature in a set of ten last millennium simulations from the climate model CESM1 (Otto-Bliesner et al., 2016). At interannual timescales, internal fluctuations are dominant everywhere while, mainly in the tropics, a larger contribution of the response to the forcings can be found at multidecadal timescales (i.e. 50-year means). The surface average of the ratios over the Northern Hemisphere for annual means, decadal means and 50-year means are $0.45,0.77$ and 1.25 , respectively. The corresponding values for the Southern Hemisphere are 0.44, 0.72 and 1.27. For the hemispheric mean temperatures (i.e., when the surface average is computed first before estimating the standard deviations), the relative contribution of the forced response is much larger with ratios of $1.13,1.72$ and 2.53 for the Northern Hemisphere mean temperature and $0.75,1.58$ and 2.66 for the Southern Hemisphere mean.

Many studies have also emphasized the role of internal variability in recent and future changes (Hawkins and Sutton, 2009; Boer, 2011; Deser et al., 2014), even though the external forcing will likely be much larger in the future (compared to the $850-1850$ period) due to large anthropogenic greenhouse gases emissions. The last millennium therefore provides an ideal baseline to estimate the magnitude of natural and of internal variability at various spatial and temporal scales. For instance, this period can be used to evaluate the probability of extreme events such as droughts or floods before the dominant impact of greenhouse gas forcing, and the processes responsible for these events, as well as to test the stationarity of the teleconnections within the climate system (e.g., PAGES 2k Consortium, 2013; Ortega et al., 2015; Coats et al.. 2016).

\section{The influence of the natural forcing}

Although natural forcing may be relatively weak at the regional scale, it is possible to detect and attribute statisticallyitsinfluenceonNorthHemispheretemperature during the last millennium, in particular the imprint of
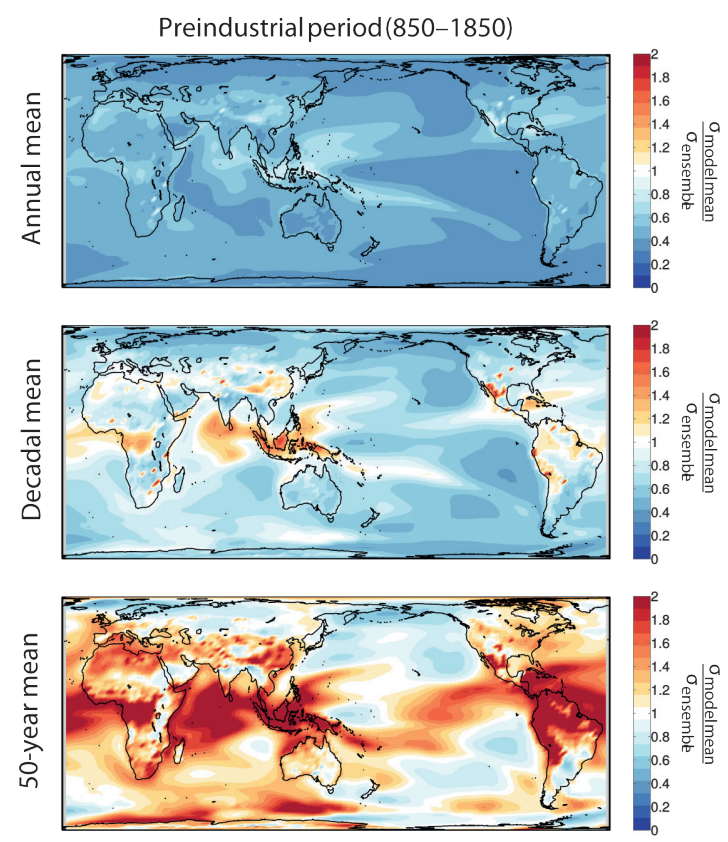

Figure 1: Ratio of the standard deviation of the ensemble mean of an ensemble of 10 simulations performed with CESM1 (Otto-Bliesner et al., 2016) over the mean standard deviation of the ensemble members around this ensemble mean, for the 2-meter air temperature. The standard deviations are computed over the period C.E. 850-1850 for (top panel) annual mean values (middle panel) decadal-means and (bottom panel) 50-year means. The ensemble mean is representative of the forced response while the range of the ensemble around this ensemble mean provides an estimate of the internal variability as simulated by the model.

volcanic forcing (Schurer et al., 2013). Major volcanic eruptions induce a global-scale cooling in the years following an event. Furthermore, changes in the frequency of the eruptions and their cumulative effects are also responsible for a significant part of the temperature difference between the medieval climate anomaly and the little ice age (Schurer et al., 2013; McGregor et al., 2015).

It has been mentioned above that model results overall agree with reconstructions but a more detailed analysis indicates that many of them tend to simulate a response to volcanic eruptions that is larger than in the reconstructions, with the largest differences in the Southern Hemisphere (Neukom et al., 2014; PAGES $2 \mathrm{k}$-PMIP3, 2015). The correlation of temperature changes among the continents and between the hemispheres is also higher in the model simulations than in the reconstructions (Neukom et al., 2014; PAGES 2k-PMIP3, 2015). This high spatial coherence may be due either to uncertainties in the external forcing estimates, to a too strong and homogenous response to external forcings in the climate model simulations (Stoffel et al., 2015; LeGrande et al., 2016), or to an underestimation of the magnitude of internal variability in the models (which induces changes much less coherent among continents 
than the external forcings). Alternatively, uncertainty in the proxy-based reconstructions, due to the non-climatic noise, could lead to an underestimation of the coherency of the changes between regions. Determining the origin of those discrepancies will require to investigate all those elements simultaneously. A more objective model-data comparison is in particular required, including forward modules that simulate explicitly the proxy variables measured such as tree ring width or isotope composition (Evans et al., 2013). Indeed, a significant part of the mismatch may simply come from the differences in the variables that are compared between proxies and models.

\section{Changes in ocean circulation}

The changes in ocean circulation could potentially provide large contributions to the decadal variability over the last millennium. In the North Atlantic, some model results and reconstructions have suggested that decadal to centennial variations in the intensity of both the subpolar gyres and the meridional overturning circulation induced important changes in the oceanic heat transport, and thus had large-scale impacts on climate (e.g., Lund et al., 2006; McCarthy et al., 2015; Moreno-Chamarro et al., 2016).

Confirming those hypotheses about the role of ocean circulation is a challenge because the available proxy data is much more abundant over the continents than over the ocean and globally only a few marine records have high enough resolution to correctly represent decadal fluctuations. Compilations of observations have confirmed a global oceanic cooling over the period 8501850, compatible with the one reconstructed for the continents (McGregor et al., 2015). At regional scales, new high-resolution oceanic observations (e.g. Reynolds et al., 2016) and syntheses (as in McGregor et al., 2015) are under way and significant progresses on our understanding of past oceanic changes are expected in the coming years.

\section{The influence of the external forcing on the modes of climatic variability}

The climate system variability is organized in largescale modes of variability that are mainly governed by the dynamics of the ocean and the atmosphere. Wellknown examples of these variability modes are the ElNiño Southern Oscillation (ENSO), the North Atlantic Oscillation (NAO) or the Atlantic Multidecadal Variability (AMV). While ENSO impacts the variability of the tropical Pacific, with many teleconnections world-wide, the NAO is focussed on local wind variations in the North Atlantic sector, and the AMV on sea-surface temperature variability in the Atlantic, potentially related with the large-scale Atlantic meridional overturning circulation (AMOC).

Volcanic eruptions, by cooling the climate at the global scale, might strongly impact the fates of these variability modes and trigger a phase shift. The instrumental era is clearly too short to draw robust conclusions on such potential responses, as it mainly includes five large volcanic eruptions (Krakatau in 1883, Santa María in 1902, Agung in 1963, El Chichón in 1982 and Pinatubo in 1991). On the basis of analyses over the last millennium, some indications exist that volcanic eruptions might promote a positive phase of ENSO the year following a large eruption (e.g., Emile-Geay et al., 2008). Similarly, it has been recently shown that the largest eruptions of the last millennium are almost systematically followed by a positive phase of the NAO, particularly clear for the second winter after the eruptions (Ortega et al., 2015, Fig. 2). For the AMV and AMOC, a few recent studies suggest that volcanic eruptions may act as a pacemaker of their decadal variability over the last millennium (Otterå et al., 2011; Swingedouw et al., 2015). Nevertheless, no entirely clear and robust conclusions concerning the exact impact of volcanic eruptions on these variability modes can be drawn, notably due to difficulties of climate models to reproduce such impacts and the intricacy to separate the contribution of the forcing from the stochastic internal fluctuations (Swingedouw et al., 2017).

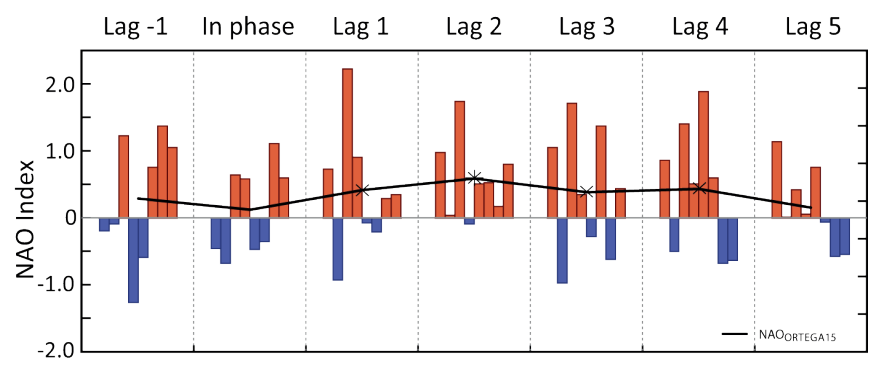

Figure 2: Composite (black line) and individual (colored bars) $\mathrm{NAO}$ responses to 8 of the strongest eruptions in the last millennium, as described by a multi-proxy NAO reconstruction covering this period (Ortega et al., 2015). Note that compared to Ortega et al. (2015), we have refined the selection of events to only consider those for which the date of the eruption is well constrained (see Swingedouw et al, 2017). Significance is assessed following a Monte Carlo approach with 1,000 random selections of 8 years from the NAO reconstruction. Significant values at the 90\% and 95\% confidence levels are represented by crosses and stars, respectively.

\section{Further developments and perspectives}

A promising way forward to reduce the uncertainties is the combination of paleo-data and model results to reconstruct as accurately as possible the state of the system over the past millennium. Although many challenges remain, such reanalyses for the past millennium are currently under development (Goosse et al., 2012; Hakim et al., 2016; PAGES, 2017). In addition to contributing to a better understanding of the dynamics of the system, those reconstructions could provide a test bed, complementary to the last century, for decadal prediction systems (Meehl et al., 2014), in order to evaluate their skill in a wider range of conditions. However, the ability to generate the initial climatic conditions for such retrospective 
predictions (hindcasts) is a dominant issue and the small amount of available data, notably in the ocean realm, strongly limits for the moment the breadth of the tests that can be performed over these past periods.

Many of the conclusions and the questions raised above for the last millennium correspond to research priorities for the more recent past (i.e., the instrumental period) as well. The advantage of the investigations covering the last millennium is the possibility to analyze longer time series, and thus increase the signal-to-noise ratio for the detection and attribution, for example, of forced signals. The disadvantage compared to the instrumental period is the scarcity and larger uncertainties of the proxy records and the larger resources needed to perform model simulations spanning several centuries. Despite those challenges, the information brought by the instrumental and pre-instrumental periods is very complementary, justifying strong interactions and collaborations.

\section{Acknowledgements}

Hugues Goosse is Research Director within the Fonds National de la Recherche Scientifique (F.R.S.-FNRSBelgium). Didier Swingedouw is supported by the French Centre National de la Recherche Scientifique (CNRS). The work of Pablo Ortega is funded by the NERC research Project DYNAMOC (NE/ M005127/1). This note is a contribution to the PAGES2k working group of PAGES. Support for PAGES activities is provided by the US and Swiss National Science Foundations, US National Oceanographic and Atmospheric Administration and by the Future Earth program.

\section{References}

Boer, G.J., 2011: Decadal potential predictability of twenty-first century climate. Climate Dynamics, 36, 1119-1133.

Coats, S., J.E. Smerdon, Cook B.I., R. Seager, E.R.Cook, and K.J. Anchukaitis, 2016: Internal ocean-atmosphere variability drives megadroughts in Western North America. Geophys. Res. Lett., 43, 9886-9894.

Deser C., A. Phillips, M.A. Alexander, and B. Smoliak, 2014: Projecting North American Climate over the next 50 Years: uncertainty due to internal variability. J. Climate, 27, 2271-2296.

Emile-Geay, J., R. Seager, M. A. Cane, E. R. Cook, G.H. Haug, 2008: Volcanoes and ENSO over the past millennium. J. Clim., 21, 3134-3148.

Evans, M.N., S. E.Tolwinski-Ward, D.M. Thompson, and K.J. Anchukaitis, 2013: Applications of proxy system modeling in high resolution paleoclimatology. Quat. Sci., Rev., 76, 16-28.
Goosse, H., H. Renssen, A. Timmermann, and R.S. Bradley, 2005: Internal and forced climate variability during the last millennium: a model-data comparison using ensemble simulations. Quat. Sci. Rev., 24, 1345-1360.

Goosse, H., E Crespin, S. Dubinkina, M.F. Loutre, M. E. Mann, H. Renssen, Y. Sallaz-Damaz, and D. Shindell, 2012: The role of forcing and internal dynamics in explaining the "Medieval Climate Anomaly". Clim. Dyn., 39, 2847-2866.

Hakim, G.J., J. Emile-Geay, E.J. Steig, D. Noone, D.M. Anderson, R. Tardif, N. Steiger, and W.A. Perkins, 2016: The Last Millennium Climate Reanalysis Project: frame work and first results. J. Geophys.l Res.: Atmos., 121, 6745-6764.

Hawkins, E., and R. Sutton, 2009: The potential to narrow uncertainty in regional climate predictions. Bull. Am. Met. Soc., 90, 1095-1107.

Jungclaus, J. H. et al., 2010 : Climate and carbon-cycle variability over the lastmillennium. Clim. Past, 6, 723-737.

LeGrande, A., K. Tsigaridi,s and S.E. Bauer , 2016: Role of atmospheric chemistry in the climate impacts of stratospheric volcanic injections. Nature Geoscience, 9, 652-655.

Lund, D.C., J. Lynch-Stieglitz, and W.B. Curry, 2006: Gulf Stream density structure and transport during the past millennium. Nature, 444, 601-604.

Mann, M., Z. Zhang, S. Rutherford, R. Bradley, M. Hughes, D. Shindell, C., Ammann, G., Faluvegi and F. Ni, 2009: Global signatures and dynamical origins of the Little Ice Age and Medieval Climate Anomaly. Science, 326, 1256-1260.

McCarthy, G.D. I. D. Haigh, J.l J.-M. Hirschi, J. P. Grist, and D. A. Smeed, 2015: Ocean impact on decadal Atlantic climate variability revealed by sea-level observations. Nature, 521, 508-510.

McGregor, H.V., et al., 2015: Robust global ocean cooling trend for the past two millennia. Nature Geoscience, 8, 671-677.

Masson-Delmotte, V. et al. , 2013. Information from Paleoclimate Archives, in: Climate Change 2013: The Physical Science Basis. Contribution of Working Group I to the Fifth Assessment Report of the Intergovernmental Panel on Climate Change, edited by: T.F. Stocker et al., Cambridge University Press, Cambridge, United Kingdom and New York, NY, USA, 2013.

Meehl, G.A., et al., 2009: Decadal Prediction Can It Be Skillful? Bull. Amer. Met. Soc., 90, 1467-1485.

Moreno-Chamarro E., D. Zanchettin, K. Lohmann, and J.H. 
Jungclaus, 2016: An abrupt weakening of the subpolar gyre as trigger of Little Ice Age-type episodes. Clim. Dyn. DOI 10.1007/s00382-016-3106-7

Neukom, R., et al., 2014: Inter-hemispheric temperature variability over the last millennium. Nature Clim. Change, 4, 362-367.

Ortega, P., F. Lehner, D. Swingedouw, V. Masson-Delmotte, C.C. Raible, M. Casado, and P. Yiou, 2015: A model-tested North Atlantic Oscillation reconstruction for the past millennium. Nature, 523, 71-74.

Otterå, O.H., M. Bentsen, H. Drange and L. Suo, 2010: External forcing as a metronome for Atlantic multidecadal variability. Nature Geoscience, 3, 688-694.

Otto-Bliesner, B.L., E.C. Brady, J. Fasullo, A. Jahn, L. Landrum, S. Stevenson, N. Rosenbloom, A. Mai, and G. Strand, 2016: Climate Variability and Change since 850 C.E.: An Ensemble Approach with the Community Earth System Model (CESM). Bull. Amer. Met. Soc., 97, 735-754.

PAGES, 2017: DAPS [online]. Available from http://www. pastglobalchanges.org/165-initiatives/working-group/ daps. Accessed on 10 May 2017.

PAGES 2k Consortium, 2013: Continental-scale temperature variability during the last two millennia. Nature Geosciences 6, 339-346.

PAGES 2k-PMIP3 group, 2015: Continental-scale temperature variability in PMIP3 simulations and PAGES $2 \mathrm{k}$ regional temperature reconstructions over the past millennium. Clim. Past, 11, 1673-1699.

Reynolds, D.J., et al., 2016: Annually resolved North Atlantic marine climate over the last millennium. Nature Communication, in press.

Schurer, A. P., G.C. Hegerl, M. E. Mann, S. F. B. Tett and S. J. Phipps, 2013: Separating forced from chaotic climate variability over the Past Millennium. J. Climate 26, 69546973, 2013.

Stoffel, M., et al., 2015: Estimates of volcanic-induced cooling in the Northern Hemisphere over the past 1,500 years. Nat. Geosci., 8, 784-788.

Swingedouw, D., P. Ortega,J. Mignot,E. Guilyardi,V. MassonDelmotte, P. G. Butler and M. Khodri, 2015: Bidecadal North Atlantic ocean circulation variability controlled by timing of volcanic eruptions. Nature Communications, 6 , 6545

Swingedouw, D., J. Mignot, P. Ortega, M. Khodri, M. Menegoz, C. Cassou, and V. Hanquiez, 2017: Impact of explosive volcanic eruptions on the main climate variability modes. Glob. Planet. Changes, 150, 24-45 . 


\section{Abrupt Northward Shift of SPCZ position in the late-1920s Indicates Coordinated Atlantic and Pacific ITCZ Change}

\section{Braddock K. Linsley ${ }^{1}$, Robert B. Dunbar ${ }^{2}$, Donna Lee ${ }^{1}$, Neil Tangri², Emilie Dassié1,3}

1 Lamont-Doherty Earth Observatory, 61 Route 9W, Palisades, NY 10964, USA

2 Department of Environmental Earth Systems Science, Stanford University,

Stanford, CA, 94305, USA

3 Laboratoire d'Océanographie et du Climat: LOCEAN - IPSL, UMR 7159 CNRS/UPMC/IRD,

Université P. et M. Curie, 4 place Jussieu, 75252 Paris cedex 05, France

\section{Introduction}

Patterns of climate variability are often studied by evaluating instrumental or paleo-data from regions that have the highest correlations to the target climate mode. For example, past variations in ENSO have been primarily evaluated by compiling or reconstructing sea surface temperature (SST) in the Nino3.4 $\left(5^{\circ} \mathrm{N}-5^{\circ} \mathrm{S}\right.$; $\left.120^{\circ} \mathrm{W}-170^{\circ} \mathrm{W}\right)$ and Nino3 $\left(5^{\circ} \mathrm{N}-5^{\circ} \mathrm{S} ; 90^{\circ} \mathrm{W}-150^{\circ} \mathrm{W}\right)$ regions in the equatorial Pacific (e.g.: Trenberth 1997; Urban et al., 2000; Cobb et al., 2013). However, critical information on the spatial extent of a target climate mode can also be gained by studying conditions on the nodal line perimeter of the climate pattern where on average there is no correlation $(\mathrm{R}=\sim 0)$ between the climate parameter being reconstructed and the target mode.

During El Niño and La Niña events in the Pacific, the largest SST anomalies are focused in an elongated E-W pattern or footprint that is generally symmetric around $0^{\circ}$ latitude in the central Pacific. Individual ENSO events display differences in both the amplitude and the longitude of the largest SST anomalies and cluster analysis of the last 50 years of Pacific SST data indicate that there are three primary El Niño patterns and one primary La Niña pattern (Chen et al., 2015). The mean of these ENSO event patterns results in the classic footprint in ENSOrelated SST anomalies surrounded by a perimeter where SST is on average not positively or negatively correlated with ENSO (see Fig. 1). This perimeter reflects a nodal line where on average SST variability is not correlated to ENSO. Instrumental data suggest that the average ENSO nodal line for all types of El Niño and La Niño events has been relatively stable over the last $\sim 50$ years.

In the South Pacific, the ENSO nodal line runs northwest to southeast though Samoa $\left(14^{\circ} \mathrm{S}, 172^{\circ} \mathrm{W}\right)$ and American Samoa $\left(14^{\circ} \mathrm{S}, 169.5^{\circ} \mathrm{W}\right)$ to French Polynesia $\left(17^{\circ} \mathrm{S}\right.$, $150^{\circ} \mathrm{W}$ )(Fig. 1). This location is nearly identical to the nodal line for the decadal mode of SST variability in the
Pacific (the Pacific Decadal Oscillation (PDO)). Since the PDO appears to have both subtropical and tropical origins (Newman et al., 2016), the congruence of ENSO and PDO nodal lines in some regions is not unexpected. This region in the South Pacific is also the central rainfall axis of the South Pacific Convergence Zone (SPCZ) which trends northwest to southeast from the Equator in the western Pacific through Samoa and American Samoa.

The SPCZ is the largest spur of the Intertropical Convergence Zone (ITCZ) and a key hydrologic feature in the tropics yet its dynamics and even current position are poorly represented in climate models (Vincent 1994; Vincent et al., 2009; Cai et al., 2012; Evans et al., 2015). Atmospheric data indicate a close relationship between SPCZ movements and ENSO in this region. Over the last 30 years, instrumental precipitation data indicate that during most El Niño events the SPCZ moves a few degrees northward (Gouriou and Delcroix 2002; Vincent et al., 2009; Salinger et al., 1995). Southward SPCZ shifts occur during La Niña events (Gouriou and Delcroix 2002, Vincent et al., 2009; Cai et al., 2012). During very strong El Niño events such as 1982/83 and 1997/98, and during some moderate strength El Niño's such as 1991-1992, the SPCZ can collapse onto the equator (so-called zonal SPCZ events; Vincent et al., 2009; Linsley et al., 2017). Both SPCZ responses during El Niño result in saltier and slightly cooler conditions on average in the area of the SPCZ central rainfall axis as the SPCZ shifts northeast and the westward flowing South Equatorial Current (SEC) advects relatively salty water into the region.

In an effort to track past changes in the SPCZ response to ENSO events and the PDO we have analyzed sub-seasonal skeletal $\delta^{18} 0$ in a Porites lutea coral core from the island of Ta'u in the Manua Island group on the eastern side of American Samoa. Ta'u Island is located in the center of the SPCZ and on the nodal line region for both ENSO and 
the PDO. Variability of surface oceanographic conditions in American Samoa are closely related to SEC dynamics and SPCZ movements. This is the first 50+ year coral $\delta^{18} 0$ reconstruction from Samoa and American Samoa.

\section{Methods}

In November 2011 we cored a large colony of Porites lutea on the western side of the island of Ta'u located at S 14 15' 33.74": W $169^{\circ} 30^{\prime}$ 01.61" (or S 14 15.566, W 16930.027 ) on an exposed outer reef in $7.5 \mathrm{~m}$ (25 feet) of water (water depth to top of coral). Core sections from the Ta'u-1 core were sawed longitudinally in half and $5 \mathrm{~mm}$ thick slabs cut at Stanford University and shipped to the Lamont-Doherty Earth Observatory (LDEO) for isotopic analysis. At LDEO, slabs were cleaned in a deionized water bath with a probe sonicator $(500 \mathrm{~W}$, $20 \mathrm{kHz}$ ). Slabs were then oven dried at $50^{\circ} \mathrm{C}$. Once dried, the slabs were X-rayed in an HP cabinet X-ray system (at $35 \mathrm{Kv}$ ). The X-ray positives were used to identify growth band orientation and the maximum growth axis down each slab section as a guide to the subsampling path. Subannual samples were hand-drilled from the slabs at $1 \mathrm{~mm}$ intervals by excavating a $3 \mathrm{~mm}$ wide by $2 \mathrm{~mm}$ deep trough with a variable speed Dremel drill fit with a spherical carbide bit. samples). With the Isoprime we dissolved $\sim 80-120 \mu \mathrm{g}$ coral powder aliquots in $\sim 100 \% \mathrm{H}_{3} \mathrm{PO}_{4}$ at $\sim 90^{\circ} \mathrm{C}$. With the Delta V-Kiel IV we dissolved $\sim 50-80 \mu \mathrm{g}$ coral powders in $\sim 100 \% \quad \mathrm{H}_{3} \mathrm{PO}_{4}$ at $\sim 70^{\circ} \mathrm{C}$. NBS-19 standards were analyzed 5 to 6 times per day. To assess external precision and sample homogeneity, 209 replicate samples were analyzed ( $8.2 \%$ replication). The standard deviation of NBS-19 standards analyzed was $0.06 \%$ for $\delta^{18} 0$. The average difference of the replicate $\delta^{18} 0$ analyses was $0.082 \%$. All results are reported relative to VPDB (in \%o).

The samples from the core's live-collected top, serve to anchor the chronology for the $\delta^{18} \mathrm{O}$ series to November 2011. Below this section, annual $\delta^{18} 0$ minima and maximum were attributed to seasonal maxima and minima in SST, respectively. Verification of this approach comes from pseudo-coral forward modeling where we used instrumental SST and sea surface salinity (SSS) to generate a modeled coral $\delta^{18} 0$ series from 2008 to 1981 (Fig. 2). This model assumes all variability in coral $\delta^{18} 0$ at Ta'u is due to SST and SSS. Ta'u- 1 annual average coral $\delta^{18} \mathrm{O}$ and annual average pseudo-coral $\delta^{18} \mathrm{O}$ significantly correlate $(\mathrm{R}=0.77 ; \mathrm{p}<0.001)$ with annual average correlations between coral $\delta^{18} 0$ and SST and SSS of -0.58

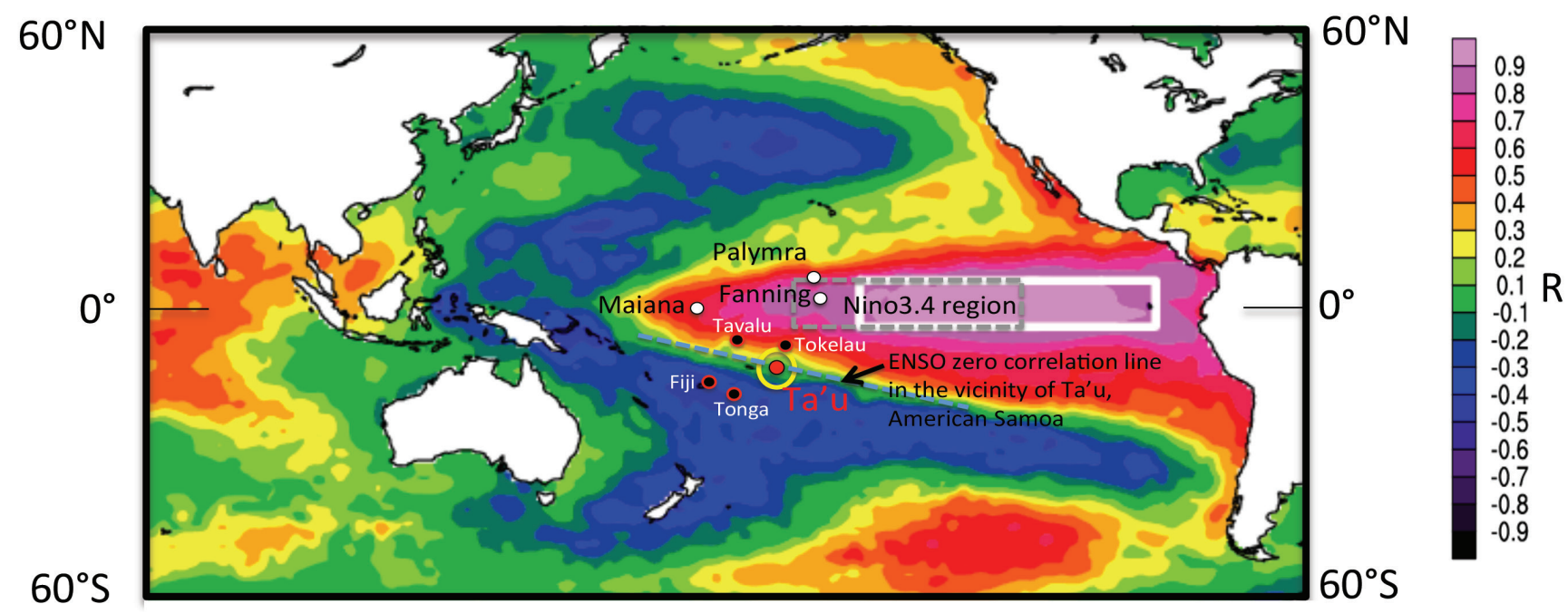

Figure 1: Average correlation pattern of SST to Nino3 SST. Red-purple colors indicate positive correlation and green-blue colors indicate negative correlation. White box indicates the Nino3 region for monitoring ENSO sign and strength and black dashed box the Nino3.4 region. Yellow circle highlights the location of our Ta'u coral site in American Samoa. Note that the zero correlation line (nodal line) runs SE-NW right through Samoa. Also shown are the locations of Fanning, Palmyra and Maiana (see Fig. 3C) and Fiji, Tonga, Tokelau and Tavalu (see Fig. 4).

Sample powders were analyzed on either an Elementar Isoprime mass spectrometer equipped with a dualinlet and Multiprep or a Themo-Fisher Delta $\mathrm{V}+$ mass spectrometer with dual-inlet and Kiel IV carbonate reaction device. The instruments are in the same laboratory at LDEO and have been cross-calibrated. They use the same $\mathrm{CO}_{2}$ reference gas and dewatered phosphoric acid is made using the same protocols for each instrument. Here we report the $\delta^{18} 0$ results of the analysis of this upper $2.6 \mathrm{~m}$ of core $(n=2,5651 \mathrm{~mm}$ and 0.64 respectively. This pseudo-coral comparison verifies our chronology and indicates that Porites coral $\delta^{18} \mathrm{O}$ at Ta'u is a function of both SST and SSS and where interannual changes in SST and SSS have additive effects on interannual coral $\delta^{18} \mathrm{O}$ variability. This $2.6 \mathrm{~m}$ section of core extends from November 2011 to January 1800.

\section{Results and Discussion}

Although on average there is no correlation between SST variability in American Samoa and Nino3.4 or Nino3 SST 

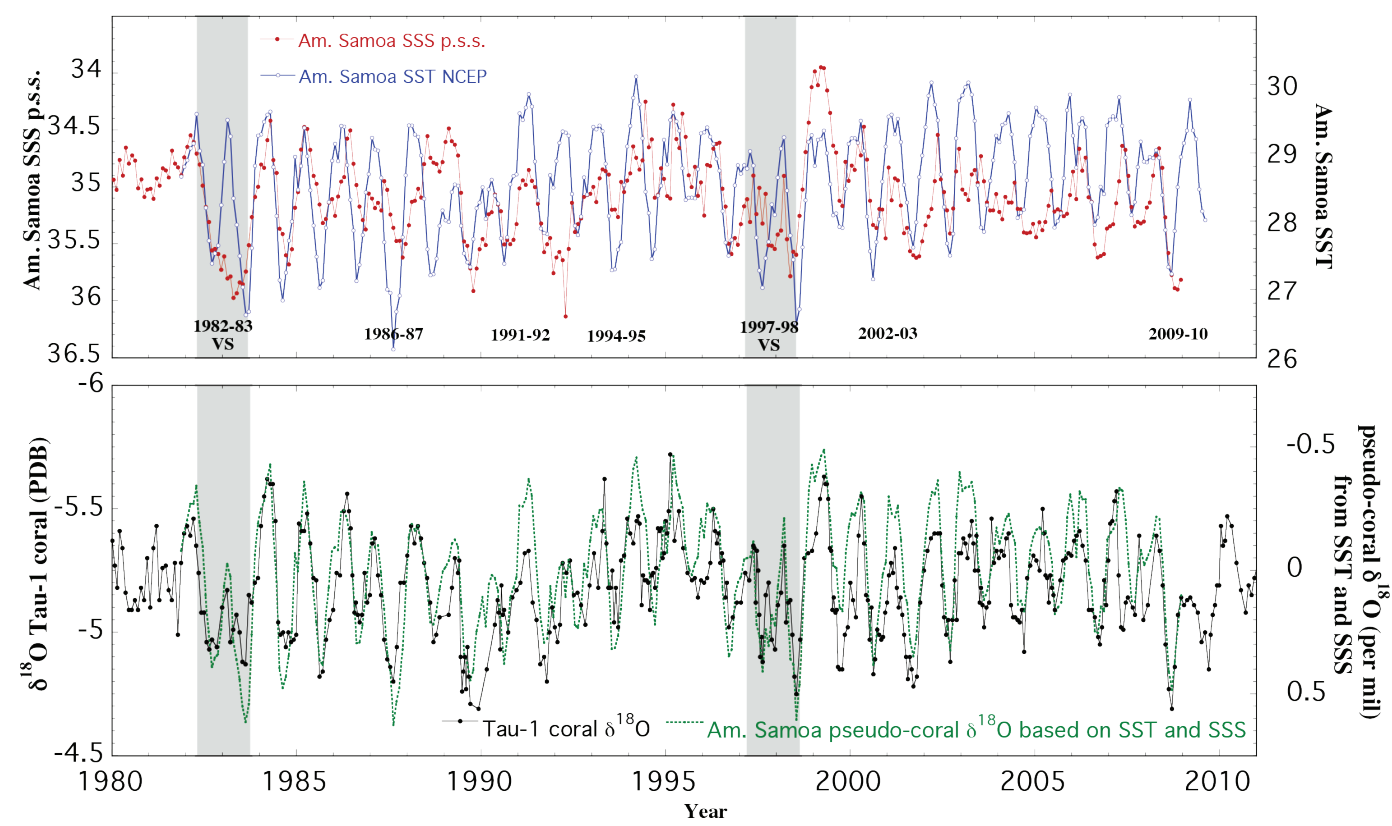

Figure 2: (top): Sea surface temperature (SST) (NCEP) and sea surface salinity (SSS; Delcroix et al., 2011) for the grids containing Ta'u, American Samoa. (bottom): Ta'u coral $\delta^{18} \mathrm{O}$ from the Ta'u-1 Porites coral core and "pseudo-coral $\delta^{18} \mathrm{O}^{\prime}$ calculated from SST and SSS. The very strong (VS) EI Niño events of 1982/93 and 1997/98 are indicated by gray shading. During these events the SPCZ collapsed onto the equator (so-called zonal SPCZ events). Annual average $\delta^{18} \mathrm{O}$ and pseudo-coral $\delta^{18} \mathrm{O}, \mathrm{R}=0.77(\mathrm{p}<0.001)$. This correspondence demonstrates that coral $\delta^{18} \mathrm{O}$ at Samoa is accurately recording surface ocean conditions.

over the last 30 years (see Fig. 1), large El Niño events result in elevated SSS in the Samoa region today (Gouriou and Delcroix 2002; Hasson et al., 2013)(see Fig. 2). There has been a close relationship between SPCZ movements, ENSO and the eastern extent of the western Pacific warm pool with the SPCZ shifting northeast during El Niño events and southwest during La Niña events (Gouriou and Delcroix 2002, Vincent et al., 2009). This SPCZ re-positioning results in more saline conditions on average in the Samoa region during El Niño as the SPCZ shifts northeast and the westward flowing SEC advects relatively salty water into the region.

To evaluate interannual and lower frequency changes in Ta'u- 1 coral $\delta^{18} \mathrm{O}$ for comparison to equatorial indices of ENSO, we filtered the monthly coral $\delta^{18} \mathrm{O}$ series in two ways. Our first approach was to 24 month high-pass filter and then detrend the coral $\delta^{18} 0$ series due to the presence of a significant secular coral $\delta^{18} 0$ trend. The detrending was accomplished using Singular Spectrum Analysis to isolate and then remove the first principal component (the secular trend). This filtered Ta'u $\delta^{18} \mathrm{O}$ time series was then compared to 7 month running average filtered Nino3.4 SST anomalies (see Fig. 3A). The second filtering approach was to apply only a 24 month high-pass filter (leaving the trend in place) to facilitate direct comparison to equatorial coral $\delta^{18} 0$ records (see Fig. 3C). We use a composite average of three coral $\delta^{18} \mathrm{O}$ records from Fanning (Cobb et al., 2013), Palmyra (Cobb et al., 2013) and Maiana (Urban et al., 2000) as a coral $\delta^{18} \mathrm{O}$-based index of equatorial ENSO state (termed FPM; see Linsley et al., 2015).
Comparing the Ta'u coral $\delta^{18} 0$ record to the timing of equatorial ENSO variability indicates a striking phase shift in the decadal mean correlation in the late 1920s. Running correlations between the Ta'u $\delta^{18} 0$ results and Nino3.4 SST and the FPM equatorial composite coral $\delta^{18} 0$ highlights the abruptness of the phase shift in the 1920s (see Fig. 3B and D). Sea surface temperature (using ERSST) at American Samoa shows no change in phasing with Nino3.4 SST in the 1920s (not shown) pointing to a change in the timing of interannual surface salinity variability. The Ta'u coral $\delta^{18} 0$ series indicates that the relationship between El Niño events and more saline conditions in this central region of the SPCZ existed only back to 1927, when there was an abrupt change. Prior to 1927, the Ta'u coral $\delta^{18} 0$ record contains distinct evidence that on average fresher conditions occurred during El Niño events in Samoa/American Samoa (Fig. 3A and C). This is exactly the situation which occurs today north of Samoa between $7^{\circ} \mathrm{S}$ and $8^{\circ} \mathrm{S}$ near the island groups of Tokelau $\left(8^{\circ} \mathrm{S}, 172^{\circ} \mathrm{W}\right)$ and Tavalu $\left(7^{\circ} \mathrm{S}, 179^{\circ} \mathrm{E}\right.$ ) (see Fig. 4). Surface salinity is significantly lower during El Niño events in the region extending NW-SE including the Tavalu and Tokelau Island groups at $7-8^{\circ} \mathrm{S}$. At the same time, surface salinity increases at Fiji, Tonga and Samoa (Fig. 4).

These observations indicate that the mean position of the SPCZ must have been shifted southwest of its current position during at least the $\sim 50$ year period prior to the late 1920 s combined possibly with a reduced latitudinal migration to the northeast during El Niño. This reorganization would explain the fresher conditions during El Niño recorded in our Ta'u coral $\delta^{18} 0$ record in 


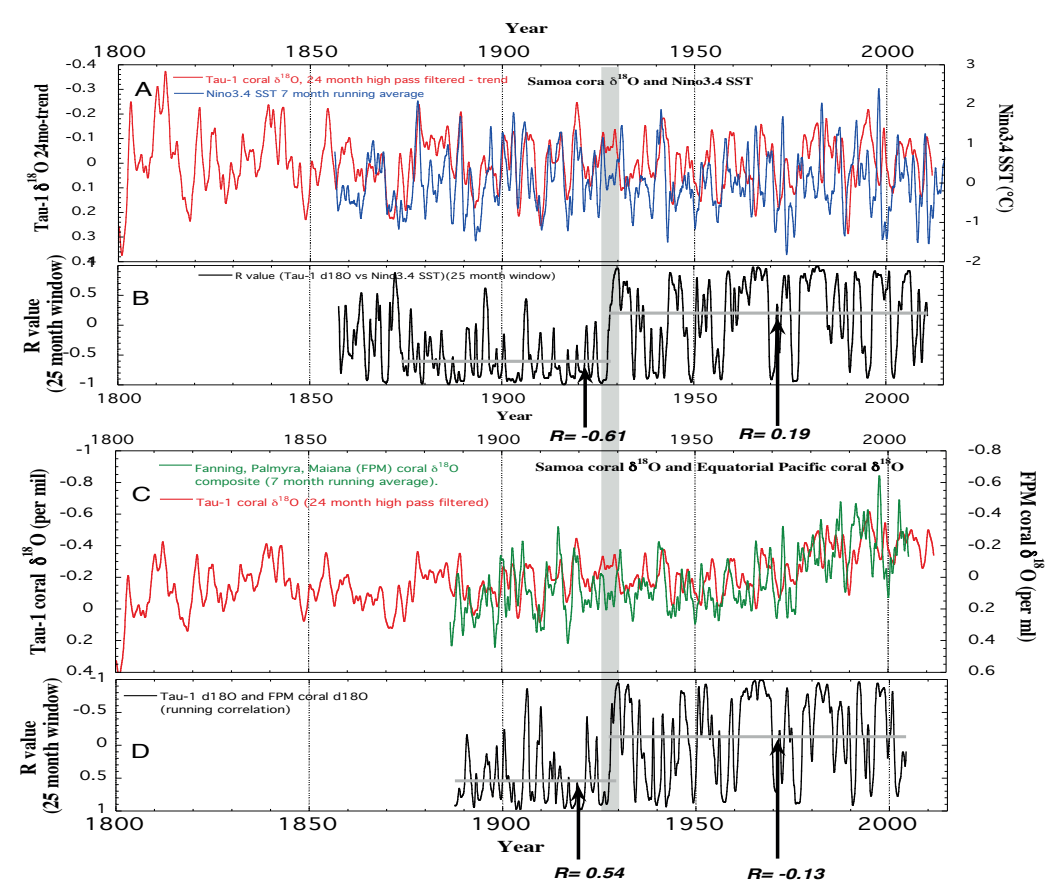

Figure 3: Comparison of Ta'u (American Samoa) coral $\delta^{18} \mathrm{O}$ to: (A) Nino3.4 SST and (C) an equatorial Pacific composite coral $\delta^{18} \mathrm{O}$ record from Fanning, Palmyra and Maiana (FPM)(Linsley et al., 2015). Panels B and D show the 25 month running correlation between the series. Horizontal gray bars in $B$ and $D$ indicate average correlation ( $R$ value) across the interval. In panel $A$, arrows indicate El Niño events where it was distinctly cooler and saltier at Samoa. Note that on average after 1927, warmer conditions in the Niño3.4 area (El Niño) occurred when it was cooler and saltier at Samoa. Before 1927, the opposite pattern is observed; fresher and warmer conditions at Samoa corresponded with El Niño conditions on the equator back to 1872 AD (see panel B)

this period prior to 1927 . This is the opposite response to the higher salinity conditions that occur during El Niño events at Ta'u beginning at $\sim 1930$. The abruptness of the shift in El Niño response in the late 1920s suggests a rapid reorganization of climate patterns in the South Pacific. Based on observational data in the Atlantic, the timing of this abrupt change in SPCZ position occurred during a phase change of the Atlantic Multidecadal Oscillation (AMO) when SST in the North Atlantic abruptly warmed in the mid-1920a as the AMO changed from a negative to positive phase and the ITCZ in the Atlantic shifted north (e.g.; Knight et al., 2006; Zhang and Delworth, 2006; García-García and Ummenhofer 2015). If the SPCZ central axis also shifted north in the mid-1920s as our Ta'u coral $\delta^{18} \mathrm{O}$ indicates, this would point to a coordinated ITCZ change in both the Atlantic and Pacific basins. However, the AMO also changed phase in the late 1960s when our Ta'u results do not indicate a phase change between SPCZ

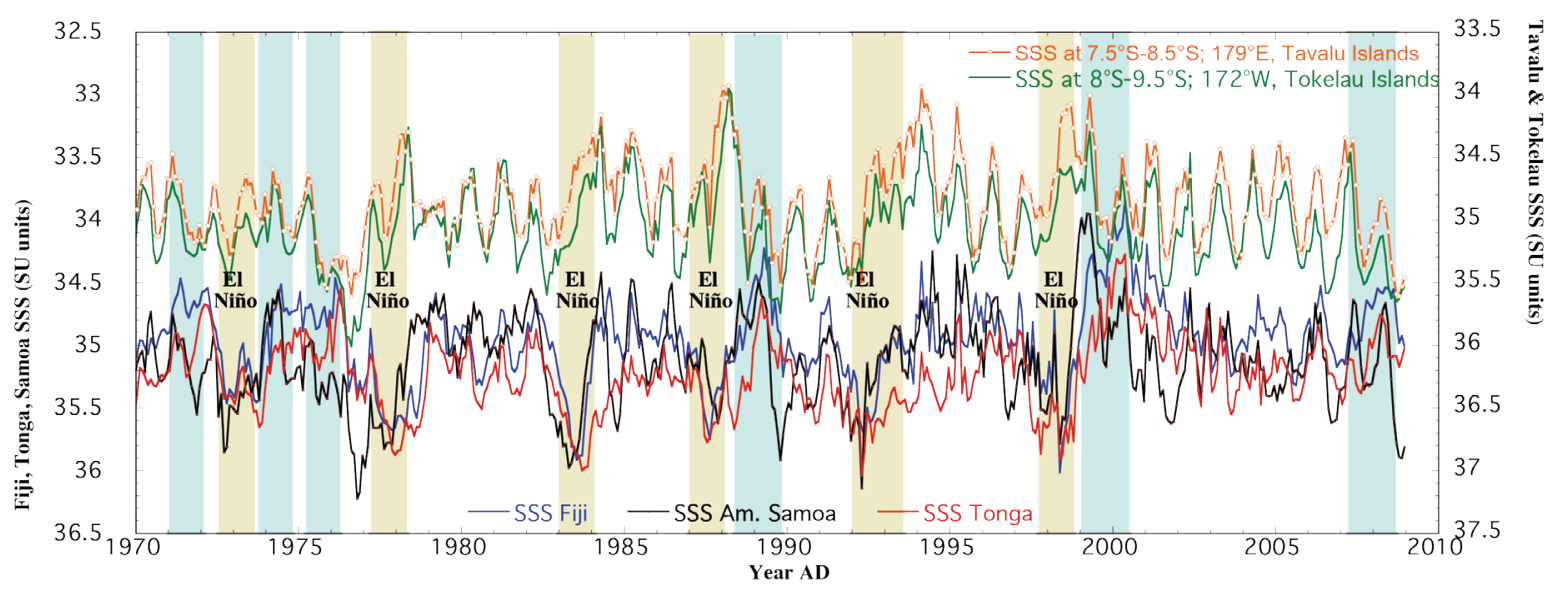

Figure 4: Monthly surface salinity from near Fiji, American Samoa, Tonga, and near Tokelau and Tavalu (north and northwest of Samoa respectively) (data from Delcroix et al., 2011). Note the strong freshening in the regions of the Tokelau and Tavalu Islands during EI Niño (tan bars) when the SPCZ shifts northeast. Fiji and Tonga experience higher salinities during El Niño whereas Samoa surface salinity has a more intermediate response. Blue bars are La Niña events. 
variability and equatorial ENSO. The lack of a change in SPCZ-ENSO phasing in the late 1960s when the AMO shifted from a positive phase to a negative phase suggests that there was something climatically different in the late 1920s and/or that the SPCZ and ITCZ are not connected causally. The 1920's were also a time when the PDO changed phase, although this phase change was gradual and appears to have started in the early 1920s. Other clues to significant tropical-subtropical re-organization in the late 1920s at the same time as the SPCZ and Atlantic ITCZ shifted north are a 1920 s shift to weaker Pacific trade winds (Thompson et al., 2014). Further interpretation of these preliminary observations of SPCZ position change in the late 1920s will require future work.

\section{References}

Cai W., M. Lengaigne, S. Borlace, M. Collins, T. Cowan, M. J. McPhaden, A. Timmermann, S. Power, J. Brown, C. Menkes, A. Ngari, E. M. Vincent, M. J. Widlansky, 2012: More extreme swings of the SPCZ due to greenhouse warming, Nature, 488, 365-369, doi:10.1038/nature11358.

Chen, D. , T. Lian, C. Fu, M. A. Cane, Y. Tang, R. Murtugudde, X. Song, Q. Wu, L. Zhou, 2015: Strong influence of westerly wind bursts on El Niño diversity, Nature Geoscience, vol 8, May 2015, doi:10.1038/NGE02399.

Cobb, K. M., N. Westpha, H.R. Sayani, J.T. Watson, E. Di Lorenzo, H. Cheng, R.L. Edwards, and C.D. Charles, 2013: Highly Variable El Niño-Southern Oscillation Throughout the Holocene, Science, 339, no. 6115, pp. 67-70,. doi:10.1126/science.1228246.

Delcroix, T., G. Alory, S. Cravatte, T. Correge, and M. J. McPhaden, 2011: A gridded sea surface salinity data set for the tropical Pacific with sample applications (19502008), Deep Sea Res., Part I, 58(1), 38-48, doi:10.1016/j. dsr.2010.11.002.

Evans. J.P. K. Bormann, J. Katzfey, S. Dean, R. Arritt, 2015: Regional climate model projections of the South Pacific Convergence Zone, Clim. Dynamics, DOI 10.1007/ s00382-015-2873-x.

García-García, D., and C. C. Ummenhofer (2015), Multidecadal variability of the continental precipitation annual amplitude driven by AMO and ENSO, Geophys. Res. Lett., 42, 526-535, doi:10.1002/2014GL062451.

Gouriou Y, T. Delcroix, 2002: Seasonal and ENSO variations of sea surface salinity and temperature in the South Pacific Convergence Zone during 1976-2000. J Geophys Res Oceans 107(C12):8011. doi:10.1029/2001jc000830. Hasson, E.A., T. Delcroix, R. Dussin, 2013: An assessment of the mixed layer salinity budget in the tropical Pacific Ocean. Observations and modelling (1990-2009), Ocean Dynamics DOI 10.1007/s10236-013-0596-2.
Knight, J. R. C. K. Folland, J. A. Scaife, 2006: Climate impacts of the Atlantic multidecadal oscillation, Geophts. Res. Lett., vol 33, L17706, doi:10.1029/2006GL026242

Linsley, B. K., H. C. Wu, E. P. Dassié, and D. P. Schrag, 2015: Decadal changes in South Pacific sea surface temperatures and the relationship to the Pacific decadal oscillation and upper ocean heat content, Geophys. Res. Lett., 42, doi:10.1002/2015GL063045.

Linsley, B. K., H. C. Wu, T. Rixen, C. D. Charles, A. L. Gordon, M. D. Moore, 2017: SPCZ Zonal Events and Downstream Influence on Surface Ocean Conditions in the Indonesian Throughflow Region, Geophys. Res. Lett., 43, doi:10.1002/2016GL070985.

Newman, M., M.A. Alexander, T.R. Ault, K.M. Cobb, C. Deser, E. Di Lorenzo, N.J. Mantua, A.J. Miller, S. Minobe, H. Nakamura, N. Schneider, D.J. Vimont, A.S. Phillips, J.D. Scott, C.A. Smith, 2016: The Pacific decadal oscillation, revisited. J. Climate, vol. 29, 4399-4427, June 2016.

Salinger, M. J., B. B. Fitzharris, J. E. Hay, P. D. Jones, and J. P. Schmidely-Leleu, 1995: Climate trends in the south-west Pacific, Int. J. Climatol., 15, 285-302.

Thompson, D. M., J. E. Cole, G. T. Shen, A. W. Tudhope, G. M. Meehl, 2014: Early twentieth-century warming linked to tropical Pacific wind strength, Nature Geoscience, published online December 22, 2014, doi: 10.1038/ Ngeo2321.

Trenberth, K. E. (1997) The Definition of El Niño. Bulletin of the American Meteorological Society, 78, 2771-2777.

Urban, F. E., J.E. Cole, J. T. Overpeck, 2000: Influence of mean climate change on climate variability from a 155year tropical Pacific coral record, Nature, 407, 989-993.

Vincent, D., The South Pacific convergence zone (SPCZ): A review, 1994: Mon. Weather Rev., 122, 1949-1970.

Vincent, E. M., M. Lengaigne, C. E. Menkes, N. C. Jourdain, P. Marchesiello, and G. Madec 2009: Interannual variability of the South Pacific Convergence Zone and implications for tropical cyclone genesis, Clim. Dyn., 36(9-10), 18811896, doi:10.1007/s00382-009-0716-3.

Zhang, R., T. L. Delworth, 2006: Impact of Atlantic multidecadal oscillation on India/Sahel rainfall and Atlantic hurricanes, Geophys. Res. Lett., vol. 33, L17712, doi:10.1029/2006GL026267. 


\author{
Hans W. Linderholm ${ }^{1}$ and Chris K. Folland ${ }^{1,2,3,4}$ \\ 1 University of Gothenburg, Sweden \\ 2 Met Office Hadley Centre, UK \\ 3 University of East Anglia, UK \\ 4 University of Southern Queensland, Australia
}

\section{The summer North Atlantic Oscillation (SNAO)}

The influence of the North Atlantic Oscillation (NAO) on climate in the North Atlantic region has been highlighted over the past few decades. Although most prominent during winter, the NAO is one of the few modes of variability that persist throughout the year, although there are systematic differences in its configuration through the seasons (Barnston and Livezey, 1987). This is related to seasonal variations of the North Atlantic jet stream which on average moves northwards in summer relative to winter. Consequently, the positive and negative nodes of the dipole NAO pattern have more northerly positions during summer. Until recently, most studies of the link between the NAO and climate have focused on winter, but after a thorough study of the summer NAO (SNAO) by Folland et al. (2009, henceforth F09), attention has also been directed to summer.

During summer the NAO pattern has its pressure centres located over the British Isles/Scandinavia and Greenland (Hurrell and Folland, 2002). Due to the lack of data from its northern node, SNAO has largely been defined until now from the variability of the southern node. F09 defined the SNAO as the first eigenvector of pressure at mean sea level (PMSL) anomalies (PMSLA) over the extratropical European-North Atlantic sector $\left(25-70^{\circ} \mathrm{N}, 70^{\circ} \mathrm{W}-50^{\circ} \mathrm{E}\right)$ in July and August (JA). The SNAO time series shows large interannual to decadal variability as does the winter $\mathrm{NAO}$, but the correlation between them is very low. The SNAO phase is strongly related to changes in Atlantic and European summer storm tracks (Dong et al., 2013). In its positive phase, the SNAO is associated with anticyclonic conditions over Northern Europe, yielding sunny, warm and dry conditions there. Accordingly, the positive phase of the SNAO is related to summer droughts from the UK to Scandinavia in particular, and a northerly position of the main storm track. In the negative SNAO phase, the storm track moves $\sim 10^{\circ}$ further south, giving cloudy, wet and cooler conditions over this region. The relationship with surface climate is surprisingly strong for southern Europe and more or less the opposite, especially in the eastern Mediterranean (Chronis et al., 2011). Climatic influences outside northwestern Europe have also been noted, e.g. eastern North America (Hardt et al., 2010) and East Asia (Linderholm et al., 2011).

On interannual to multidecadal timescales, SNAO variability can be linked to variations in North Atlantic surface temperature (SST). Observations and models indicate an association between the Atlantic Multidecadal Oscillation (AMO) (Kerr, 2000) and the SNAO for periods greater than 10 years (F09) such that a cold (warm) phase of the AMO corresponds a positive (negative) phase of the SNAO, clearly seen in Sutton and Dong (2012).

Recently, the potential influence of Arctic climate change, particularly related to the large reduction in sea ice coverage, on mid-latitude circulation patterns has been studied (e.g. Overland and Wang, 2010; Francis and Skific, 2015). For instance, Wu et al. (2013) suggested that winter sea ice concentration conditions west of Greenland influences the following summer atmospheric circulation over northern Eurasia. Using observations, Knudsen et al. (2015) found a link between anomalous Arctic sea ice melt and changes in midlatitude atmospheric patters during summer, as did Screen (2013) using an atmospheric general circulation model. Petrie et al. (2015), using a fully coupled climate model, found that sea ice loss together with increased SST in the Labrador Sea affects the summer atmospheric circulation over the North Atlantic region.

Within an ongoing International CLIVAR Climate of the $20^{\text {th }}$ Century (C20C) Project (Kinter and Folland, 2011) and a project supported by the Swedish Research council, studies have been underway to describe SNAO variability on decadal to multicentury timescales, mechanisms behind its variability and its potential predictability. Recent work has extended the definition of the SNAO to include June in addition to July and August, and new data sets allow this definition to be extended spatially to include data from the whole Arctic. This work, to be reported elsewhere, does not change the fundamental spatial or temporal character of the SNAO but it is better aligned to important aspects of seasonal forecasting 

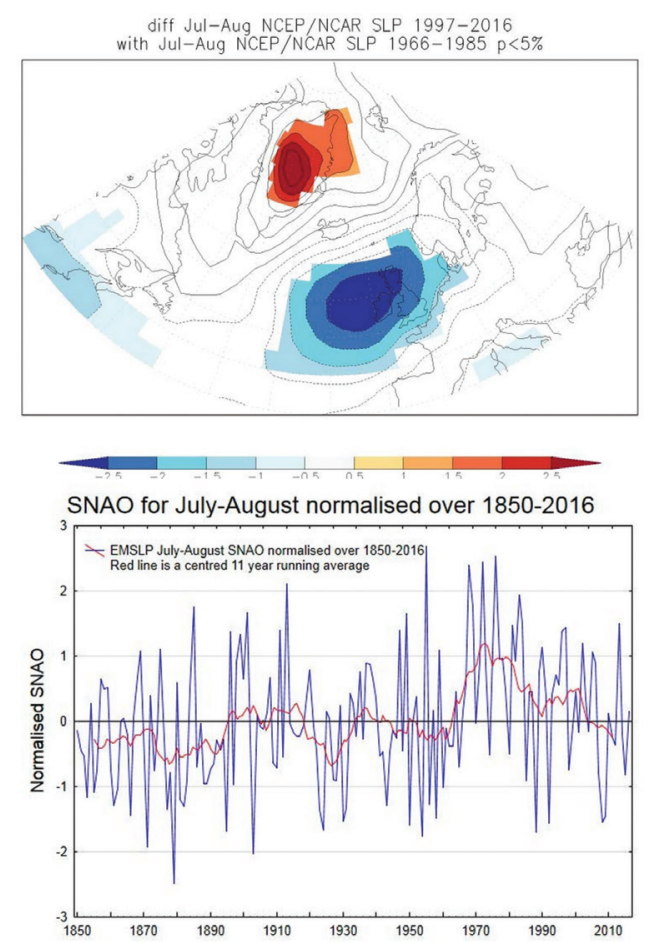

Figure 1: (Top Panel) Differences in pressure at mean sea level over the North Atlantic and Europe in July and August between the two decades 1997-2016 and the two decades 1966-1985, together with significances of these differences at the 5\% level. (Bottom Panel) Variations in the July and August SNAO, 1850-2016

research. Here we confine ourselves to the JA SNAO as discussed in F09 and show a key result that indicates that over the last 5 decades the JA SNAO emerges naturally as a key component of JA atmospheric circulation change. Fig. 1 (top panel) shows the difference in pressure at mean sea level using the NCEP Reanalysis between the two most recent decades 1997-2016 and the two decades 1966-1985. These periods have been chosen to illustrate the character of a large decline in the JA SNAO (Fig 1, bottom panel). This shows that the last half century contains the largest coherent fluctuation of the SNAO since 1850 with a large decline in its value since the 1970s. However the recent relatively negative level of the SNAO is quite similar to its average level in the late nineteenth century, so that the very positive levels of the 1970s in particular are the more unusual. Fig 1 (top panel) shows that the difference pattern appears to be very like the negative pattern of the SNAO. Thus the SNAO, defined from an eigenvector analysis over the much longer period 18812003 and explaining about $28 \%$ of the mean July and $\mathrm{Au}-$ gust variance over this period, dominates the changing pattern of interdecadal July and August decadal pressure at mean sea level since the 1970 s over the North Atlantic and Europe. In fact the centres of difference over Greenland and near the United Kingdom are both significant at the $0.1 \%$ level. The negative centre over the UK has, for instance, led to markedly wetter late summers over England and Wales in the most recent decade in contrast to expected long term changes found in many papers to- wards more anticyclonic, dry, conditions arising from anthropogenic warming (e.g. F09). Research is underway, including the use of CMIP5 models, to attempt to explain this large short term change in climate, particularly sea surface temperatures in the Atlantic and the global tropics and possible influences of changing Arctic sea ice extents (Screen, 2013; Petrie et al., 2015). Other aspects of the behaviour of the SNAO on interannual to century time scales are summarised annually in State of the Climate publications (e.g. Allan and Folland, 2016).

\section{SNAO variability during the last millennium}

Several studies have shown that tree growth variations across Europe are linked to SNAO-like atmospheric circulation patterns (e.g. Seftigen et al., 2013), suggesting the suitability of using tree-ring data to reconstruct the SNAO before the observational record. Indeed, F09 used tree-ring data from western Norway and northern UK to produce a reconstruction of the JA SNAO back to $1706 \mathrm{CE}$, verified by long instrumental records from the UK. Using a tree-ring network with much larger spatial distribution, the reconstruction was extended back to $1441 \mathrm{CE}$, providing opportunities to study e.g. associations between the SNAO and European/Sahel drought (Linderholm et al., 2009) and associations between the SNAO and summer climate in East Asia in a long-term context (Linderholm et al., 2013). Here we present a preliminary new reconstruction where the target season was extended to JJA. This should also help from a tree-ring perspective as the growth of trees in northwestern Europe is influenced by temperature or precipitation in June as well. This reconstruction, based only on tree-ring data from the southern node region of the SNAO (i.e. UK and Fennoscandia), which extends back to $1200 \mathrm{CE}$, is shown in Fig. 2. In light of the potential influences of Arctic sea ice as noted above, it is also compared to northeastern Canadian summer sea ice cover (SIC) variations inferred from coralline algae (Halfar et al., 2013), and a multi-proxy reconstruction of the AMO (Mann et al., 2009). On multidecadal timescales, a sustained period of negative SNAO during the Little Ice Age (LIA) coincided with high SIC (note that SIC is inverted in Fig. 2). Also the positive SNAO in the twentieth century corresponds to a significant decrease in SIC. However, no stable association between the SNAO and summer SIC during the last six centuries is evident. This may be because none actually exists, despite an apparent influence, where reduced Arctic sea ice extents favour the negative SNAO implied by Screen (2013), or the variation of drivers not studied here is more important. To better assess the potential influence of Arctic sea ice on the SNAO in a long-term context, additional SIC proxies are needed. The long-term evolution of the AMO is in general (except for the 1200s) quite similar to that of the SNAO: negative (positive) multidecadal phases of the the AMO correspond to periods of negative (positive) SNAO. Our tentative comparison suggests that both longterm changes in the AMO and SIC are of opposite signs in their apparent influences on the recent shorter-term 


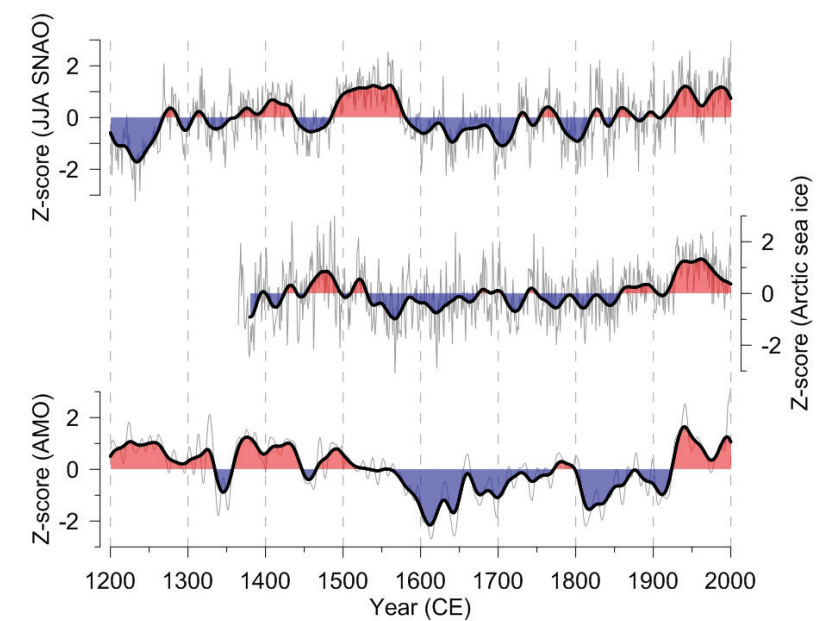

Figure 2: A preliminary reconstruction of the JJA SNAO, based on tree-ring data from Fennoscandia and the UK, (upper panel) compared to inferred (inverted) sea ice variability in the eastern Canadian Arctic (middle panel), derived from coralline alge and representing the region $85-60^{\circ} \mathrm{W}, 55-73^{\circ} \mathrm{N}$, (Halfar et al., 2013, data available at www.ncdc.noaa.gov/ paleo-search/study/15454), and a reconstruction of the AMO (lower panel, Mann et al. (2009)). All records have been z-scored. Thick lines represent 30-year variability. Note that positive algal proxy anomalies correspond to below normal sea ice coverage.

behaviour of the SNAO. Still, this apparent contradiction may be due to the data used here. For instance, the AMO index used here was derived from a gridded reconstruction of temperatures mainly based on terrestrial proxies only. The recent increase in the spatiotemporal representation of palaeoclimate proxies, e.g. within the PAGES $2 \mathrm{k}$ initiative, provides new the opportunities for improving the multicentury reconstruction of indices like the AMO and different Arctic sea ice parameters.

\section{Acknowledgements}

The paper contributes to the CLIVAR International Climate of the Twentieth Century Plus (C20C+) project and the PAGES 2k Network. Past Global Changes (PAGES) is supported by the US and Swiss National Science Foundations. HL and CF were funded by the Swedish Research Council (VR, grant 2012- 5246) and CF by the Joint UK BEIS/Defra Met Office Hadley Centre Climate Programme (GA01101) and the Climate Science to Service Partnership (CSSP-China). We thank Yochanan Kushnir for comments on an earlier version of the manuscript.

\section{References}

Allan, R., and C.K. Folland, 2016: Atmospheric circulation. 1. Sea level Pressure. State of the Climate 2015. Bull. Amer. Meteor. Soc. 97, S36-38.

Barnston, A.G. and R.E. Livezey, 1987: Classification, seasonality and persistence of low-frequency atmospheric circulation patterns. Mon. Wea. Rev., 115, 1083-1126.

Chronis, T., D.E. Raitsos, D. Kassis, and A. Sarantopoulos,
2011: The Summer North Atlantic Oscillation Influence on the Eastern Mediterranean. J. Clim, 24: 5584-5596.

Dong, B., R.T. Sutton, T. Woollings, and K. Hodges, 2013: Variability of the North Atlantic summer storm track: mechanisms and impacts on European climate. Environ. Res. Lett. 8: 034037.

Folland, C.K., J. Knight, H.W. Linderholm, D. Fereday, S. Ineson, and J.W. Hurrell, 2009: The Summer North Atlantic Oscillation: past, present and future. J. Clim, 22: 10821103.

Francis, J., and N. Skific, 2015: Evidence linking rapid Arctic warming to mid-latitude weather patterns. Phil. Trans. R. Soc. A 373; 20140170

Halfar, J., W.H. Adey, A. Kronz, S. Hetzinger, E. Edinger, and W.W. Fitzhugh, 2013: Arctic sea ice decline archived by multicentury annual-resolution record from crustose coralline algal proxy. PNAS, 110, 19737-19741.

Hardt, B., H.D. Rowe, G.S. Springer, H. Cheng, and R.L. Edwards, 2010: The seasonality of east central North American precipitation based on three coeval Holocene speleothems from southern West Virginia. Earth Plan. Sci. Lett., 295: 342-348

Hurrell JW. and Folland CK. 2002: A change in the summer circulation over the North Atlantic. CLIVAR Exch., 25: $52-54$.

Kerr, R. A., 2000: A North Atlantic climate pacemaker for the centuries. Science, 288, 1984-1985.

Kinter, J. and C.K Folland, 2011: The International CLIVAR Climate of the 20th Century Project: Report of the Fifth Workshop. CLIVAR Exchanges, 57, 39-42. DOI:

Knudsen, EM. Orsolini, YJ. Furevik, T. and Hodges, KI. 2015: Observed anomalous atmospheric patterns in summers of unusual Arctic sea ice melt. J Geophys Res-Atmos 120: 2595-2611. DOI:

Linderholm, H.W., C.K., Folland, and A., Walther, 2009: A multicentury perspective on the summer North Atlantic Oscillation (SNAO) and drought in the eastern Atlantic Region, J. Quat. Sci., 24: 415-425.

Linderholm HW. T. Ou, J-H. Jeong, C.K. Folland, D. Gong, H. Liu, Y. Liu, and D. Chen, 2011: Interannual Teleconnections between the Summer North Atlantic Oscillation and the summer East Asian Monsoon. J.Geophys. Res, 116: D13107

Linderholm, H.W., A. Seim, T. Ou, J-H. Jeong, Y. Liu, X. Wang, G. Bao, and C. Folland, 2013: Exploring teleconnections between the summer NAO (SNAO) and climate in 
East Asia over the last four centuries - a tree-ring per spective. Dendrochronologia 31: 297-310.

Mann, M.E., Z. Zhang, S. Rutherford, R.S. Bradley, M.K. Hughes, D. Shindell, C. Ammann, G. Faluvegi, and F. Ni, 2009: Global signatures and dynamical origins of the Little Ice Age and Medieval Climate Anomaly. Science, 326, 1256-1260.

Overland, J.E., and M. Wang, 2010: Large-scale atmospheric circulation changes are associated with the recent loss of Arctic sea ice, Tellus A, 62: 1-9.

Petrie, RE., Shaffrey L. C. and R. T. Sutton, 2015: Atmospheric Impact of Arctic Sea ice Loss in a Coupled OceanAtmosphere Simulation. J. Clim, 28 9606-9622.

Screen, J.A. 2013: Influence of Arctic sea ice on European summer precipitation. Env. Res. Lett., 8, doi:10.1088/1748-9326/8/4/044015.

Seftigen, K., H.W. Linderholm, I. Drobyshev, and M. Niklasson, 2013: Reconstructed drought variability in east-central Sweden since the 1650s. International Journal of Climatology 33: 2449-2458.

Sutton, R. T. and B. Dong, 2012: Atlantic Ocean influence on a shift in European climate in the 1990s, Nat. Geosci., 5, 788-792, doi:10.1038/ngeo1595.

Wu, B.Y., R.H. Zhang, R. D'Arrigo, and J.Z. Su, 2013: On the Relationship between Winter Sea ice and Summer Atmospheric Circulation over Eurasia. J Climate, 26, 5523-5536. 


\title{
A last millennium perspective on North Atlantic \\ variability: exploiting synergies between models \\ and proxy data
}

doi: 10.22498/pages.25.1.61

\section{Pablo Ortega ${ }^{1}$, Jon Robson ${ }^{1}$, Paola Moffa-Sanchez², David Thornalley², Didier Swingedouw ${ }^{4}$}

\author{
1 NCAS-Climate, Department of Meteorology, University of Reading, Reading, UK \\ 2 School of Earth and Ocean Sciences, Cardiff University, Cardiff, UK \\ 3 Department of Geography, University College London, London, UK \\ 4 EPOC/CNRS, Université de Bordeaux, Bordeaux, France
}

\section{Introduction}

The North Atlantic is a key region for decadal prediction as it has experienced significant multi-decadal variability over the observed period. This variability, which is thought to be intrinsic to the region, can potentially modulate, either by amplifying or mitigating, the global warming signal from anthropogenic greenhouse emissions. For example, studies suggest that the North Atlantic contributed to the recent hiatus period between 1998 and 2012, by triggering an atmospheric response which impacted on the eastern tropical Pacific (e.g. McGregor et al., 2014). The subpolar North Atlantic is also a major $\mathrm{CO}_{2}$ sink, and therefore of great importance for the global carbon cycle (Perez et al., 2013).

One of the key players in the North Atlantic region is the Atlantic Meridional Overturning Circulation (AMOC), which is associated with sinking due to deep water formation in the Labrador and Nordic Seas. The AMOC is the primary control of the poleward heat transport in the Atlantic region. Therefore, the AMOC is associated with important climate impacts, and plays an active role in various feedback mechanisms with, for example, sea ice (Mahajan et al., 2011) and the atmospheric circulation (Gastineau and Frankignoul, 2012). The AMOC has exhibited abrupt variations in the past (e.g. the last glacial period, Rahmstorf, 2002) and could experience a major slowdown in the future due to the combined effect of surface warming and Greenland ice sheet melting on deep water formation (Bakker et al., 2016). The possibility of such a shutdown has stimulated considerable international efforts to observe and reconstruct the past AMOC changes. Only by understanding its natural variability will we be able to detect and anticipate an anthropogenic impact on the AMOC.

Decadal modulations are also found in other large-scale modes of climate variability, such as the North Atlantic Oscillation (NAO) (Stephenson et al., 2000), the Subpolar Gyre strength (SPG) (Häkkinen and Rhines, 2004) and the Atlantic Multidecadal Variability (AMV) (Enfield et al., 2001), which have all been linked with widespread climate impacts over the surrounding continents. Modelling studies suggest that all these modes interact with the AMOC (Gastineau and Frankignoul, 2012; Hátún et al., 2005; Knight et al., 2005) but the exact interrelationships are complex and remain to be disentangled. Also to be determined are the underlying mechanisms responsible for the decadal and centennial AMOC modulations, with different climate models showing different key drivers (Menary et al., 2015a). Similarly, the exact impact of the natural external forcings (e.g. volcanic aerosols, solar irradiance) on the variability of these different largescale climate modes still remains unclear.

\section{A unique opportunity to deepen our understanding} The study of the last millennium climate provides us with an ideal framework to investigate natural climate variability and associated mechanisms within the North Atlantic. It is particularly interesting because it provides a long-term context of naturally forced variability which is useful (i) to assess whether current or future changes in these variables are unprecedented, (ii) to robustly test the effects of natural forcings on their variability (e.g. by increasing the sample size of major volcanic events), and (iii) to better characterise the typical timescales of the key variables at play (e.g. AMOC, AMV, SPG).

The availability of data to undertake these analyses is rapidly increasing thanks to joint efforts from the modelling and paleoclimate data communities. The Paleoclimate Modelling Intercomparison Project (PMIP) is now entering its fourth phase, and includes a set of coordinated "tier 1 " experiments for the last millennium (Jungclaus et al., 2016), with all models using, for the first time, the same "default" external forcing configuration. Additional sensitivity experiments to explore the uncertainty in external forcings are also envisaged. The ultimate purpose of this exercise is to evaluate 
the skill of models against well-documented climatic epochs, in order to reduce the uncertainty for future climate projections. Additionally, the OCEAN2K initiative within the PAGES2k network has prepared a first sea surface temperature (SST) synthesis dataset (McGregor et al., 2015), including 29 peer-reviewed and publicly available reconstructions from marine-archives in the Atlantic ocean, all of them covering, at least partly, the last 2000 years. Phase 2 of the OCEAN2K initiative aims to advance this field by addressing different topics, specifically two working groups will compile and study paleoceanographic reconstructions related to the dynamical overturning changes in the North Atlantic, one specifically focused on the proxy data, and the other in model-data comparisons.

\section{Our current knowledge of the last millennium from observations and paleoclimate records}

Because of the dynamic and large-scale nature of the AMOC, robust observations of its variability require extensive (and costly) measurement arrays. The first continuous measurements of its strength date back to 2004 , when the RAPID observing array at $26^{\circ} \mathrm{N}$ was deployed. The first decade of observations exhibits a weakening of about 0.5 Sv per year (Smeed et al., 2014). An obvious question is whether this decline is linked to the effect of global warming or instead reflects natural multi-decadal variability. Different approaches have been considered to reconstruct the AMOC changes back in time and give a longer context to this trend; however, the connection of these indirect estimates with the AMOC can present important uncertainties, which can contribute to conflicting conclusions. For example, Rahmstorf et al. (2015) uses AMOC covariances with SSTs to produce an AMOC reconstruction for the last millennium (Fig. 1a). A drawback of this reconstruction is that it employs a gridded surface temperature reconstruction (Mann et al., 2008) mostly based on indirect proxy evidence from continental areas. This index suggests that the AMOC has been weakening since the beginning of the $20^{\text {th }}$ century, which Rahmstorf et al (2015) suggest is a consequence of Greenland ice sheet melting. A similar centennial trend is found in Dima and Lohmann (2010), which uses SST observations to make inferences about the large-scale circulation. However, other studies based on different techniques contradict these results. For instance, two independent reconstructions of the ocean circulation based on sea level data (McCarthy et al., 2015) and deep Labrador Sea densities (Robson et al., 2016) show no major long-term trends during the industrial period.

On longer time-scales, rather than aiming to reconstruct the AMOC as a whole, investigation of individual surface and deep components of the AMOC may be more easily realized. Proxy-based reconstructions of the Florida Current transport (Lund et al., 2006) and the surface ocean circulation near the North Icelandic shelf (Wanamaker et al., 2012) are both suggestive of a strengthening of the AMOC during the last two centuries (Fig. 1b), following a minimum during the cold interval termed the Little Ice Age (LIA). These results are therefore also in stark contrast with the Rahmstorf et al. (2015) reconstruction. Reconstructions of the vigour of the Nordic Seas Overflows (Fig. 1c) show multi-centennial changes across the last millennium. Interestingly, there is evidence of a potential anti-phase relationship between the overflows East and West of Iceland, with the Denmark Strait Overflow Water (DSOW) strengthening when the Iceland Scotland Overflow Water (ISOW) is weaker, and vice versa (Moffa-Sanchez et al. 2015). This configuration suggests a constant flow of deep dense waters over the Greenland Scotland Ridge through the last millennium. If we assume that the AMOC does exhibit significant centennial variability, the inferred near-constancy of the Nordic Overflows possibly implicates changes in Labrador Sea Water formation as a key driver of centennial AMOC variability as suggested by Moffa-Sanchez et al. (2014b) for the LIA, which would parallel its important role in recent decadal changes.

We turn now our attention to other major contributors to North Atlantic climate variability in the last millennium. The role of the atmosphere has been invoked to explain another important centennial-scale climate event: the Medieval Climate Anomaly (MCA). A bi-proxy NAO reconstruction (Trouet et al., 2009) shows persistent strong positive phases during this period, followed by a shift towards more negative phases that could have partly contributed to the MCA-LIA transition (Fig. 1d, light green line). However, these remarkable multi-centennial changes are less evident in a more recent annuallyresolved reconstruction based on multiple proxy records (Fig. 1d, dark green line, Ortega et al., 2015). Of relevance for prediction purposes, this recent reconstruction suggests that volcanic aerosols can induce positive NAO phases peaking 2 years after the eruptions. Mid-sized volcanic eruptions can also impact the ocean and act as a pacemaker of the intrinsic oceanic variability, as shown for two independent proxy reconstructions of the AMV and the AMOC-driven changes in the nutrient supply North of Iceland (Swingedouw et al., 2015). Likewise, decadal climate fluctuations can be associated with, for example, the occurrence of Great Salinity Anomalies (Belkin et al., 1998). All of these processes (forced and unforced) can have different impacts on the variability of the major large-scale ocean modes in the North Atlantic. Indeed, the available reconstructions highlight prominent centennial changes in the AMOC (Fig. 1a), multidecadal changes in the AMV (Fig. 1e) and decadal changes in the SPG strength (Fig. 1f).

Disentangling the interplay between these different modes of variability and the wider climate system is still not possible due to the uncertainties and sparsity of current reconstructions. Yet, paleoclimatology is a growing field and the spatial distribution and number 


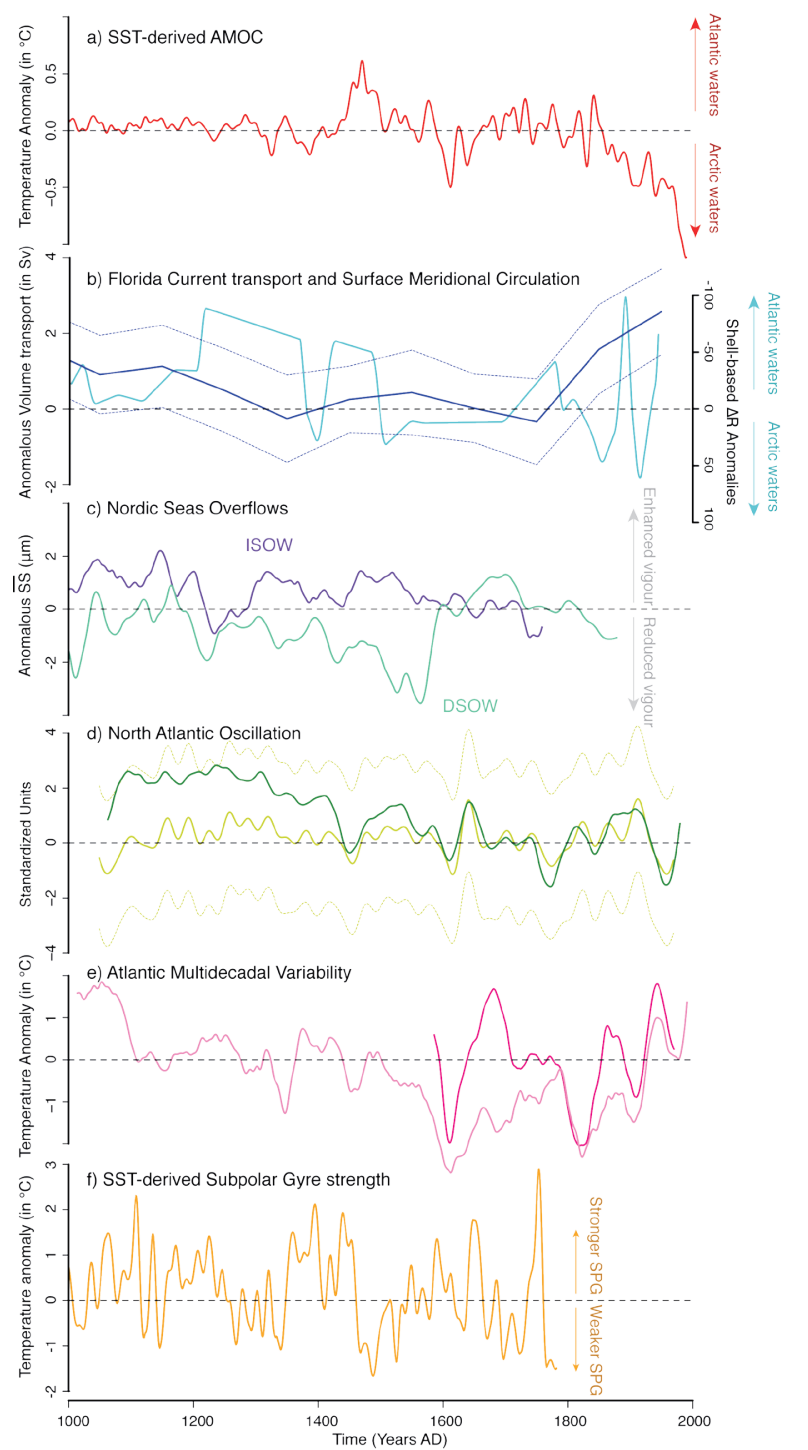

Figure 1: Last-millennium paleo-climate evidence for the North Atlantic: a) Surface temperature-derived AMOC reconstruction (Rahmstorf et al., 2015), b) Estimates of the Florida current (blue line; Lund et al., 2006) and northwardflowing surface transport across the North-Icelandic shelf (light blue line; Wanamaker et al., 2012), c) sortable silt )-derived Denmark Strait Overflow Water (DSOW) and Iceland-Scotland Overflow Water (ISOW) flow speed (MoffaSanchez et al., 2015), d) reconstructed NAO evolution (dark green line, Trouet et al., 2009; light green lines, Ortega et al., 2015), e) estimates of AMV (light pink line, Mann et al., 2009; dark pink line Gray et al., 2004) and f) SST-derived changes in the Subpolar Gyre Strength (Moffa-Sánchez et al., 2014a). All panels show anomalous values with respect to the common period 1572-1787. All data were decadally smoothed, except for the Florida Current record, which is centennially resolved, and the NAO and overflow reconstructions, instead smoothed at 30 years to better highlight the multi-decadal changes.

of high-resolution proxy records is continuously increasing, especially for the last millennium, which should soon allow more reliable reconstructions. In particular, the production of new subdecadally resolved marine proxies is necessary to provide first-hand insights about the past changes in the ocean. Until now, these have been largely inferred from continental records and therefore rely on atmospheric teleconnections that are still not totally understood. In addition, extending the current network of terrestrial records is also important to better constrain the concomitant atmospheric changes and continental impacts.

\section{Insights from climate models}

Climate models provide a complementary source of information for the last millennium, allowing us to test different hypotheses, such as the external forcing conditions, and their effect on the major climate excursions (e.g. MCA, LIA, industrial global warming). Their horizontal and vertical resolution, as well as the representation of key physical processes (e.g. ocean eddies, aerosol-cloud and sea-ice interactions), are being continuously improved, offering unique access to the complexity of the climate system. One common aspect to most atmosphere-ocean general circulation models (AOGCMs) is that they naturally generate decadal fluctuations in the North Atlantic under fixed external forcing conditions. However, there is considerable diversity in the mechanisms that lead to such decadal variability. For example, studies with idealized models suggest that multi-decadal oscillations (particularly linked to the AMV) can emerge in the absence of interactive ocean dynamics (Clement et al., 2015; Srivastava and DelSole, 2017). More generally, the preferential timescale of the internal variability is associated with ocean adjustment processes that are strongly model dependent (Menary et al., 2015a), suggesting an important sensitivity to model biases (Menary et al., 2015b). Encouragingly, a multi-model comparison in control simulations $(\mathrm{Ba}$ et al., 2014) reports reasonable consistency in terms of the major interactions in the North Atlantic; 8 out of 10 models show a close link between AMV and the AMOC and most of them exhibit a lagged relationship between the SPG changes and those in the AMOC. However, none of the models in Ba et al. (2014) appear to support a significant relationship between the AMOC and the NAO at decadal timescales, a result inconsistent with other studies supporting a driving role of the NAO on decadal AMOC variability (e.g. Ortega et al., 2011; Mecking et al., 2014). Ba et al. (2014) also noted that salinity-driven density anomalies seem to play a dominant role in North Atlantic convection, and therefore, on the AMOC. Yet, the salinity contribution might be over-represented due to important cold model biases, which could potentially compromise the realism of their described interrelationships.

To date, only a limited number of studies have systematically assessed the effect of external forcings on these modes of climate variability. For example, GómezNavarro and Zorita (2013) found no evidence of coherent changes in NAO variability across a large ensemble of last millennium AOGCM simulations, suggesting that all NAO variability was internally driven. This, however, might be 
due to well-known limitations in the previous generation of AOGCMs (PMIP3 and older), either due to a coarse representation of the stratosphere, or to a simplistic implementation of the radiative forcings. Indeed, the CNRM-CM5 model, which has a highly resolved stratosphere, and was not included in the previous analysis, shows a consistent strong positive NAO response to volcanic eruptions. Volcanic forcing is also found to excite an heterogeneous range of responses of both the AMOC and AMV, as shown for several last millennium simulations in Swingedouw et al. (2017). Thus, in light of these large model uncertainties, proxy records provide essential information to assess the degree of realism of models, and thus identify the most reliable ones.

\section{Combining model and paleoclimate data}

There are multiple ways in which model simulations and proxy reconstructions can benefit from each other. Besides the obvious use of paleoclimate records as a reference benchmark for climate models, models can also prove extremely useful (i) for the climatic interpretation of proxies (e.g., Bakker et al., 2015), (ii) to evaluate the validity of different reconstruction techniques (e.g., Moreno-Chamarro et al., 2017), and (iii) to guide future paleo-oceanographic efforts to new regions and variables with relevant climate information.

The latter point can be addressed with model-derived ocean fingerprints (Zhang, 2008), highlighting covariability between the large-scale climate modes and other more easily observed climate variables. These, however, need to be considered with caution, as important differences can emerge from the various models, and also at different timescales (Muir and Fedorov, 2015). In Fig. 2 we explore the potential of ocean fingerprints for the identification of suitable proxies to produce separate distinct reconstructions of the AMV, AMOC and SPG strength. The figure depicts the correlation of the simulated SST fields with the large-scale variability (AMOC, AMV, SPG) in two 300-yr high-resolution AOGCM control experiments with different ocean and atmosphere components. All data is decadally smoothed with 10 -year running means to focus on the multidecadal co-variability. Interestingly, despite some apparent differences between the models, robust features are also discerned. The impact of the AMOC on SSTs is most pronounced when the AMOC leads by 6 years, with both simulations showing an area of maximum correlations in the eastern SPG, for which some SST-sensitive proxy records are available (green dots and yellow stars in Fig. 2). By contrast, correlations with the AMV show a larger-scale structure that extends to the subtropical North Atlantic. Thus, the addition of existing proxy records near West Africa and the Brazilian coast could help to disentangle AMV variability from that of the AMOC. As for the SPG strength, both models exhibit a coherent SST dipole between the Gulfstream and the Gulf of Saint Lawrence, which could have encouraging potential for reconstruction purposes due to the high availability of proxy records in both regions.
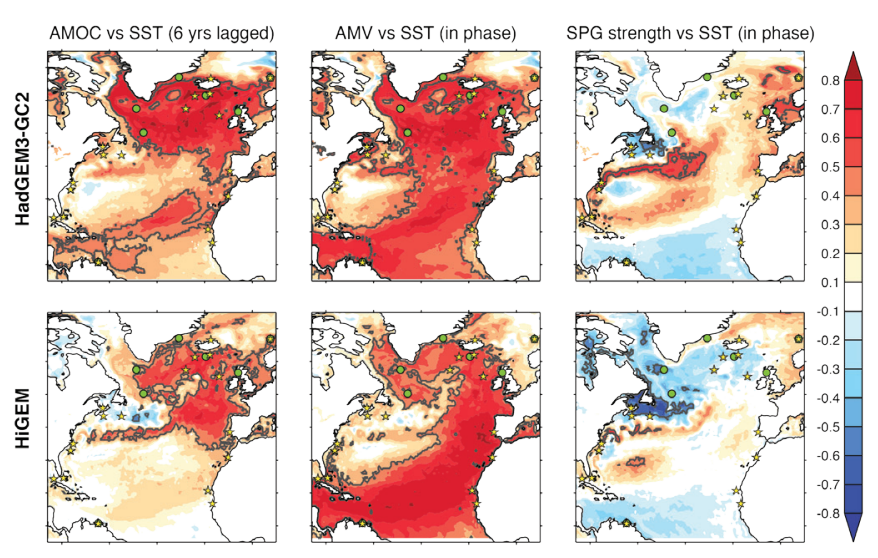

Figure 2: Spatial correlations between a selection of North Atlantic climate indices and the SST fields in two 300-yr long preindustrial control runs with HadGEM3-GC2 (Ortega et al., 2016; top) and HiGEM (Shaffrey et al., 2009; bottom). All data were low-pass filtered at 10 years to highlight the decadal variability. In-phase correlations are shown for the AMV and SPG strength indices. For the AMOC index, SSTs are delayed by 6 years (the lag with maximum correlations). Significant values at the 95\% confidence level are highlighted with thick grey contours. Yellow stars indicate the location of the SST reconstructions compiled by the OCEAN2K community (McGregor et al., 2015) and green circles the position of other temperaturerecordsalsoavailable(Risebrobakkenetal., 2003; Cage and Austin, 2010; Wurtzel et al., 2013; Moffa-Sánchez et al., 2014a,b; Hoogakker et al., 2015; Miettinen et al., 2015).

Although the comparison of the co-variability patterns in these two high-resolution models is largely consistent, broader multi-model comparisons are still necessary to evaluate which fingerprints are robust. Coarser lastmillennium simulations are also required in order to test if and how the inclusion of forced centennial variability impacts the simulated covariances - we suspect that it does, since previous studies with transient simulations exhibit a clear "warming hole" SST response to long-term forced AMOC changes (Drijfhout et al., 2012; Rahmstorf et al., 2015), not present in Fig. 2. The multi-model assessment could be extended to other AMOC-sensitive climate variables that are well captured by proxies, such as sea level height. As an alternative to the use of ocean fingerprints, proxies of deep-ocean flow speed, based on sortable silt measurements, and $\delta^{13} \mathrm{C}$ records may also be used to infer past changes in the deep ocean circulation. Although informative, the interpretation of some of these proxies with regards to AMOC is not straightforward, carbon-isotope enabled climate models highlight that $\delta^{13} \mathrm{C}$ variability cannot always be interpreted in terms of changing AMOC (Bakker etal., 2015; Blaschek etal., 2015). Likewise, the link of local flow speed to the largescale circulation is not always obvious, and sholud be supported through the use of high-resolution climate models, and where possible, with related observational data. 
A final approach to combining model simulations and paleoclimate records to better constrain past climate evolution is the use of data assimilation techniques. A first attempt has been made with a simplified climate model, although this showed limited reliability in the North Atlantic ocean (Goosse et al., 2010). Recently, the launch of a last millennium climate reanalysis (LMR) project (Hakim et al., 2016) has fostered research on this topic, and will hopefully lead soon to the first AOGCM-based reanalysis covering the last millennium, providing key information about both externally-forced and internallydriven changes in the North Atlantic.

The latest advances by the paleoclimate and modelling communities thus present us with a unique opportunity to further our understanding of the main processes that shaped climate variability in the North Atlantic over the last millennium. To this end, exploiting model-data synergies will be essential because it will help to improve reconstructions, and to identify the most reliable climate model simulations.

\section{Acknowledgements}

We are grateful to David Lund (University of Connecticut) for sharing the data of the Florida Current reconstruction with us, and to all the researchers that made their data available online. The GC2 model data used in this study was kindly provided to us by the UK Met Office, which keeps the ownership rights under Crown Copyright. Finally, we acknowledge the support from NERC (project DYNAMOC, NE/ M005127/1) and ANR (HAMOC project, ANR-13-BS06-0003).

\section{References}

Ba, J., Keenlyside, N.S., Latif, M., Park, W., Ding, H., Lohmann, K., Mignot, J., Menary, M., Otterå, O.H., Wouters, B., Salas y Melia, D., Oka, A., Bellucci, A., Volodin, E., 2014. A multi-model comparison of Atlantic multidecadal variability. Clim. Dyn. 43, 2333-2348. doi:10.1007/ s00382-014-2056-1

Bakker, P., Govin, A., Thornalley, D.J.R., Roche, D.M., Renssen, H., 2015. The evolution of deep-ocean flow speeds and $\delta 13 \mathrm{C}$ under large changes in the Atlantic overturning circulation: Toward a more direct modeldata comparison. Paleoceanography 30, 95-117. doi:10.1002/2015PA002776

Bakker, P., Schmittner, A., Lenaerts, J.T.M., Abe-Ouchi, A., Bi, D., van den Broeke, M.R., Chan, W.-L., Hu, A., Beadling, R.L., Marsland, S.J., Mernild, S.H., Saenko, O.A., Swingedouw, D., Sullivan, A., Yin, J., 2016. Fate of the Atlantic Meridional Overturning Circulation: Strong decline under continued warming and Greenland melting. Geophys. Res. Lett. 43, 12,212-252,260. doi:10.1002/2016GL070457

Belkin, I.M., Levitus, S., Antonov, J., Malmberg, S.-A., 1998. 'Great Salinity Anomalies' in the North Atlantic. Prog.
Oceanogr. 41, 1-68. doi:http://dx.doi.org/10.1016/ S0079-6611(98)00015-9

Blaschek, M., Renssen, H., Kissel, C., Thornalley, D., 2015. Holocene North Atlantic Overturning in an atmosphereocean-sea ice model compared to proxy-based reconstructions 1503-1524.

doi:10.1002/2015PA002828.Received

Cage, A.G., Austin, W.E.N., 2010. Marine climate variability during the last millennium: The Loch Sunart record, Scotland, UK. Quat. Sci. Rev. 29, 1633-1647. doi:http:// dx.doi.org/10.1016/j.quascirev.2010.01.014

Clement, A., Bellomo, K., Murphy, L.N., Cane, M.A., Mauritsen, T., Rädel, G., Stevens, B., 2015. The Atlantic Multidecadal Oscillation without a role for ocean circulation. Science (80-. ). 350, 320-324.

Dima, M., Lohmann, G., 2010. Evidence for Two Distinct Modes of Large-Scale Ocean Circulation Changes over the Last Century. J. Clim. 23, 5-16. doi:10.1175/2009JCLI2867.1

Drijfhout, S., van Oldenborgh, G.J., Cimatoribus, A., 2012. Is a Decline of AMOC Causing the Warming Hole above the North Atlantic in Observed and Modeled Warming Patterns? J. Clim. 25, 8373-8379. doi:10.1175/ JCLI-D-12-00490.1

Enfield, D.B., Mestas-nuñez, A.M., Trimble, P.J., 2001. The Atlantic Multidecadal Oscillation and its Relationship to Rainfall and River Flows in the Continental U . S . A research article resubmitted to Geophysical Research Letters. Atlantic 28, 2077-2080.

Gastineau, G., Frankignoul, C., 2012. Cold-season atmospheric response to the natural variability of the Atlantic meridional overturning circulation. Clim. Dyn. 39, 37-57. doi:10.1007/s00382-011-1109-y

Gómez-Navarro, J.J., Zorita, E., 2013. Atmospheric annular modes in simulations over the past millennium: No longterm response to external forcing. Geophys. Res. Lett. 40, 3232-3236. doi:10.1002/grl.50628

Goosse, H., Crespin, E., de Montety, A., Mann, M.E., Renssen, H., Timmermann, A., 2010. Reconstructing surface temperature changes over the past 600 years using climate model simulations with data assimilation. J. Geophys. Res. Atmos. 115, n/a-n/a. doi:10.1029/2009JD012737

Gray, S.T., Graumlich, L.J., Betancourt, J.L., Pederson, G.T., 2004. A tree-ring based reconstruction of the Atlantic Multidecadal Oscillation since 1567 A.D. Geophys. Res. Lett. 31, L12205. doi:10.1029/2004GL019932

Hakim, G.J., Emile-Geay, J., Steig, E.J., Noone, D., Anderson, 
D.M., Tardif, R., Steiger, N., Perkins, W.A., 2016. The last millennium climate reanalysis project: Framework and first results. J. Geophys. Res. Atmos. 121, 6745-6764. doi:10.1002/2016JD024751

Häkkinen, S., Rhines, P.B., 2004. Decline of subpolar North Atlantic circulation during the 1990s. Science 304, 555-559. doi:10.1126/science.1094917

Hátún, H., Sandø, A.B., Drange, H., Hansen, B., Valdimarsson, H., 2005. Influence of the Atlantic subpolar gyre on the thermohaline circulation. Science (80). 309, 1841-1844.

Hoogakker, B.A.A., McCave, I.N., Elderfield, H., HillaireMarcel, C., Simstich, J., 2015. Holocene climate variability in the Labrador Sea. J. Geol. Soc. 172, 272-277. doi:10.1144/jgs2013-097

Jackson, L.C., Peterson, K.A., Roberts, C.D., Wood, R.A., 2016. Recent slowing of Atlantic overturning circulation as a recovery from earlier strengthening. Nat. Geosci 9, 518-522.

Jungclaus, J.H., Bard, E., Baroni, M., Braconnot, P., Cao, J., Chini, L.P., Egorova, T., Evans, M., González-Rouco, J.F., Goosse, H., Hurtt, G.C., Joos, F., Kaplan, J.O., Khodri, M., Klein Goldewijk, K., Krivova, N., LeGrande, A.N., Lorenz, S.J., Luterbacher, J., Man, W., Meinshausen, M., Moberg, A., Nehrbass-Ahles, C., Otto-Bliesner, B.I., Phipps, S.J., Pongratz, J., Rozanov, E., Schmidt, G.A., Schmidt, H., Schmutz, W., Schurer, A., Shapiro, A.I., Sigl, M., Smerdon, J.E., Solanki, S.K., Timmreck, C., Toohey, M., Usoskin, I.G., Wagner, S., Wu, C.-Y., Yeo, K.L., Zanchettin, D., Zhang, Q., Zorita, E., 2016. The PMIP4 contribution to CMIP6 - Part 3: the Last Millennium, Scientific Objective and Experimental Design for the PMIP4 past1000 simulations. Geosci. Model Dev. Discuss. 2016, 1-34. doi:10.5194/ gmd-2016-278

Knight, J.R., Allan, R.J., Folland, C.K., Vellinga, M., Mann, M.E., 2005. A signature of persistent natural thermohaline circulation cycles in observed climate. Geophys. Res. Lett. 32, 1-4. doi:10.1029/2005GL024233

Lund, D.C., Lynch-Stieglitz, J., Curry, W.B., 2006. Gulf Stream density structure and transport during the past millennium. Nature 444, 601-604. doi:10.1038/ nature 05277

Mahajan, S., Zhang, R., Delworth, T.L., 2011. Impact of the Atlantic Meridional Overturning Circulation (AMOC) on Arctic Surface Air Temperature and Sea Ice Variability. J. Clim. 24, 6573-6581. doi:10.1175/2011JCLI4002.1

Mann, M.E., Zhang, Z., Hughes, M.K., Bradley, R.S., Miller, S.K., Rutherford, S., Ni, F., 2008. Proxy-based reconstructions of hemispheric and global surface temperature variations over the past two millennia. Proc. Natl. Acad. Sci. U. S. A. 105, 13252-13257. doi:10.1073/ pnas.0805721105

Mann, M.E., Zhang, Z., Rutherford, S., Bradley, R.S., Hughes, M.K., Shindell, D., Ammann, C., Faluvegi, G., Ni, F., 2009. Global signatures and dynamical origins of the Little Ice Age and Medieval Climate Anomaly. Science 326, 12561260. doi:10.1126/science. 1177303

McCarthy, G.D., Haigh, I.D., Hirschi, J.J.-M., Grist, J.P., Smeed, D. a., 2015. Ocean impact on decadal Atlantic climate variability revealed by sea-level observations. Nature 521, 508-510. doi:10.1038/nature 14491

McGregor, S., Timmermann, A., Stuecker, M.F., England, M.H., Merrifield, M., Jin, F.-F., Chikamoto, Y., 2014. Recent Walker circulation strengthening and Pacific cooling amplified by Atlantic warming. Nat. Clim. Chang. 4, 888892.

McGregor, H. V, Evans, M.N., Goosse, H., Leduc, G., Martrat, B., Addison, J.A., Mortyn, P.G., Oppo, D.W., Seidenkrantz, M.-S., Sicre, M.-A., Phipps, S.J., Selvaraj, K., Thirumalai, K., Filipsson, H.L., Ersek, V., 2015. Robust global ocean cooling trend for the pre-industrial Common Era. Nat. Geosci 8, 671-677.

Mecking, J. V., Keenlyside, N.S., Greatbatch, R.J., 2014. Stochastically-forced multidecadal variability in the North Atlantic: A model study. Clim. Dyn. 43, 271-288. doi:10.1007/s00382-013-1930-6

Menary, M.B., Hodson, D.L.R., Robson, J.I., Sutton, R.T., Wood, R.A., 2015. A Mechanism of Internal Decadal Atlantic Ocean Variability in a High-Resolution Coupled Climate Model. J. Clim. 28, 7764-7785. doi:10.1175/ JCLI-D-15-0106.1

Menary, M.B., Hodson, D.L.R., Robson, J.I., Sutton, R.T., Wood, R.A., Hunt, J.A., 2015. Exploring the impact of CMIP5 model biases on the simulation of North Atlantic decadal variability. Geophys. Res. Lett. 42, 5926-5934. doi:10.1002/2015GL064360

Miettinen, A., Divine, D. V, Husum, K., Koç, N., Jennings, A., 2015. Exceptional ocean surface conditions on the SE Greenland shelf during the Medieval Climate Anomaly. Paleoceanography 30, 1657-1674. doi:10.1002/2015PA002849

Moffa-Sánchez, P., Born, A., Hall, I.R., Thornalley, D.J.R., Barker, S., 2014a. Solar forcing of North Atlantic surface temperature and salinity over the past millennium. Nat. Geosci 7, 275-278. doi:10.1038/ngeo2094

Moffa-Sánchez, P., Hall, I.R., Barker, S., Thornalley, D.J.R., Yashayaev, I., 2014b. Surface changes in 
the eastern Labrador Sea around the onset of the Little Ice Age. Paleoceanography 29, 160-175. doi:10.1002/2013PA002523

Moffa-Sanchez, P., Hall, I.R., Thornalley, D.J.R., Barker, S., Stewart, C., 2015. Changes in the strength of the Nordic Seas Overflows over the past 3000 years. Quat. Sci. Rev. 123, 134-143. doi:10.1016/j.quascirev.2015.06.007

Moreno-Chamarro, E., Ortega, P., González-Rouco, F., Montoya, M., 2017. Assessing reconstruction techniques of the Atlantic Ocean circulation variability during the last millennium. Clim. Dyn. 48, 799-819. doi:10.1007/ s00382-016-3111-x

Muir, L.C., Fedorov, A. V, 2015. How the AMOC affects ocean temperatures on decadal to centennial timescales: the North Atlantic versus an interhemispheric seesaw. Clim. Dyn. 45, 151-160. doi:10.1007/s00382-014-2443-7

Ortega, P., Hawkins, E., Sutton, R., 2011. Processes governing the predictability of the Atlantic meridional overturning circulation in a coupled GCM. Clim. Dyn. 37, 1771-1782. doi:10.1007/s00382-011-1025-1

Ortega, P., Lehner, F., Swingedouw, D., Masson-Delmotte, V., Raible, C.C., Casado, M., Yiou, P., 2015. A model-tested North Atlantic Oscillation reconstruction for the past millennium. Nature 523, 71-4. doi:10.1038/nature14518

Ortega, P., Robson, J.I., Sutton, R.T., Martins, A., 2016. Mechanisms of decadal variability in the Labrador Sea and the wider North Atlantic in a high-resolution climate model. Clim. Dyn. Published Online.

Perez, F. F., H. Mercier, M. Vazquez-Rodriguez, P. Lherminier, A. Velo, P. C. Pardo, G. Roson, and A. F. Rios (2013), Atlantic Ocean $\mathrm{CO}_{2}$ uptake reduced by weakening of the meridional overturning circulation, Nat. Geosci. 6, 146-152.

Rahmstorf, S., 2002. Ocean circulation and climate during the past 120,000 years. Nature 419, 207-214. doi:10.1038/nature01090

Rahmstorf, S., Box, J.E., Feulner, G., Mann, M.E., Robinson, A., Rutherford, S., Schaffernicht, E.J., 2015. Exceptional twentieth-century slowdown in Atlantic Ocean overturning circulation. Nat. Clim. Chang. 5, 475-480. doi:10.1038/nclimate2554

Risebrobakken, B., Jansen, E., Andersson, C., Mjelde, E., Hevrøy, K., 2003. A high-resolution study of Holocene paleoclimatic and paleoceanographic changes in the Nordic Seas. Paleoceanography 18, 1017. doi:10.1029/2002PA000764

Robson, J., Ortega, P., Sutton, R., 2016. A reversal of climatic trends in the North Atlantic since 2005. Nat. Geosci. 9, 513-517.

Shaffrey, L., Stevens, I., Norton, W.A., Roberts, M.J., Vidale, P.L., Harle, J.D., Jrrar, A., Stevens, D.P., Woodage, M.J., Demory, M.E., Donners, J., Clark, D.B., Clayton, A., Cole, J.W., Wilson, S.S., Connolley, W.M., Davi, T.M., Martin, G.M., 2009. U.K. HiGEM: The New U.K. HighResolution Global Environment Model-Model Description and Basic Evaluation. J. Clim. 22, 1861-1896. doi:10.1175/2008JCLI2508.1

Smeed, D.A., McCarthy, G., Cunningham, S.A., FrajkaWilliams, E., Rayner, D., Johns, W.E., Meinen, C.S., Baringer, M.O., Moat, B.I., Duchez, A., Bryden, H.L., 2014. Observed decline of the Atlantic meridional overturning circulation 2004 to 2012. Ocean. Sci. 10, 29-38. doi:10.5194/os-1029-2014

Srivastava, A., DelSole, T., 2017. Decadal predictability without ocean dynamics. Proc. Natl. Acad. Sci. . doi:10.1073/pnas.1614085114

Stephenson, D.B., Pavan, V., Bojariu, R., 2000. Is the North Atlantic Oscillation a random walk? Int.J.Climatol.20,1-18. doi:10.1002/(SICI)1097-0088(200001)20:1<1::AIDJOC456>3.0.CO;2-P

Swingedouw, D., Mignot, J., Ortega, P., Khodri, M., Menegoz, M., Cassou, C., Hanquiez, V., 2017. Impact of explosive volcanic eruptions on the main climate variability modes. Glob. Planet. Change Submitted.

Swingedouw, D., Ortega, P., Mignot, J., Guilyardi, E., Masson-Delmotte, V., Butler, P.G., Khodri, M., Séférian, R., 2015. Bidecadal North Atlantic ocean circulation variability controlled by timing of volcanic eruptions. Nat. Commun. 6, 6545. doi:10.1038/ncomms7545

Trouet, V., Esper, J., Graham, N.E., Baker, A., Scourse, J.D., Frank, D.C., 2009. Persistent positive North Atlantic oscillation mode dominated the Medieval Climate Anomaly. Science 324, 78-80. doi:10.1126/ science. 1166349

Wanamaker, A.D., Butler, P.G., Scourse, J.D., Heinemeier, J., Eiríksson, J., Knudsen, K.L., Richardson, C. a., 2012. Surface changes in the North Atlantic meridional overturning circulation during the last millennium. Nat. Commun. 3, 899. doi:10.1038/ncomms1901

Wurtzel, J.B., Black, D.E., Thunell, R.C., Peterson, L.C., Tappa, E.J., Rahman, S., 2013. Mechanisms of southern Caribbean SST variability over the last two millennia. Geophys. Res. Lett. 40, 5954-5958. doi:10.1002/2013GL058458

Zhang,R.,2008. Coherentsurface-subsurfacefingerprint of the Atlantic meridional overturning circulation. Geophys. Res. Lett. 35, L20705. doi:10.1029/2008GL035463 


\title{
Reconciling disparate views on decadal climate variability from proxies and models
}

doi: 10.22498/pages.25.1.68

\author{
Toby R. Ault \\ Dept. of Earth and Atmospheric Sciences, Cornell University, USA
}

\section{Introduction}

Researchers studying decadal variability over the instrumental period are often confronted with two major obstacles. First, the observational record is short compared to the timescales of interest, sampling at best only a few realizations of decadal-scale phenomena (Meehl et al., 2009). Second, most climate variables include long-term trends driven by human activity (e.g., land use change, aerosol pollution, and of course the impact of greenhouse gas emissions), which sometimes mask decadal variability from natural causes. The climate research community therefore often turns to both paleoclimate archives of past changes, as well as multi-century integrations of general circulation models (GCMs). Both types of data can provide insights into the amplitudes, patterns, and plausible mechanisms of internal decadal variability, which could ultimately help inform and evaluate predictions of near-term climate evolution. In principle, proxy and GCM data should yield a consistent view of the climate system on these timescales. In practice, current paleoclimate data-model comparisons of decadal variability must contend with at least one of the challenges delineated below. To address these concerns, I submit several heuristic recommendations to help to identify fundamental similarities-and critical differences-between paleoclimate and climate model perspectives on decadal variability of the last millennium.

\section{(i) Paleoclimate archives filter climate variability in} ways that are difficult to quantify.

Most paleoclimate archives "redden" climate information by storing information from one time period to the next (e.g., Matalas, 1962; Evans et al., 2013; Ault 2013; Dee et al., 2015). This reddening, in turn, has the effect of amplifying decadal fluctuations in proxy records relative to their climatic drivers. Consequently, the mere presence of high amplitude decadal variability in a given paleoclimate time series cannot be taken as evidence of correspondingly energetic climatic variability (the details of this effect are considered extensively in Ault et al., 2013 and also Dee et al., in revision).

In addition to reddening the spectrum of underlying climate variables, many paleoclimate archives preferentially record information from certain seasons. For example, St. George et al. (2010) showed that treering reconstructions of North American PDSI (Cook et al.,
2004) exhibit variable seasonal sensitivity to temperature and precipitation depending on the region. In the US Southwest, for example, the PDSI is highly sensitive to winter moisture, while in the Pacific Northwest, it depends more strongly on summer temperature. These seasonal dependencies reflect, in part, the dependence of tree growth on different environmental factors during the seasonal cycle (St George and Ault, 2014), a finding consistent with basic dendroclimatological theory (Fritts, 1976). On interannual timescales, diagnosing the filtering effects of tree growth on climate input is relatively straightforward because data are annually resolved and overlap with the instrumental period. However, this problem has not been widely studied on decadal time horizons, and it remains a possibility that trees grow in response to different climate factors across timescales (e.g., Franke et al., 2013).

(ii) Forward models of paleoclimate archives might be biased by spatial and temporal patterns in GCMs. Given the tendency for proxies to redden and filter climate information, one might be tempted to simply run GCM output through "forward models" of various proxy systems and compare the resulting output with actual archives. Caution would be recommended for such an approach because models themselves exhibit systematic geographic and frequency biases. Consider a case in which a forward model of tree-ring growth is run to predict annual ring-width anomalies as a function of monthly temperature and precipitation (e.g. the "Vaganov-Shashkin-Lite" model of Tolwinski-Ward et al., 2011; VS-Lite). If this model were to be run with raw output from a GCM with a wet bias (as is common for the American Southwest), VS-Lite would produce simulations where tree growth is never limited by the availability of soil moisture, even during the "driest" year. Similar considerations apply to other types of proxy systems, and although standard bias-correction techniques are available for removing systematic model errors (e.g. Maurer et al., 2007), these tools have not been widely adopted for paleoclimate model-data comparisons.

(iii) Climate teleconnections are not necessarily stable through time. There are inherent biases in the structure of GCM teleconnections linking remote climate variations (e.g., in the Pacific basin) to the locations 
where there are paleoclimate records (e.g., the American Southwest). For example, Coats et al. (2013) found that El Niño/Southern Oscillation teleconnections in GCMs: (a) are not well simulated by some models in the American Southwest, and (b) are not always stable in all models from one century to the next. These considerations extent to decadal timescales and observations data; Newman et al., (2016) argued that the spatial pattern of the Pacific Decadal Oscillation (PDO) during the 20th Century might not be representative of decadal variability in that basin over the last millennium, and hence the teleconnections driven by this climate mode may have been different in the past. Consequently, both GCMs and proxies may be susceptible to aliasing by changes in the large-scale structure of processes that generate decadal variability.

\section{Suggestions to improve our understanding of decadal variability in proxies and models.}

The list of considerations above implies at least four key principles should be followed when attempting to characterize decadal variability in a given system or region using paleoclimate data and climate model output. These include:

1. Comparisons are likely to be most meaningful if reconstructed phenomena are compared with model phenomena (e.g., Fig. 1), as opposed to local or regional variations. Reconstructions of largescale climate modes tend to rely on networks of paleoclimate archives, often from different proxy types (e.g., Emile-Geay et al., 2013). Accordingly, such networks can minimize the effects of proxy filtering as well as differences in spatial scales between model grids and individual sites. Moreover, if teleconnection patterns change through time, a large-scale network of sites will be better suited to "see" the same phenomena even if its spatial imprint varies.

2. Decadal variability inferred from both paleoclimate and GCM sources should be evaluated against an appropriately defined null hypothesis. In a simple, univariate setting, such a null hypothesis is usually the spectrum generated by an AR(1) processes. For more complicated systems, or for multivariate cases, a more sophisticated method for generating the null distribution might be needed.

3. Methodologies for comparing decadal variability in proxies and climate models should employ time series analysis and spectral techniques alike. While the former can help isolate the role of external forcings if the temporal evolution of those forcings is known, the latter can identify timescales at which models and proxies exhibit fundamentally different amplitudes of variability.

4. Finally, researchers should consider using forward models of paleoclimate archives to characterize the imprint of proxy systems on the continuum of variability encoded in existing records (e.g., Dee et al., 2015; Dee et al., in revision). Such analyses will help isolate climate, as opposed to non-climate, sources of decadal variability.

An example of how a few of these principles can be applied is shown in Fig. 1 (adapted from Ault et al., 2013). Here NIN03.4 spectra from reconstructions (Emile-Geay et al., 2013) and last millennium model output (OttoBliesner et al., 2016) are compared against the null distribution of ENSO variations with no changes to the external boundary conditions (as in Ault et al., 2013). Here a linear inverse model (LIM) has been used to generate the null distribution (see Ault et al., 2013 and Newman et al., 2011 for details). At the longest resolvable timescales (centuries), the null hypothesis can be rejected for the reconstructions, but not for the model runs. At higher (interannual) frequencies, the reconstructions are well within the null distribution, whereas the model oscillations are not (because this version of the model produces ENSO fluctuations that are too high amplitude in comparison to observations).

While the null hypothesis can be rejected for the centennial timescales in the reconstruction, and the interannual ones in the model, it cannot be rejected for the amplitudes of multidecadal (50-100 year) variations in either data type. This approach could help identify the timescales that require the greatest attention by both paleoclimate and climate modeling research communities to understand the processes responsible for generating low-frequency variability.

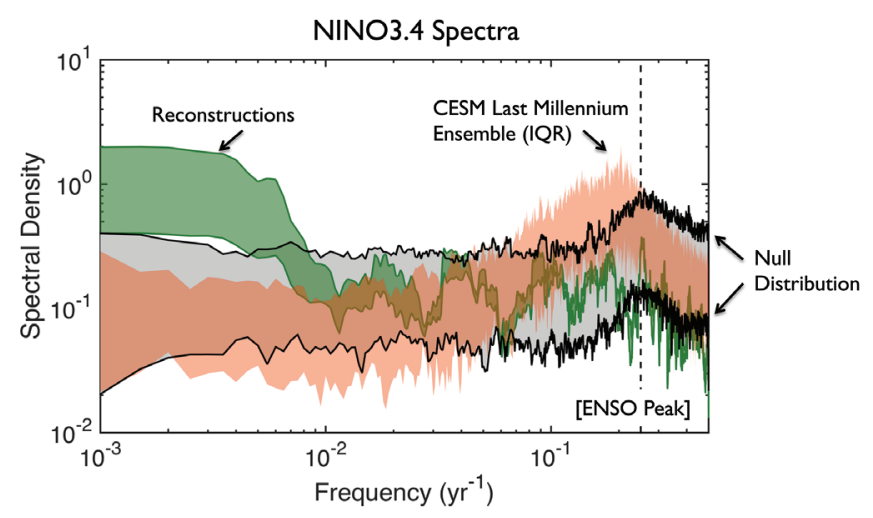

Figure 1: Power spectra of NINO3.4 time series derived from a LIM (black lines with gray shading), multi-proxy paleoclimate reconstructions (green; Emile-Geay et al., 2013), and the CESM Last Millennium Ensemble inner quartile range (IQR) (red; Otto-Bliesner et al., 2016). The vertical dashed line marks the middle of the 2-7 year peak typically associated with ENSO in observations

\section{Acknowledgements}

I would like to thank Scott St. George for helpful suggestions. This work was partially funded by NSF Grant AGS 1602564. 


\section{References}

Ault, T. R., Cole, J. E., Overpeck, J. T., Pederson, G. T., George, S. S., Otto-Bliesner, B., Woodhouse, C. A., and Deser, C. (2013). The continuum of hydroclimate variability in western North America during the last millennium. Journal of Climate.

Coats, S., Smerdon, J. E., Cook, B. I., and Seager, R. (2013). Stationarity of the tropical pacific teleconnection to North America in CMIP5/PMIP3 model simulations. Geophysical Research Letters, 40(18):4927-4932.

Cook, E. R., Woodhouse, C. A., Eakin, C. M., Meko, D. M., and Stahle, D. W. (2004). Long-term aridity changes in the western United States. Science, 306(5698):1015-1018.

Dee, S., Emile-Geay, J., Evans, M. N., Allam, A., Steig, E. J., and Thompson, D. (2015). PRYSM: An open-source framework for PRoxY System Modeling, with applications to oxygenisotope systems. Journal of Advances in Modeling Earth Systems, pages $n / a-n / a$.

Dee, S., Parsons, L., Loope, G., Ault, T., Overpeck, J., and Emile-Geay, J. (under revision for Earth and Planetary Science Letters.). Improved spectral comparisons of paleoclimate models and observations via proxy system modeling: implications for multi-decadal variability.

Emile-Geay, J., Cobb, K. M., Mann, M. E., and Wittenberg, A. T. (2013). Estimating Central Equatorial Pacific SST variability over the Past Millennium. Part 2: Reconstructions and Implications. Journal of Climate.

Evans, M. N., Tolwinski-Ward, S. E., Thompson, D. M., and Anchukaitis, K. J. (2013). Applications of proxy system modeling in high resolution paleoclimatology. Quaternary Science Reviews (accepted).

Franke, J., Frank, D., Raible, C. C., Esper, J., and Broennimann, S. (2013). Spectral biases in tree-ring climate proxies. Nature Climate Change, 3(4):360-364.

Fritts, H. C. (1976). Tree Rings and Climate. Academic Press.

Fritts, H. C., Smith, D. G., Cardis, J. W., and Budelsky, C. A. (1965). Tree-Ring Characteristics Along a Vegetation Gradient in Northern Arizona. Ecology, 46(4):393-401.

MATALAS, N. C. (1962). STATISTICAL PROPERTIES OF TREE RING DATA. International Association of Scientific Hydrology. Bulletin, 7(2):39-47.

Maurer, E. P., Brekke, L., Pruitt, T., and Duffy, P. B. (2007). Fine-resolution climate projections enhance regional climate change impact studies. Eos, Transactions American Geophysical Union, 88(47):504-504.

Meehl, G. A., Goddard, L., Murphy, J., Stouffer, R. J., Boer, G., Danabasoglu, G., Dixon, K., Giorgetta, M. A., Greene,
A. M., Hawkins, E., Hegerl, G., Karoly, D., Keenlyside, N., Kimoto, M., Kirtman, B., Navarra, A., Pulwarty, R., Smith, D., Stammer, D., and Stockdale, T. (2009). Decadal Prediction: Can It Be Skillful? Bulletin of the American Meteorological Society, 90(10):1467+.

Newman, M., Alexander, M. A., Ault, T. R., Cobb, K. M., Deser, C., Di Lorenzo, E., Mantua, N. J., Miller, A. J., Minobe, S., Nakamura, H., Schneider, N., Vimont, D. J., Phillips, A. S., Scott, J. D., and Smith, C. A. (2016). The Pacific Decadal Oscillation, Revisited. Journal of Climate, 29:4399-4427. Otto-Bliesner, B. L., Brady, E. C., Fasullo, J., Jahn, A., Landrum, L., Stevenson, S., Rosenbloom, N., Mai, A., and Strand, G. (2016). Climate Variability and Change since 850 CE: An Ensemble Approach with the Community Earth System Model. Bulletin of the American Meteorological Society, 97(5):735-754.

St. George, S. and Ault, T. R. (2014). The imprint of climate within Northern Hemisphere trees. Quaternary Science Reviews, 89:1-4.

St George, S., Meko, D. M., and Cook, E. R. (2010). The seasonality of precipitation signals embedded within the North American Drought Atlas. Holocene, 20(6):983988.

Tolwinski-Ward, S., Evans, M., Hughes, M., and Anchukaitis, K. (2010). An efficient forward model of the climate controls on interannual variation in tree-ring width. Climate Dynamics, pages 1-21. 
doi: $10.22498 /$ pages.25.1.71

\title{
PAGES2k Coordinators*
}

\author{
PAGES IPO, Falkenplatz 16, Bern, Switzerland
}

\section{Introduction}

The past 2000 years (the " $2 \mathrm{k}$ " interval) provides critical context for our understanding of recent anthropogenic forcing of the climate, as well as baseline information about Earth's natural climate variability. It also provides opportunities to improve the interpretation of paleoclimate proxy observations, and to perform outof-sample evaluation of the climate and earth system models that are used to generate projections of future climate change.

\section{Achievements of the PAGES 2k Network}

In 2008 PAGES initiated the $2 \mathrm{k}$ Network, to coordinate and integrate regional efforts to assemble existing proxy data and generate climate reconstructions. Nine regional groups were established during the course of the initiative, spanning eight continents and the global ocean. Phase 1 (2008-2013) focused on generating regional temperature reconstructions. During Phase 2 (2014-2016), as a natural step forward, a number of trans-regional groups emerged from amongst the community, focusing on topical challenges such as methods development, data-model comparison, database construction and large-scale climate.
Along with the many products and publications of the regional groups, the initiative spawned a number of successful, large network-wide projects. The first key product was the coordinated publication of temperature reconstructions from seven continents, which informed the Fifth Assessment Report of the Intergovernmental Panel on Climate Change (PAGES 2k Consortium, 2013). For the first time, continental-scale temperature histories spanning the $2 \mathrm{k}$ interval were systematically compared. The results showed that there were no globallyconsistent temperature fluctuations consistent with a worldwide "Medieval Warm Period" or "Little Ice Age" (Figure 1). However, there was a near-global long-term cooling trend during the Common Era, which culminated in a cold interval from 1580 to $1880 \mathrm{CE}$. In contrast, the period from 1971 to $2000 \mathrm{CE}$ was the warmest during the last 1400 years. Through this publication, the $2 \mathrm{k}$ Network received considerable attention outside the field of paleoclimate and amongst the general public and it remarks a milestone in making $2 \mathrm{k}$ paleoclimate science accessible and understandable to a wider audience. It currently ranks in the 99th percentiles of Earth and Planetary Sciences articles of the same age and document

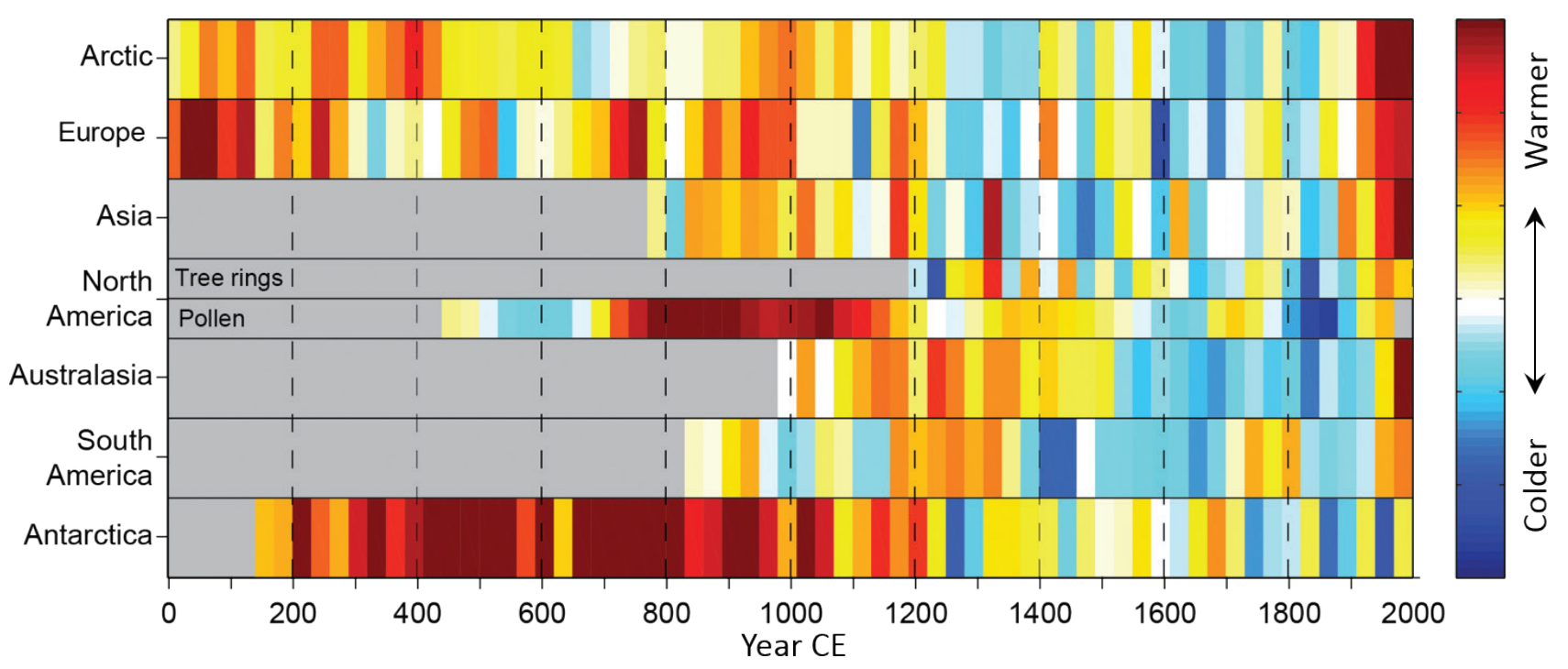

Figure 1: 30-year-mean temperatures for the seven PAGES 2k Network regions, standardized to have the same mean (0) and standard deviation (1) over the period of overlap among records (1190-1970 CE). North America includes a shorter tree-ring based and a longer pollen-based reconstruction. Adapted from PAGES2k Consortium (2013). 


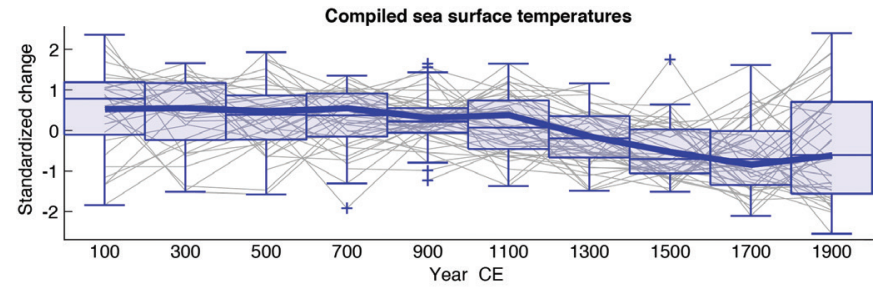

Figure 2: Global SSTS over the last 2000 years: A cooling over the past two millennia was reversed only in the most recent two centuries. Fifty-seven previously published and publicly available marine sea surface temperature reconstructions were combined and compiled into 200-year brackets, represented by the boxes. The thin horizontal lines dividing each box are the median of the values in that box. The thick blue line is the median of these values weighted for differences in the region of the global ocean in which they were found. Modified from McGregor et al. (2015).

type in terms of citations, Mendeley readers and tweets, and it received 27 mass media mentions (www.scopus. com).
In collaboration with the Paleoclimate Modelling Intercomparison Project (PMIP), these regional reconstructions were compared with transient simulations of the last millennium (850 to $1850 \mathrm{CE}$ ). The resulting publication identified a consistency in the general tendencies, but temperature changes in different regions correlated more closely with each other within the simulations than within the reconstructions (PAGES2k-PMIP3 group, 2015). Subsequent efforts by the Ocean2k Working Group found that a robust long-term cooling trend also occurred over the global ocean during the pre-industrial Common Era (Figure 2; McGregor et al., 2015). Comparison with climate model simulations suggested that this trend was driven by clusters of volcanic eruptions.

Combination of the continental reconstructions with temperature histories from ocean basins over the last 500 years yielded the curious finding of an early onset of industrial-era warming, which could already be detected in the mid-19th century over the tropical oceans and Northern Hemisphere continents (Figure 3; Abram et

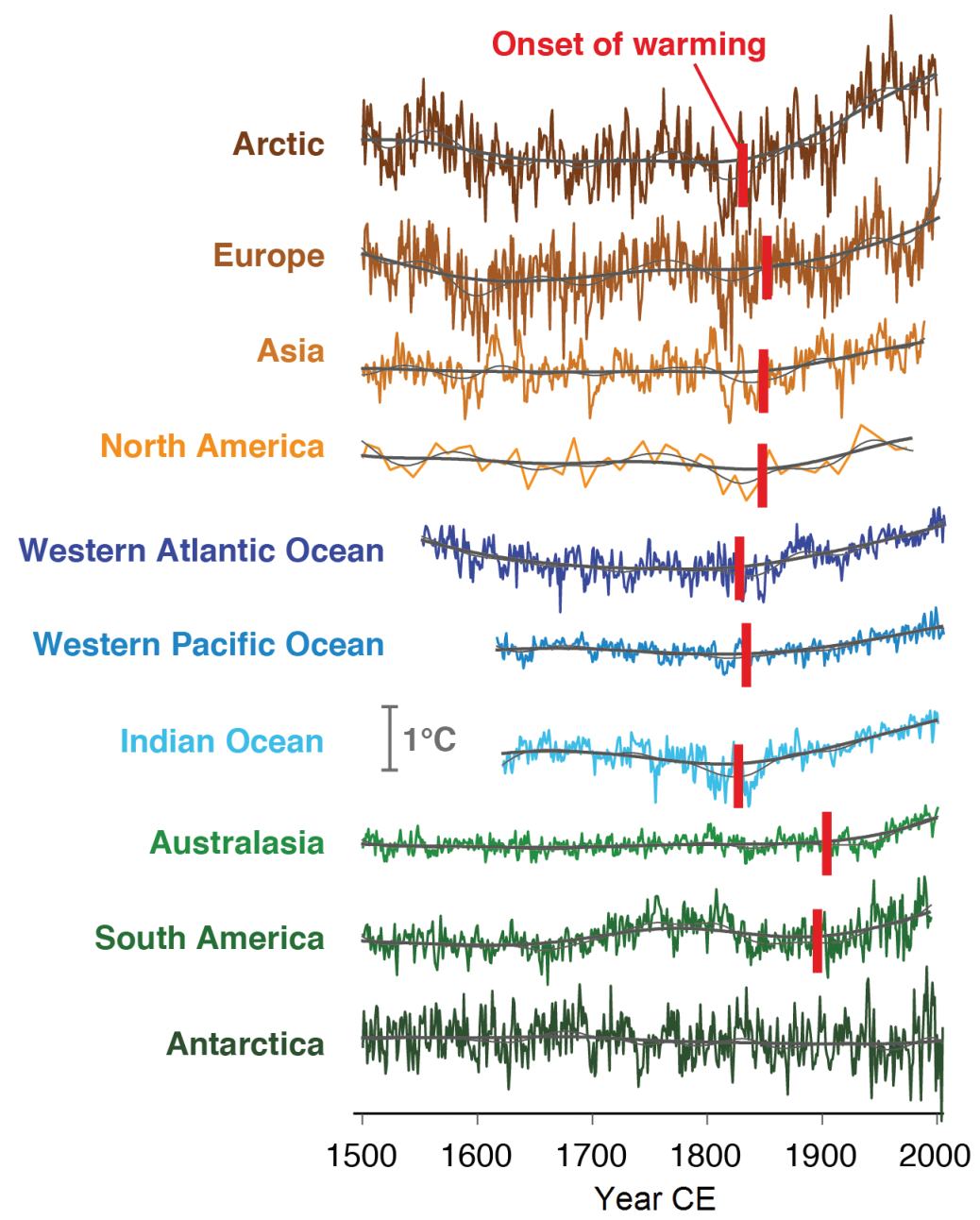

Figure 3: Onset of industrial-era warming in regional temperature reconstructions. Regional reconstructions since 1500 CE (coloured lines) with 15-yr (thin black lines) and 50-yr (thick black lines) Gaussian smoothing, shown alongside the median time of onset for sustained, significant industrial-era warming assessed across $15-50$-yr filter widths (vertical red bars). Grey $1^{\circ} \mathrm{C}$ scale bar denotes the $y$-axis scale of each regional temperature reconstruction. Modified from Abram et al. (2016). 


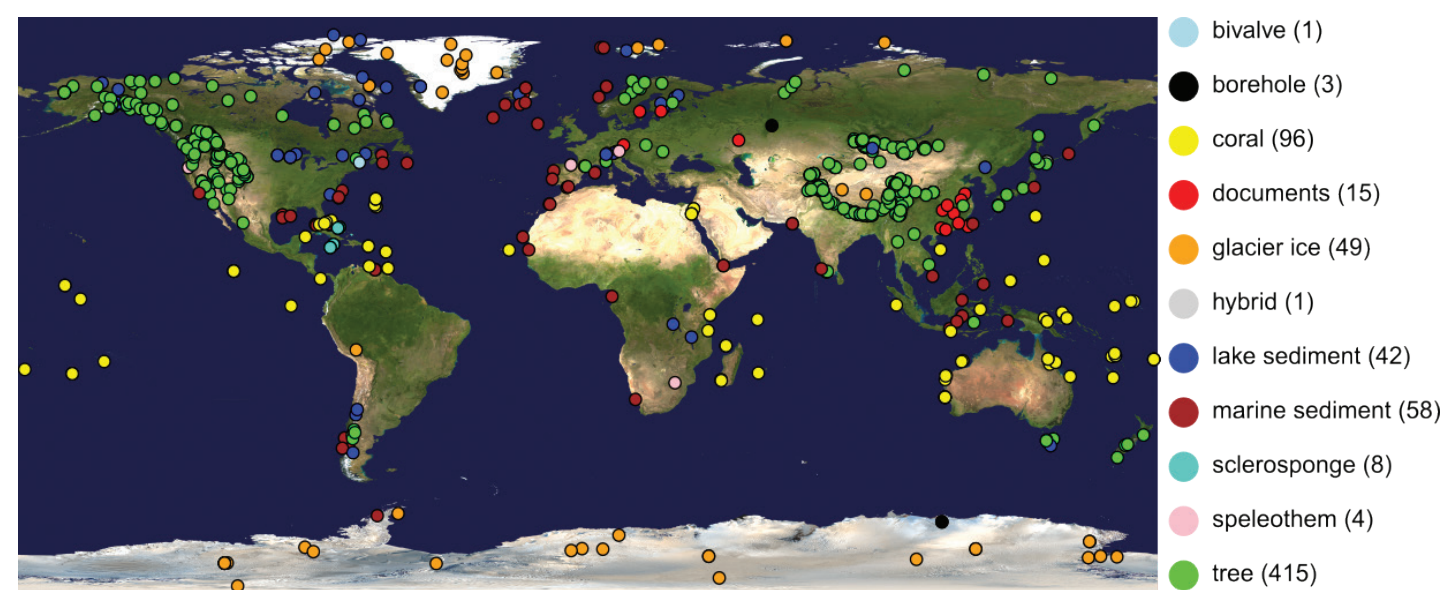

Figure 4: Quality screened proxy records assembled in the PAGES2k temperature database at the end of Phase 2 (PAGES $2 k$ Consortium, in press). Number of records per archive is indicated in the legend. Background image from http://visibleearth.nasa. gov.

al., 2016). This trans-regional effort highlighted that the effect of greenhouse-gas forcing on temperatures started earlier than is suggested by instrumental data alone. Additionally, a spatial reconstruction of precipitation across the Northern Hemisphere for the past 1200 years, in comparison with climate model simulations, suggests that models do not yet accurately simulate longterm hydroclimate variability (Ljungqvist et al., 2016). Finally, a community-wide effort of Phase 2 has been to systematically organize temperature-sensitive proxy data and metadata covering the $2 \mathrm{k}$ interval into a common database product, to facilitate future assessments of temperature variability during this period.

Common to all these community products has been a tremendous collaborative effort involving hundreds of scientists from all regions of the globe, aiming to improve our understanding of mechanisms of climate variation on interannual to bicentennial time scales by contributing expert knowledge, data and metadata. As an example of the impressive progress in data collection and synthesis, Figure 4, shows the current availability of qualityscreened temperature-sensitive proxy data (PAGES $2 \mathrm{k}$ Consortium, in press).

\section{Our vision for Phase 3}

The goals of Phase 3 (2017-2019), which was launched in May 2017 at the PAGES Open Science Meeting in Zaragoza, Spain, are to:

1. Further understand the mechanisms driving regional climate variability and change on interannual to centennial time scales (Theme: "Climate Variability, Modes and Mechanisms");

2. Reduce uncertainties in the interpretation of observations imprinted in paleoclimatic archives by environmental sensors (Theme: "Methods and Uncertainties")

3. Identify and analyse the extent of agreement between reconstructions and climate model simulations (Theme: "Proxy and Model Understanding")
Research is organized as a linked network of well-defined projects and targeted manuscripts, identified and led by $2 \mathrm{k}$ members. This bottom-up concept of trans-regional projects initiated and conducted by community members has successfully emerged during Phase 2 and is expected to further stimulate collaboration within the $2 \mathrm{k}$ Network. The $2 \mathrm{k}$ projects focus on specific scientific questions aligned with Phase 3 goals, rather than being defined along regional boundaries. Along with the products of the individual projects, one or more community wide projects are envisaged for Phase 3.

As mentioned above, an enduring element from earlier phases of PAGES $2 \mathrm{k}$ will be a culture of collegiality, transparency, and reciprocity. Phase 3 seeks to stimulate community based projects and to facilitate collaboration of researchers from different regions and career stages, drawing on the breadth and depth of the global PAGES $2 \mathrm{k}$ community. A key vision of PAGES $2 \mathrm{k}$ is to support endto-end workflow transparency, open data and knowledge access, which are key conditions for the inclusion of future PAGES $2 \mathrm{k}$ projects. The initiative seeks to further develop collaborations with other research communities and engage with stakeholders at the project and network level through interaction with related institutions or initiatives such as Future Earth, WCRP, IPCC and EarthCube.

\section{Call for participation}

There are many ways to participate in, and to be part of, the PAGES $2 \mathrm{k}$ community. You may contribute to the ongoing database and knowledge-base efforts with your data and expertise. You may initiate a new $2 \mathrm{k}$ project, or participate in an emerging one, by contributing towards project coordination, data-analysis, interpretation or writing. In the spirit of Phases 1 and 2, PAGES $2 \mathrm{k}$ projects are expected to be inclusive and open to any researcher who wishes to contribute. Members from related communities including CLIVAR scientists are warmly welcomed to be part of or even initiate $2 \mathrm{k}$ projects. 
If you would like to participate in Phase 3 of the PAGES $2 \mathrm{k}$ Network or simply to receive updates, please visit http:// www.pastglobalchanges.org/ini/wg/2k-network/ intro to join our mailing list or contact a coordinating committee member. A call for new PAGES $2 \mathrm{k}$ projects will soon be issued via the mailing list.

\section{References}

Abram, N.J., McGregor, H.V., Tierney, J.E., Evans, M.N., McKay, N.P. Kaufman, D.S., Thirumalai, K., and PAGES 2k Consortium, 2016: Early Onset of Industrial-Era Warming across the Oceans and Continents. Nature, 536, 411-18.

Ljungqvist, F.C., Krusic, P.J., Sundqvist, H.S., Zorita, E., Brattström, G. and Frank, D., 2016: Northern Hemisphere Hydroclimate Variability over the Past Twelve Centuries. Nature, 532, 94-98.

PAGES 2k Consortium, 2013: Continental-scale temperature variability during the past two millennia. Nature Geoscience, 6, 339-346.

PAGES 2k Consortium: A global multiproxy database for temperature reconstructions of the Common Era. Scientific Data, in press.

PAGES2k-PMIP3 group, 2015: Continental-Scale Temperature Variability in PMIP3 Simulations and PAGES $2 \mathrm{k}$ Regional Temperature Reconstructions over the Past Millennium. Climate of the Past, 11, 1673-99.

McGregor, H.V., Evans, M.N., Goosse, H., Leduc, G., Martrat, B., Addison, J.A., Graham M.P., Oppo, D.W., Seidenkrantz, M., Sicre, M., Phipps, S.J., Selvaraj, K., Thirumalai, K., Filipsson, H.L., and Ersek, V., 2015: Robust Global Ocean Cooling Trend for the Pre-Industrial Common Era. Nature Geoscience, 8, 671-77.

\section{*PAGES2k Coordinators:}

Nerilie Abram, The Australian National University, Canberra, Australia, nerilie.abram@anu.edu.au

Oliver Bothe, Helmholtz-Zentrum Geesthacht, Geesthacht, Germany, ol.bothe@gmail.com

Hans Linderholm, University of Gothenburg, Göteborg, Sweden, hansl@gvc.gu.se

Belen Martrat, Spanish Council for Scientific Research, Barcelona, Spain, \& University of Cambridge, Cambridge, UK, belen.martrat@idaea.csic.es

Helen McGregor, University of Wollongong, Wollongong, Australia,mcgregor@uow.edu.au

Raphael Neukom, University of Bern, Switzerland, neukom@giub.unibe.ch
Steven Phipps, University of Tasmania, Hobart, Australia, Steven.Phipps@utas.edu.au

Scott St. George, University of Minnesota, Minneapolis, USA, stgeorge@umn.edu

Lucien von Gunten, PAGES International Project Office, Bern, Switzerland, lucien.vongunten@pages.unibe.ch 
Editorial

Yochanan Kushnir, Christophe Cassou, Scott St George

An overview of decadal-scale sea surface temperature variability in the observational record

Clara Deser, Adam Phillips.

Global impacts of the Atlantic Multidecadal Variability during the boreal winter

Yohan Ruprich-Robert, Rym Msadek..

Arctic sea ice seasonal-to-decadal variability and long-term change

Dirk Notz.

Decadal climate variability and the global energy balance

Richard P. Allan.

Toward predicting volcanically-forced decadal climate variability

Davide Zanchettin, Francesco S.R. Pausata, Myriam Khodri, Claudia Timmreck, Hans Graf, Johann H. Jungclaus,

Alan Robock, Angelo Rubino, Vikki Thompson

Towards the prediction of multi-year to decadal climate variability in the Southern Hemisphere

Scott Power, Ramiro Saurral, Christine Chung, Rob Colman, Viatcheslav Kharin, George Boer, Joelle Gergis,

Benjamin Henley, Shayne McGregor, Julie Arblaster, Neil Holbrook, Giovanni Liguori.

Initialization Shock in CCSM4 Decadal Prediction Experiments

Haiyan Teng, Gerald A. Meehl, Grant Branstator, Stephen Yeager, Alicia Karspeck.

Internal and forced decadal variability: lessons from the past millennium

Hugues Goosse, François Klein, Didier Swingedouw, Pablo Ortega.

Abrupt Northward Shift of SPCZ position in the late-1920s Indicates Coordinated Atlantic and Pacific ITCZ Change Braddock K. Linsley, Robert B. Dunbar, Donna Lee, Neil Tangri, Emilie Dassié.

Summer North Atlantic Oscillation (SNAO) variability on decadal to palaeoclimate time scales

Hans W. Linderholm, Chris K. Folland.

A last millennium perspective on North Atlantic variability: exploiting synergies between models and proxy data

Pablo Ortega, Jon Robson, Paola Moffa-Sanchez, David Thornalley, Didier Swingedouw.

Reconciling disparate views on decadal climate variability from proxies and models

Toby R. Ault..

The third phase of the PAGES $2 \mathrm{k}$ Network

PAGES2k Coordinators

The CLIVAR Exchanges is published by the International CLIVAR Project Office ISSN No: 1026-0471

The PAGES Magazine is published by the PAGES International Project Office ISSN No.: 2411-605X

Editors: Nico Caltabiano (ICPO) and Lucien von Gunten (PAGES IPO)

Guest editors: Yochanan Kushnir (Lamont-Doherty Earth Observatory, USA),

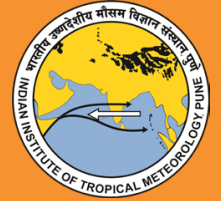

Christophe Cassou (CNRS-CERFACS, France) and Scott St George (University of Minnesota, USA)

Layout: Harish J. Borse, ICMPO at IITM, Pune, India

This issue's DOl: 10.22498/pages.25.1

Hardcopy circulation: 2300

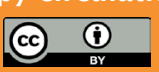

Note on Copyright

This publication is distributed under a CC-BY licence. Agreement should be obtained from the authors for the use of figures.

The PAGES International Office and its publications are supported by the Swiss Academy of Sciences and the US National Science Foundation

WCRP is sponsored by the World Meteorological Organization,the International Council for Science and the Intergovernmental Oceanographic Commission of UNESCO.

Contact:

PAGES International Project Office (IPO)

Falkenplatz 16; 3012 Bern

Switzerland

pages@pages.unibe.ch

http://www.pastglobalchanges.org

\section{Contact:}

Executive Director, ICPO

First Institute of Oceanography, SOA,

6 Xianxialing Road, Laoshan District, Qingdao 266061,China icpo@clivar.org

http://www.clivar.org 